\title{
Occipital condyle width (OCW) is a highly accurate predictor of body mass in therian mammals
}

\author{
Russell K. Engelman(1)
}

\begin{abstract}
Background: Body mass estimation is of paramount importance for paleobiological studies, as body size influences numerous other biological parameters. In mammals, body mass has been traditionally estimated using regression equations based on measurements of the dentition or limb bones, but for many species teeth are unreliable estimators of body mass and postcranial elements are unknown. This issue is exemplified in several groups of extinct mammals that have disproportionately large heads relative to their body size and for which postcranial remains are rare. In these taxa, previous authors have noted that the occiput is unusually small relative to the skull, suggesting that occiput dimensions may be a more accurate predictor of body mass.

Results: The relationship between occipital condyle width (OCW) and body mass was tested using a large dataset (2127 specimens and 404 species) of mammals with associated in vivo body mass. OCW was found to be a strong predictor of body mass across therian mammals, with regression models of Mammalia as a whole producing error values ( $31.1 \%$ error) comparable to within-order regression equations of other skeletal variables in previous studies. Some clades (e.g., monotremes, lagomorphs) exhibited specialized occiput morphology but followed the same allometric relationship as the majority of mammals. Compared to two traditional metrics of body mass estimation, skull length, and head-body length, OCW outperformed both in terms of model accuracy.
\end{abstract}

Conclusions: OCW-based regression models provide an alternative method of estimating body mass to traditional craniodental and postcranial metrics and are highly accurate despite the broad taxonomic scope of the dataset. Because OCW accurately predicts body mass in most therian mammals, it can be used to estimate body mass in taxa with no close living analogues without concerns of insufficient phylogenetic bracketing or extrapolating beyond the bounds of the data. This, in turn, provides a robust method for estimating body mass in groups for which body mass estimation has previously been problematic (e.g., "creodonts" and other extinct Paleogene mammals).

Keywords: Body size, Mass estimation, Allometry, Non-linear regression, Non-linear allometry

\section{Background}

Body size (body mass) is a particularly important feature of an organism's biology, as it is correlated with dietary habits [1-4], basal metabolic rate [5], population density

\section{Correspondence: neovenatoridae@gmail.com}

Department of Biology, Case Western Reserve University, 10900 Euclid Avenue, Cleveland, OH 44106, USA
[6], longevity [7], reproductive rate [8], home range size [9], degree of sexual size dimorphism [10], relative brain size [11, 12], morphology and degree of morphological specialization [13], defensive behavior [14], guild structure $[15,16]$, isotope enrichment ratios [17], and extinction risk [18], among various other factors (see [19-21] and references therein). Indeed, many authors have gone so far as to say that body mass is the single most

\section{$\triangle B M C$}

(c) The Author(s). 2022 Open Access This article is licensed under a Creative Commons Attribution 4.0 International License, which permits use, sharing, adaptation, distribution and reproduction in any medium or format, as long as you give appropriate credit to the original author(s) and the source, provide a link to the Creative Commons licence, and indicate if changes were made. The images or other third party material in this article are included in the article's Creative Commons licence, unless indicated otherwise in a credit line to the material. If material is not included in the article's Creative Commons licence and your intended use is not permitted by statutory regulation or exceeds the permitted use, you will need to obtain permission directly from the copyright holder. To view a copy of this licence, visit http://creativecommons.org/licenses/by/4.0/ The Creative Commons Public Domain Dedication waiver (http://creativecommons.org/publicdomain/zero/1.0/) applies to the data made available in this article, unless otherwise stated in a credit line to the data. 
important aspect of the biology of any organism [2229]. As a result, estimations of body mass are of extreme importance when studying the paleobiology and paleoecology of a given species, both in terms of how it affects the taxon's biology and how the taxon interacts with other species in its community.

The most common method of estimating body mass in extinct animals is to use a regression equation based on skeletal measurements and body mass from a comparative sample of closely related extant species (which are often assumed to have geometric similarity). For fossil mammals, these estimates are often based on teeth, which are commonly preserved [30] and are often the only fossil remains known for many species. However, regression equations based on teeth can be problematic when trying to apply them to mammals that have no close living relatives [31, 32]. Furthermore, many of these extinct animals may exhibit dental morphologies, body proportions, and patterns of allometric scaling unlike any living species. For example, many groups of extinct mammals have disproportionately large heads relative to extant species (Fig. 1). This phenomenon has been most extensively discussed in extinct carnivorous mammals, such as sparassodonts [35, 36], mesonychians [37], and oxyaenid [38] and hyaenodont [32, 39] "creodonts," as well as some extinct carnivorans such as amphicyonids [40, 41] and nimravids [39]. However, this condition also occurs in pantodonts [42, 43], "condylarths" [44], taeniodonts [45], entelodonts [46], diprotodontoid marsupials [47], South American endemic ungulates [48-52], large-bodied rodents [53, 54], and Malagasy subfossil lemurs [55], among others. Given the disproportionately large heads of these taxa, body mass estimates based on craniodental regression equations derived from modern taxa are thought to overestimate body mass (see $[32,39,56]$ ).

Because of these difficulties with craniodental measurements many authors have considered head-body length (HBL) or postcranial measurements such as the length, diameter, or cross-sectional area of long bone diaphysis or articular surfaces of limb bones to be better estimators of body mass [32, 55, 57-59]. However, body mass estimates based on postcranial measurements present their own difficulties, which have often been under-appreciated and rarely discussed in the literature. Perhaps most importantly, the postcranium in most species of fossil mammals is either poorly known or represented by very fragmentary material, and the postcranial anatomy of even some higher-level clades remains more or less unknown (e.g., the notoungulate family Archaeohyracidae $[60,61])$. This is because taxonomic diagnoses of most extinct mammal are almost exclusively based on craniodental features, with postcranial remains usually only identified to genus or species if they directly associated with craniodental material [62-65; E. Davis, pers. comm., 2018]. Even if postcranial remains are better predictors of body mass in mammals, it is a moot point in terms of estimating body mass if no postcrania are known for the taxon.

This scarcity of postcranial remains particularly hinders attempts to use HBL to estimate body mass, a measurement which has otherwise been suggested to be one of the best estimators of body mass in fossil mammals $[52,66]$. HBL can only be accurately measured on a nearly complete, undistorted skeleton with a complete spinal column and as a result can only be applied to extremely well-known taxa $[67,68]$ (see also Sarko et al. [69] for discussion of a comparable issue in sirenians). Even well-preserved taxa are often missing one or more vertebrae and must be reconstructed by filling in missing parts with ones based on those of close relatives, which can affect body mass estimates. For example, Sinclair [33] originally restored the sparassodont Borhyaena tuberata with parts of Prothylacynus patagonicus and Thylacinus cynocephalus, whereas Argot [70] restored B. tuberata with a much shorter torso and longer limbs based on extrapolation from the known limb and vertebral dimensions of this taxon. Using the all-taxon HBL regression equation for carnivorous mammals in Van Valkenburgh [39], the reconstruction of B. tuberata in Sinclair [33] produces a body mass estimate of $22.88 \mathrm{~kg}$ whereas that in Argot [70] using the same equation produces a body mass estimate of $18.36 \mathrm{~kg}$, nearly $5 \mathrm{~kg}$ (or 20\%) lighter. Another issue is that HBL includes the length of the cranium as well as the body as a part of formulating this measurement. Thus, HBL is influenced by skull size in the same manner as craniodental measurements and can produce unreliable body mass estimates in large-headed mammals $[32,56]$.

Furthermore, although postcranial body mass estimates are often regarded as being more independent of phylogeny or biology than craniodental measurements, limb bone dimensions are still influenced by these factors. Good example of this are xenarthrans and caviomorph rodents, which have disproportionately robust hindlimbs relative to their body size [31, 71], likely because these animals often feed or mate in a bipedal stance and therefore must occasionally support all of their weight on their hindlimbs [71-73], which violates the assumption that weight is being distributed in a comparable manner across the fore- and hindlimbs in Mammalia. In particular, Millien and Bovy [31] found that extinct giant caviomorphs like Phoberomys pattersoni have hindlimb bones that are disproportionately robust to their body size even relative to extant caviomorphs, which according to these authors may have produced inaccurate body mass estimates for this taxon. This is demonstrated in the fact that, due to their 

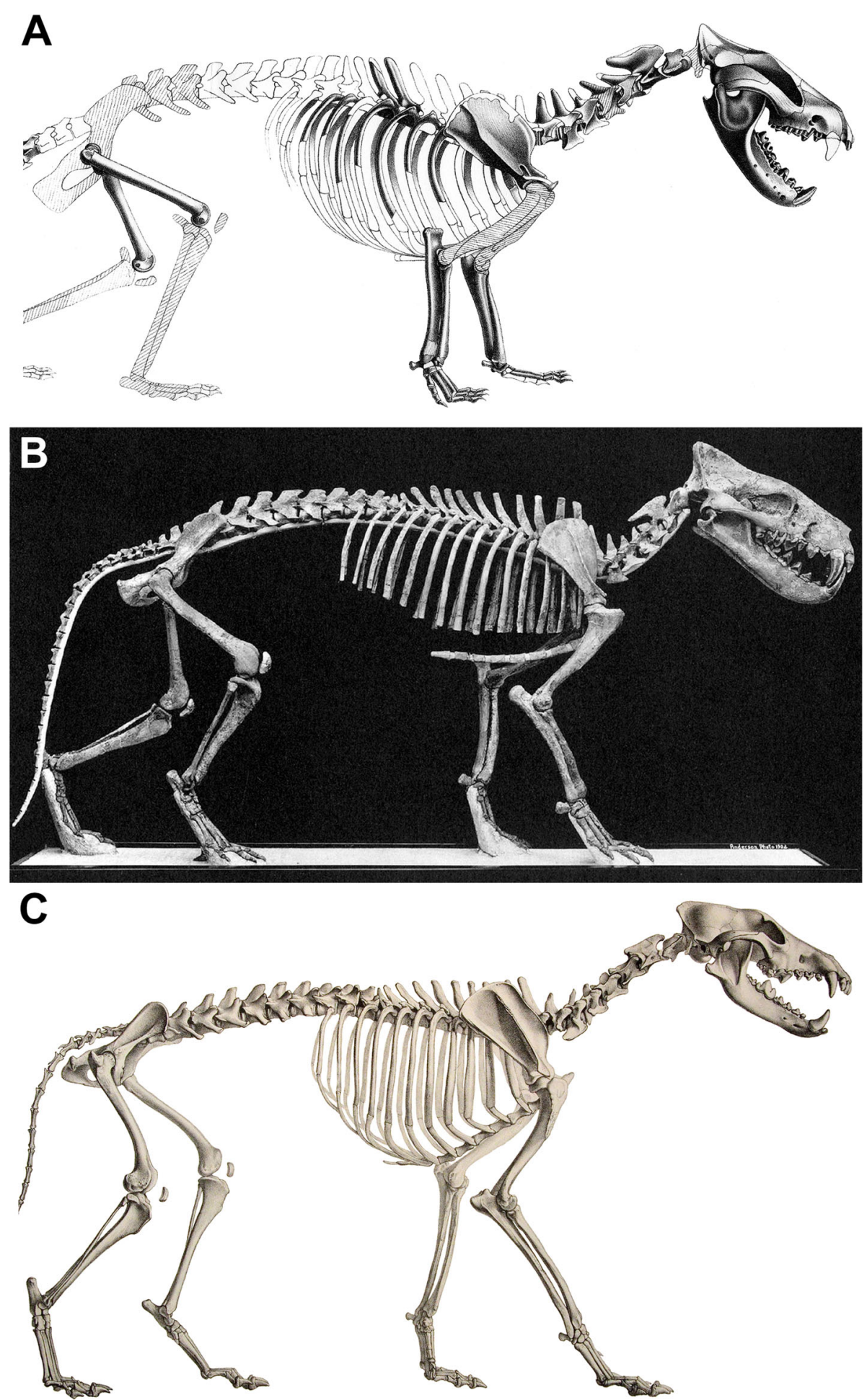

Fig. 1 Skeletal reconstructions of a borhyaenid sparassodont (A, Borhyaena tuberata; modified from Sinclair [33]), hyaenodont "creodont" (B, Hyaenodon horridus; modified from Scott and Jepsen [34]), and canid carnivoran (C, Canis lupus, public domain from Wikimedia Commons), scaled to the same thorax length (not head-body length, due to differences in relative neck length in the three taxa), illustrating the proportionally larger heads of Borhyaena and Hyaenodon 
unusually robust hindlimbs, body mass estimates for glyptodonts and extinct giant caviomorphs like Phoberomys based on the femur range from 70 to $380 \%$ higher than estimates based on the humerus [74, 75]. Compounding problems with the influence of ecology or phylogenetic signal is the fact that most extant large mammals, such as artiodactyls, equids, many carnivorans, and even rhinocerotids to some degree [76, 77], are cursorial and have relatively gracile limbs. By contrast, most of the extinct mammal groups that researchers are frequently interested in estimating body mass for, such as "creodonts" [78, 79], sparassodonts, mesonychians [37], pantodonts [80], extinct Paleogene or South American ungulates [50, 52, 81], caviomorph rodents [31], xenarthrans $[74,82]$, tend to be more ambulatory and have more robust limbs than extant large mammals. As a result, the limb dimensions of large extant mammals may not reflect the proportions of extinct taxa, and this is likely to cause errors in body mass estimation if the two are assumed to be directly comparable [31, 32, 37, $74,82]$.

A related issue is one of phylogenetic bracketing. Phylogenetic bracketing is a key concept in modern paleontology, for if a biological inference can be applied to two distinct branches of a phylogeny, it also likely applies to the extinct taxa between them as well [83]. However, many prior studies estimating body mass in wholly extinct groups of mammals often estimate mass based on regression equations derived (often by necessity) from unrelated species that do not bracket the taxon of study. For example, body masses in "creodonts" and sparassodonts have often been estimated based on regression equations derived from distantly related carnivorans, didelphimorphians, and dasyuromorphians (e.g., [32, 39, 84]), and body masses in extinct hyracoids and South American ungulates have typically been estimated based on regression equations derived from perissodactyls and artiodactyls (e.g., [81, 85, 86]). Very rarely do studies examine if the relationships in their regression equations can be more broadly applied across Mammalia or are only applicable within their respective clade (with some exceptions including [58, 87, 88]).

Even when phylogenetic bracketing is present it may not be sufficient if the variables are not broadly applicable. For example, McGrath et al. [81] noted that both postcranial and craniodental variables failed to produce reliable body mass estimates in macraucheniid litopterns, due to unique features of macraucheniids (robust limbs and complete, closed dentitions) that are not present in most extant ungulates. Similarly, Croft et al. [52] found that craniodental equations likely overestimated body mass in notoungulates due to characteristics of notoungulates not present in modern ungulates (namely large heads relative to body size). This is despite the fact that the equations used to calculate these estimates were based on perissodactyls and artiodactyls, which phylogenetically bracket litopterns and notoungulates $[89,90]$. As a result, when estimating the body mass of species belonging to wholly extinct groups, it is critical to use variables that can be confidently applied across Mammalia more generally and are not specific to a particular group.

Because of these issues, interest in potential alternative methods of estimating body mass in mammals has been steadily increasing. Recent studies have suggested that dimensions of the scapula [91], astragalus [58, 92], and calcaneus [93] may all be strong predictors of body mass. Another potential alternative to traditional craniodental and postcranial-based methods of estimating body mass, especially for the aforementioned extinct "largeheaded" taxa, are dimensions of the occiput. Argot and Babot [94] noted that although the heads of the hyaenodont "creodont" Hyaenodon and the sparassodont Callistoe are relatively large for their body size, the occiput appeared unusually small, resembling the overall disparity in size between the cranium and postcranium in these taxa. This suggests that dimensions of the occiput may scale with the size of the postcranium, rather than the cranium, and therefore may be a more accurate proxy of body size than other craniodental measurements, particularly in these large-headed extinct mammals.

There are several reasons to believe that occiput dimensions may be good estimators of body size. Because the atlanto-occipital joint is the link between the postcranium and cranium, dimensions of the occiput might be expected to more closely correlate with postcranial proportions than other craniodental measurements, as the occiput is constrained by the size of the spinal column. The occiput also shares a common developmental origin with the vertebral column separate from the rest of the skull, as the post-otic region of the skull (including the occiput) is formed by the incorporation of the anteriormost trunk somites into the cranium [95, 96]. Hence, the dimensions of the occiput can be thought of as postcranial landmarks measurable on the cranium. All of the nerves that innervate the postcranium (with the exception of the vagus nerve) pass through the foramen magnum, in addition to the vertebral arteries, anterior and posterior spinal arteries, tectorial membranes, and alar ligaments, among other structures. Given that the number of neurons per unit mass of postcranial body tissue is relatively consistent within mammals [97], this means that the size of the foramen magnum and its surrounding structures (i.e., the occiput) would be expected to closely correlate with body size (but see [98]).

More broadly, the postcranium of most terrestrial mammals is also relatively conservative, with most 
species exhibiting a relatively short neck with seven cervical vertebrae, 19-20 thoracolumbar vertebrae [99], a reduced or absent tail that contributes little to body mass compared to other chordates, and four limbs of roughly comparable size. Specifically, with regard to the tail, mammals exhibit a reduction in overall tail robustness compared to other tetrapods [100], driven by factors such as a more gracile caudal skeleton, a reduction of caudal musculature such as the reptilian caudofemoralis, and the fact that, unlike limbed squamates and crocodilians, most mammals do not use the tail as a major fat-storing organ (with some exceptions, see [101]). The reptilian caudofemoralis alone (which is not homologous to the caudofemoralis muscle in mammals and is actually absent in the latter) comprises about $1 / 3$ of total caudal muscle mass in most non-avian sauropsids and in Iguana iguana represents $\sim 3.6 \%$ of total body weight $([100,102])$. In non-avian sauropsids, the tail is typically $20 \%$ or more of total body mass (Table 1 ), whereas even in mammals with relatively long, muscular tails like Ateles the tail is no more than $8 \%$ of the total body mass (and it is typically less than 5\% in mammals without prehensile tails). As a result, the body proportions of mammals are less variable than those of most other tetrapods and thus there are fewer potentially confounding variables when estimating body size based on axial dimensions (e.g., variation in tail size, presacral vertebral counts, or bipedalism versus quadrupedalism in reptiles [22, 112, 113];).

Additionally, there is likely to be very strong stabilizing selection on the occiput. Maintaining function of the atlanto-occipital joint is critical for an individual's fitness, as luxation of this joint is almost invariably fatal [114]. Any mutation that compromised occiput function would be rapidly removed from the gene pool and as a result morphological change in this structure due to genetic drift would be low. This suggests that occiput evolution would be highly conservative and thus the occiput may be a good proxy for estimating body mass across a broad range of mammals. While it would be theoretically possible for selection to favor an occiput that is disproportionately large relative to body size (as might be expected if there were very strong stresses at the atlanto-occipital joint, such as perhaps in some horned artiodactyls; [115]), it is unlikely that many animals would have occiputs that are disproportionately small relative to body size. This is because if an animal had a disproportionately small occiput relative to its head and body it would result in a greater amount of force being applied to a smaller joint surface and thus increase the risk of atlanto-occipital luxation. Additionally, a smaller occiput would result in greater transverse torque at the atlanto-occipital joint when mediolateral forces are applied at the anterior end of the skull (as in during prey capture, inter/intraspecific combat, or otherwise interacting with a resistant object) due to the narrower distance between the condyles relative to the anteroposterior length of the skull resulting in a less stable joint. This would be even more pronounced in large-headed species because the moment arm (the anteroposterior length of the skull) is inherently longer. Therefore, if an animal has an occiput that is small relative to skull size, it is more likely that the animal merely has a disproportionately large head, with the occiput dimensions being constrained by the size of the spinal column, rather than the animal having a disproportionately small occiput relative to its body. This agrees with what is observed in taxa like Callistoe and Hyaenodon.

One measurement of the occiput that may prove particularly useful for estimating body mass in fossil mammals is occipital condylar width (hereafter abbreviated as OCW). Martin [116] used OCW to estimate body mass in extinct mammals; however, these regressions were based on a relatively small $(N=26)$, taxonomically restricted sample. After Martin [116], only a few studies have used dimensions of the occipital condyles to estimate body mass in extinct terrestrial mammals [65, 117-121]. OCW has been used more frequently to predict body mass in marine mammals (cetaceans, [122124]; sirenians, [69, 125]; pinnipeds, [126, 127]). This is in stark contrast to the large number of studies that have estimated body mass of terrestrial mammals via dimensions of postcrania, teeth, and measurements such as HBL or skull length. Many multivariate studies of body mass based on craniodental or whole-body metrics do not even consider dimensions of the occiput outside of occiput height $[86,128]$. The applicability of OCW across mammals more generally has never been tested, though it has been suggested [129]. In this study, I examine the allometric relationship between OCW and body mass in a wide range of extant mammals, calculate regression equations based on these data, and compare the accuracy of these regression equations with previous studies.

\section{Results}

\section{Data distribution and model fitting}

A strong correlation exists between OCW and body mass (Fig. 2). However, the relationship between the two variables is not log-linear. Instead, plotting $\ln \mathrm{OCW}$ against $\ln$ body mass shows the points form a curvilinear distribution that is slightly concave down, with larger mammals having proportionally larger $\mathrm{OCW}$ relative to body size (Fig. 2). This is supported by a general observation made during data collection that larger taxa had proportionally larger occipital condyles. For example, in the present study, the occipital condyles represent a proportionally smaller part of $\mathrm{OCW}$ in smaller mammals 
Table 1 Comparison of tail masses as a percent of total body mass in mammals and non-mammalian tetrapods. Note that the available data for mammals is disproportionately focused on taxa with large tails (Macropodiformes and prehensile-tailed taxa), the average mammal (e.g., Canis, Felis, Peromyscus) typically has a much smaller tail

\begin{tabular}{|c|c|c|c|c|}
\hline Taxon & Group & Family & $\%$ Tail mass & Reference \\
\hline Alligator mississippiensis & Sauropsida & Alligatoridae & $24.5 \%$ & {$[103]$} \\
\hline Alligator mississippiensis & Sauropsida & Alligatoridae & $27.8 \%$ & [104] \\
\hline Iguana iguana & Sauropsida & Iguanidae & $18.8 \%$ & [102] \\
\hline Christinus marmoratus & Sauropsida & Gekkonidae & $20-24 \%$ & {$[105]$} \\
\hline Eublepharis macularius & Sauropsida & Gekkonidae & $22 \%$ & {$[106]$} \\
\hline Plethodon cinereus & Caudata & Plethodontidae & $15-20 \%$ & [107] \\
\hline Macaca fascicularis & Mammalia & Cercopithecidae & $4 \%$ & [108] \\
\hline Macaca fuscata & Mammalia & Cercopithecidae & $0.1 \%$ & [108] \\
\hline Macaca nemestrina & Mammalia & Cercopithecidae & $0.2 \%$ & [108] \\
\hline Ateles sp. & Mammalia & Atelidae & $7.8 \%$ & [108] \\
\hline Alouatta caraya & Mammalia & Atelidae & $5.5 \%$ & [108] \\
\hline Cebus sp. & Mammalia & Cebidae & $5.4 \%$ & {$[108]$} \\
\hline Saguinus Oedipus & Mammalia & Callitrichidae & $3.0 \%$ & [108] \\
\hline Aotus trivirgatus & Mammalia & Aotidae & $4.2 \%$ & [108] \\
\hline Perodicticus potto & Mammalia & Lorisidae & $0.4 \%$ & [108] \\
\hline Otolemur crassicaudatus & Mammalia & Galagidae & $4.3 \%$ & [108] \\
\hline Galago senegalensis & Mammalia & Galagidae & $2.5 \%$ & [108] \\
\hline Tupaia glis & Mammalia & Tupaiidae & $2.6 \%$ & [108] \\
\hline Dasyprocta aguti & Mammalia & Caviidae & $<0.1 \%$ & [102] \\
\hline Dolichotis salinicola & Mammalia & Caviidae & $0.0 \%$ & [102] \\
\hline Dinomys branickii & Mammalia & Dinomyidae & $1.1 \%$ & [109] \\
\hline Erethizon dorsatum & Mammalia & Erethizontidae & $3.3 \%$ & [109] \\
\hline Coendou prehensilis & Mammalia & Erethizontidae & $8.7 \%$ & [109] \\
\hline Peromyscus maniculatus & Mammalia & Cricetidae & $1.0-4.0 \%$ & [110] \\
\hline Canis familiaris & Mammalia & Canidae & $0.4 \%$ & [108] \\
\hline Felis catus & Mammalia & Felidae & $1.3 \%$ & [108] \\
\hline Bradypus variegatus & Mammalia & Bradypodidae & $<0.1 \%$ & [102] \\
\hline Choloepus hoffmanni & Mammalia & Choloepodidae & $<0.1 \%$ & [102] \\
\hline Didelphis marsupialis & Mammalia & Didelphidae & $3.0 \%$ & [108] \\
\hline Macropus rufus & Mammalia & Macropodidae & $7.0 \%$ & [111] \\
\hline Dendrolagus matschiei & Mammalia & Macropodidae & $5.0 \%$ & [111] \\
\hline Potorous apicalus & Mammalia & Potoroidae & $3.0 \%$ & [111] \\
\hline Pseudocheirus peregrinus & Mammalia & Pseudocheiridae & $7.0 \%$ & [111] \\
\hline
\end{tabular}

like Reithrodontomys megalotis (27.9\%) and Tarsipes rostratus (35.4\%), whereas in larger mammals like Cervus canadensis (55.6\%), Ursus americanus (48.4\%), and Diceros bicornis $(55.1 \%)$ the occipital condyles comprise a greater proportion of OCW.

Assuming a log-linear model, the best-fit line systematically overestimates body mass at the extremes of the dataset and underestimates values for taxa closer to the midpoint (Additional file 1). The effects of non-linearity in the data after log-transformation can be best seen in the largest taxon in the dataset, Loxodonta africana, which also exhibits one of the largest absolute residuals under a log-linear regression model. The OCW of $L$. africana is nearly $75 \mathrm{~mm}$ wider than would be predicted based on a log-linear model (250 mm versus $175 \mathrm{~mm}$ ), and body mass under a log-linear model is overestimated by $64 \%$ (Additional file 2). For Ursus maritimus, the largest taxon in this dataset for which $N>2$, the difference in predicted versus actual OCW is less extreme $(6 \mathrm{~mm}$, or $7 \%$ of actual OCW), but still produces an 


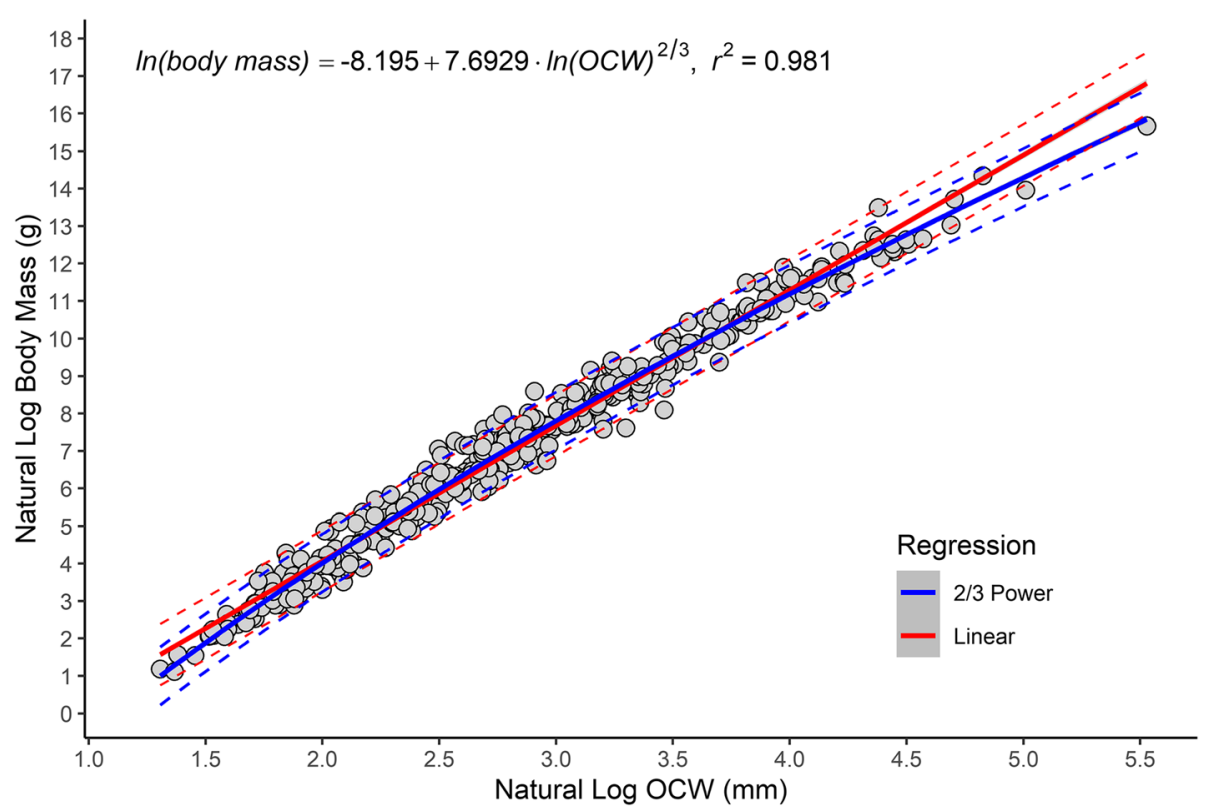

Fig. 2 Scatterplot of natural log of OCW versus natural log of body mass, showing the best fit (natural log OCW raised to the 2/3 power) regression line for all species and the non-linear distribution of the data. Linear regression is in red and 2/3 power regression is in blue. Dashed lines represent 95\% prediction intervals. Most of the species located above the upper bounds of the prediction interval are lagomorphs (see Fig. 7)

underestimate of body mass (especially compared to the final non-linear model used here). The same issue is present for the smallest mammals in this study, though is less obvious in magnitude due to the differences in scales involved. Overall, however, the data seems to curve significantly more at its upper extreme than its lower one.

When comparing several different regression models, a log-power model in which natural log OCW was raised to the $2 / 3$ power significantly outperformed a log-linear one in terms of \%PE, \%SEE, log likelihood, AIC, and BIC (Table 2). The next best-fitting model was a logquadratic model (Additional file 3), which had comparable \%PE and \%SEE but higher log likelihood, AIC, and BIC. The residuals versus fits plot for a log-linear model between $\mathrm{OCW}$ and body mass shows a distinctly nonlinear, heteroskedastic relationship (Fig. 3a), whereas under a $2 / 3$ power model (see Fig. 3b) or a log-quadratic

Table 2 Accuracy statistics for the regression model between natural log OCW and natural log body mass using the all taxon, species average dataset under several different ordinary least squares (OLS) and phylogenetic least squares (PGLS) regression models

\begin{tabular}{|c|c|c|c|c|c|c|c|c|c|c|}
\hline Method & Regression & AIC & BIC & logLik & df & $r_{\text {adj }}^{2}$ & $\% \mathrm{PE}$ & $\mathrm{CF}$ & $\% \mathrm{PE}_{\mathrm{cf}}$ & \%SEE \\
\hline$\overline{O L S}$ & Linear & 441 & 453 & -217 & 402 & 0.9784 & 34.88 & 0.905 & 38.99 & 51.50 \\
\hline OLS & 1/2 power & 409 & 421 & -201 & 402 & 0.9810 & 32.70 & 1.145 & 31.28 & 49.09 \\
\hline OLS & 1/3 power & 455 & 467 & -224 & 402 & 0.9777 & 35.22 & 1.260 & 33.80 & 52.63 \\
\hline OLS & 2/3 power & 389 & 401 & -192 & 402 & 0.9811 & 32.03 & 1.047 & 31.09 & 47.69 \\
\hline OLS & 3/4 power & 391 & 403 & -193 & 402 & 0.9809 & 32.21 & 1.004 & 32.10 & 47.82 \\
\hline OLS & Quadratic & 391 & 407 & -192 & 401 & 0.9810 & 32.05 & 1.068 & 30.98 & 47.73 \\
\hline OLS & Cubic & 393 & 413 & -191 & 400 & 0.9809 & 32.04 & 1.055 & 31.05 & 47.79 \\
\hline PGLS & Linear & 420 & 432 & -207 & 402 & - & 70.12 & 1.725 & 34.30 & 309.11 \\
\hline PGLS & 1/3 power & 367 & 379 & -180 & 402 & - & 75.61 & 1.953 & 32.95 & 276.45 \\
\hline PGLS & 2/3 power & 368 & 380 & -181 & 402 & - & 68.88 & 1.754 & 31.56 & 276.00 \\
\hline PGLS (OU) & 2/3 power & 394 & 406 & -194 & 402 & - & 32.00 & 1.046 & 31.08 & 47.45 \\
\hline
\end{tabular}

Abbreviations: PGLS (OU), phylogenetic least squares under an Ornstein-Uhlenbeck model (rather than Brownian); AIC, Akaike Information Criterion; BIC, Bayesian Information Criterion; logLik, log likelihood; $d f$, degrees of freedom; $r_{\text {adj }}^{2}$ adjusted $r^{2}$ value; $\% P E$, percent prediction error; $C F$, averaged correction factor (see "Methods"); $\% P E_{c f}$, percent prediction error after applying correction factor; \%SEE, standard error of estimate 


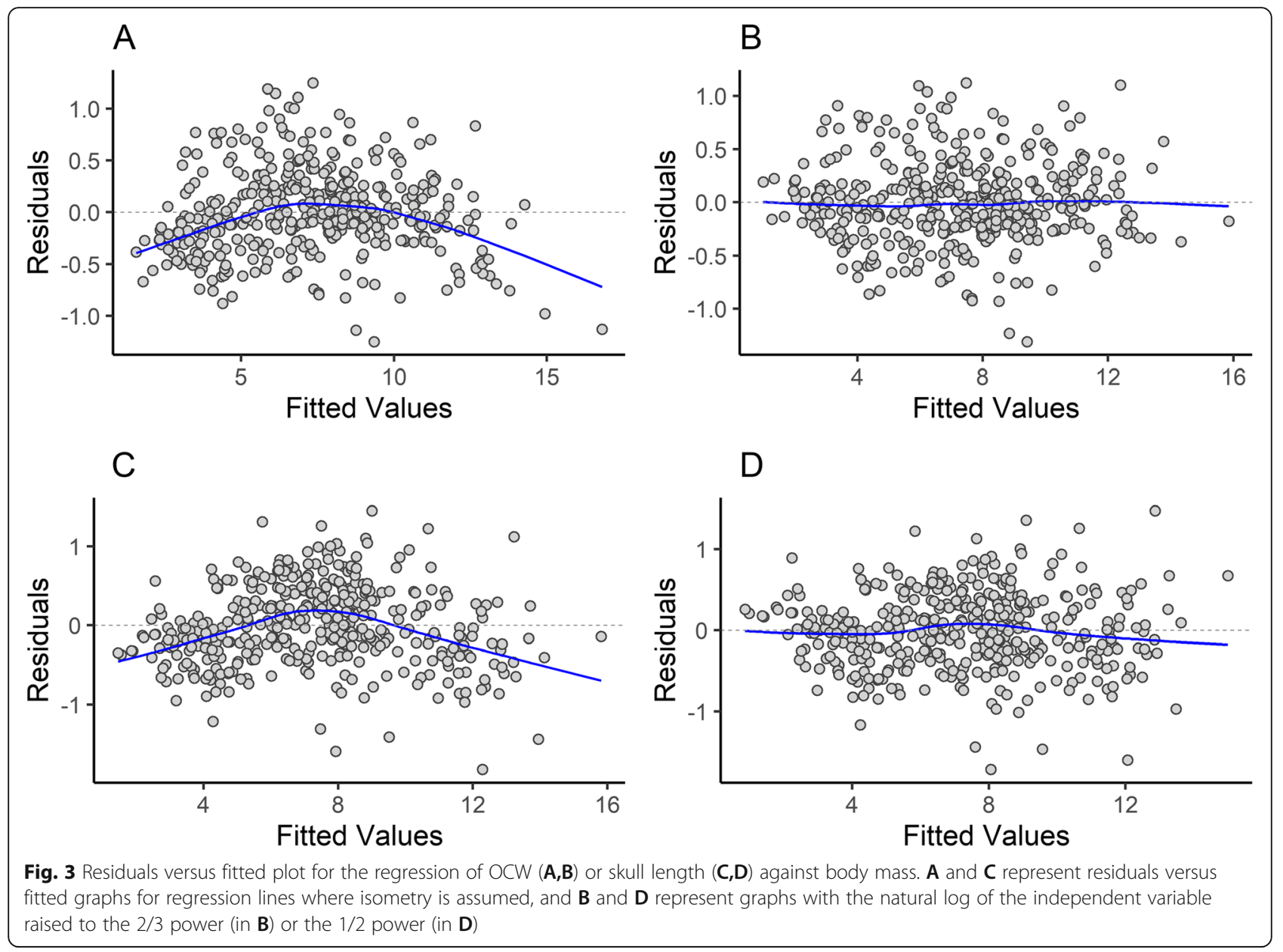

model this distribution is linearized. Empirical curve fitting of a power rule using the non-linear least squares $(n l s)$ function in $\mathrm{R}$ produced a model with an exponent of 0.688 (Table 3 ), very close to the exponent expected if the data scaled to the $2 / 3$ power $(0.667)$. The $95 \%$ confidence interval for the exponent (Table 3) rules out a strictly linear regression line, though it cannot fully rule out a $3 / 4$ power scaling relationship. Comparing the models under ANOVA found the log-quadratic and 2/3 power model to be non-significantly different $(\mathrm{F}=$

Table 3 Results of non-linear curve fitting of OCW, CBL, and HBL. The first seven regression equations are regressing natural log $\mathrm{OCW}, \mathrm{CBL}$, or HBL ( $x$ variables) against natural log body mass ( $y$ variable, in $\mathrm{g}$ ). The last two equations are regressing natural log OCW against natural $\log C B L$ and natural $\log H B L$, respectively. All equations are written in the form $\ln (y)=a \times \ln (x) \wedge b+c$

\begin{tabular}{|c|c|c|c|c|c|c|}
\hline \multirow[b]{2}{*}{ Metric } & \multicolumn{2}{|l|}{ a } & \multicolumn{2}{|l|}{ b } & \multicolumn{2}{|l|}{$\mathrm{C}$} \\
\hline & Value & $95 \% \mathrm{Cl}$ & Value & $95 \% \mathrm{Cl}$ & Value & $95 \% \mathrm{Cl}$ \\
\hline OCW & 7.289 & $(5.780,8.800)$ & 0.688 & $(0.578,0.771)$ & -7.724 & $(-9.501,-5.947)$ \\
\hline OCW (therians only) & 7.470 & $(5.958,8.981)$ & 0.679 & $(0.599,0.760)$ & -7.939 & $(-9.709,-6.168)$ \\
\hline OCW (excluding taxa) & 7.253 & $(5.931,8.575)$ & 0.694 & $(0.621,0.767)$ & -7.767 & $(-9.324,-6.209)$ \\
\hline OCW (all specimens treated independently) & 6.852 & $(6.160,7.544)$ & 0.714 & $(0.671,0.757)$ & -7.235 & $(-8.039,-6.431)$ \\
\hline OCW (average of wild-caught specimens only) & 7.694 & $(5.544,9.843)$ & 0.663 & $(0.551,0.775)$ & -8.154 & $(-10.619,-5.690)$ \\
\hline $\mathrm{CBL}$ & 18.017 & $(8.059,27.975)$ & 0.435 & $(0.288,0.581)$ & -26.885 & $(-38.366,-15.403)$ \\
\hline $\mathrm{HBL}$ & 3.747 & $(2.036,5.457)$ & 0.918 & $(0.759,1.078)$ & -11.883 & $(-15.170,-8.596)$ \\
\hline OCW versus $C B L$ & 1.001 & $(0.768,1.234)$ & 1.020 & $(0.907,1.134)$ & 1.446 & $(1.123,1.770)$ \\
\hline $\mathrm{OCW}$ versus $\mathrm{HBL}$ & 2.631 & $(1.844,3.418)$ & 0.652 & $(0.536,0.768)$ & 0.713 & $(-0.199,1.626)$ \\
\hline
\end{tabular}


0.3243, $p=0.5694$ ), but the $2 / 3$ power model is preferred here for reasons that will be detailed below. Unless otherwise mentioned, the results of this study refer to the model where log OCW is transformed by being raised to the $2 / 3$ power before regression.

The second-order term of the log-quadratic model significantly correlated with log body mass $(t=-7.384$, $p<0.001$ ), whereas under a log-cubic model the quadratic term remained significantly correlated $(t=-7.376$, $p<0.001)$ but the cubic term did not $(t=0.424, p<$ 0.672). This suggests that the addition of a quadratic term substantially improved model accuracy, but the addition of a cubic term is not statistically justifiable.

A major difference between the $2 / 3$ power model and the log-quadratic model is the distribution of leverage. In the log-linear and $2 / 3$ power model, leverage is relatively evenly distributed across the data points, although data at the extreme ends of the $x$-axis have more leverage (Additional file 2). By contrast, in the log-quadratic model, most of the points have almost no leverage, with only the points at the extreme ends of the axis influencing the shape of the quadratic curve. It is this reason, along with the fact that the shape of the log-quadratic model is very sensitive to taxon inclusion and data distribution (see below), that a simpler $2 / 3$ power model is preferred here.

When comparing log-linear regression lines for different size classes (Fig. 4), the slope of the regression line becomes noticeably shallower at larger body sizes, indicating that $\log \mathrm{OCW}$ increases at a greater rate relative to body size at larger body sizes. These differences in slope are significant when the dataset is divided into all taxa greater than or less than $1 \mathrm{~kg}$ $(t=-5.568, p<0.001)$ and $10 \mathrm{~kg}(t=-6.460, p<$ $0.001)$, but not at $100 \mathrm{~g}(t=-0.619, p=0.5360)$. However, there is no obvious inflection point that would suggest a threshold between different linear scaling models, as suggested by Economos [130], but rather a gradual change in slope. This, again, suggests the relationship between the data is non-linear and that a non-linear $2 / 3$ power or log-quadratic model is more appropriate than a log-linear one.

Transforming $\log \mathrm{OCW}$ by raising it to the $2 / 3$ power resulted in this pattern of non-linear allometry being linearized. Under a $2 / 3$ power model, when comparing the regression lines formed by all taxa above and below $1 \mathrm{~kg}$ finds both slope $(t=1.194, p=$ $0.233)$ and intercept $(t=-0.270, p=0.787)$ to be non-significantly affected by size class (Fig. 4b). The same was true when comparing slope $(t=-1.081, p$ $=0.281)$ and intercept $(t=-1.449 . p=0.148)$ for all taxa above or below $10 \mathrm{~kg}$ (Fig. 4f). The thresholds for these two bins were slightly lower or higher, respectively, than the midpoint for body mass in the data set $(4430 \mathrm{~g})$. Both slope $(t=3.083, p=0.002)$ and intercept $(t=-2.643, p=0.008)$ significantly differed between taxa above and below $100 \mathrm{~g}$ (Fig. $4 \mathrm{~d}$ ), but it is possible that this is due to the relatively smaller number of species less than $100 \mathrm{~g}$ in the present sample $(N=84,20.8 \%$ of the total sample) and the relatively narrow size range spanned by these species compared to the other two size class analyses. Even for taxa above $10 \mathrm{~kg}$, which span a similar number of species $(N=96)$, the log range of body sizes spanned by these taxa was much larger.

\section{Results of regression between OCW and body mass}

The regression equation between $\mathrm{OCW}$ and body mass has a percent prediction error (\%PE) of 31.09 (Table 4). $41.6 \%$ of taxa have an estimated body mass within $\pm 20 \%$ of the actual value, whereas $81.4 \%$ of taxa have estimates masses within $\pm 50 \%$ of the actual value. The median error $(21.73 \%)$ is much lower than the mean error, suggesting that error rates in the regression equation are being inflated by outlier points with high error. This is supported by the distribution of the residuals (Fig. 5a). Residuals of the regression equation are homoscedastic (Breusch-Pagal test for heteroscedasticity; $\mathrm{BP}=0.13618$; $\mathrm{df}=1, p=0.7121)$, as also indicated by the scalelocation plot (Fig. 6a), but have a slight positive skew primarily due to several taxa that exhibit occiput morphology that deviates from the typical mammalian condition (Fig. 5a). Skewness (0.193) is relatively low $(\leq|0.5|$, [131]), indicating the distribution of the residuals are roughly symmetrical. Excess kurtosis is 0.532, suggesting that the residuals are slightly leptokurtic (i.e., there are more observations closer to the mean than to the tails of the distribution).

The residuals of the data are not normally distributed according to a Shapiro-Wilk test $(W=0.98739, p=$ $0.0014)$. However, this is probably due to the sensitivity of the Shapiro-Wilk test to departures from normality at large sample sizes, where even small departures from normality will result in the sample failing the normality test [132]. Visual inspection of a histogram of the residuals shows the residuals follow a nearly normal distribution (Fig. 5a). Based on the large number of observations $(N=404)$ and the central limit theorem (which states at large sample sizes most bivariate independent distributions are close enough to normality for assumptions of normality to hold), the distribution of the data is close enough to normal to be used for regression [132]. The quantile-quantile plot of the residuals supports a normal distribution of the residuals (Fig. 5b), though there is a slight deviation in the upper quantile due to a longer negative tail. None of the species included in this dataset exhibit a particularly high Cook's distance in the residuals versus leverage plot, suggesting that none of the 


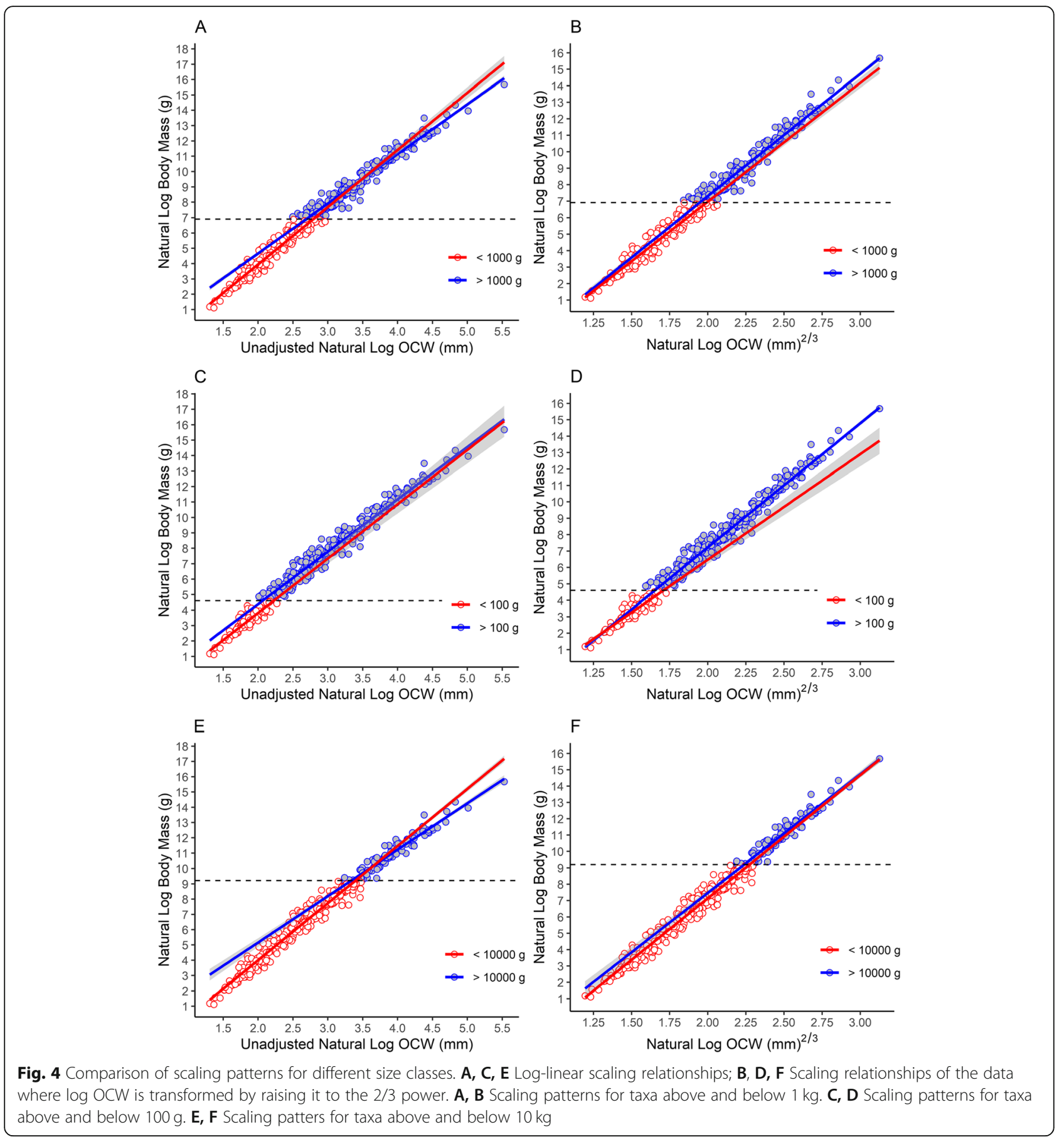

species (including those with specialized condyle morphology) significantly influence the regression model on their own (Fig. 6b).

The absolute value of the residuals is significantly correlated with the sample size for each species $(t=-$ $2.011, p=0.045)$. However, the $r^{2}$ value of this correlation is very low (0.010) and the slope is close to zero $(m=-0.00633)$. Plotting the absolute value of the residuals versus sample size does shows a general decrease in error as $N$ increases (Additional file 4), though this effect is not strong. These results are likely a consequence of the way that sampling works. Drawing from smaller sample sizes of species increases the influence of individual variation on the mean value, but a single sampled individual could by sheer random chance be close to the theoretical mean value for the species. By contrast, larger sample sizes generally "average out" individual deviations from the species average $[133,134]$. Hence, there is not 
Table 4 Results of the regressions of natural log OCW (in mm) against natural log body mass (in $\mathrm{g}$ )

\begin{tabular}{|c|c|c|c|c|c|c|c|}
\hline Dataset & $N$ & Equation & $r_{\text {adj }}^{2}$ & \%PE & $\mathrm{CF}$ & $\% \mathrm{PE}_{\mathrm{cf}}$ & \%SEE \\
\hline All species & 404 & $\ln ($ body mass $)=7.69289 \times \ln (\mathrm{OCW})^{2 / 3}-8.19502$ & 0.9810 & 32.03 & 1.047 & 31.09 & $\overline{47.69}$ \\
\hline Therians only & 401 & $\ln ($ body mass $)=7.70727 \times \ln (\mathrm{OCW})^{2 / 3}-8.21527$ & 0.9823 & 31.55 & 1.037 & 30.83 & 45.92 \\
\hline Excluding taxa & 374 & $\ln ($ body mass $)=7.76568 \times \ln (\mathrm{OCW})^{2 / 3}-8.36414$ & 0.9862 & 27.89 & 1.021 & 27.47 & 40.62 \\
\hline All species $(N \geq 6)$ & 170 & $\ln ($ body mass $)=7.68862 \times \ln (\mathrm{OCW})^{2 / 3}-8.18776$ & 0.9785 & 29.77 & 1.065 & 28.69 & 43.99 \\
\hline All species $(N \geq 6)$, excluding taxa & 160 & $\ln ($ body mass $)=7.76999 \times \ln (\mathrm{OCW})^{2 / 3}-8.2391$ & 0.9815 & 27.72 & 1.068 & 26.56 & 41.30 \\
\hline All species $(N \geq 10)$ & 75 & $\ln ($ body mass $)=7.71479 \times \ln (\mathrm{OCW})^{2 / 3}-8.19504$ & 0.9901 & 22.57 & 1.041 & 22.53 & 32.76 \\
\hline All species $(N \geq 10)$, excluding taxa & 73 & $\ln ($ body mass $)=7.71406 \times \ln (\mathrm{OCW})^{2 / 3}-8.21147$ & 0.9916 & 20.71 & 1.042 & 20.66 & 30.14 \\
\hline Species $>1000 \mathrm{~g}$ & 232 & $\ln ($ body mass $)=7.4292 \times \ln (\mathrm{OCW})^{2 / 3}-7.5507$ & 0.9526 & 30.76 & 1.080 & 30.04 & 46.17 \\
\hline Australidelphia & 32 & $\ln ($ body mass $)=8.1213 \times \ln (\mathrm{OCW})^{2 / 3}-8.9050$ & 0.9720 & 31.30 & 1.025 & 30.54 & 47.44 \\
\hline Ungulates & 61 & $\ln ($ body mass $)=7.6451 \times \ln (\mathrm{OCW})^{2 / 3}-8.0565$ & 0.9619 & 27.62 & 1.057 & 27.47 & 39.95 \\
\hline Primates & 44 & $\ln ($ body mass $)=8.2761 \times \ln (\mathrm{OCW})^{2 / 3}-9.5675$ & 0.9636 & 18.75 & 1.029 & 18.06 & 28.41 \\
\hline Rodentia & 96 & $\ln ($ body mass $)=7.8157 \times \ln (\mathrm{OCW})^{2 / 3}-8.2573$ & 0.9710 & 29.35 & 1.078 & 29.19 & 40.80 \\
\hline Sciuromorpha & 29 & $\ln ($ body mass $)=8.2497 \times \ln (\mathrm{OCW})^{2 / 3}-9.1570$ & 0.9726 & 16.63 & 1.039 & 16.45 & 24.37 \\
\hline Carnivora & 81 & $\ln ($ body mass $)=8.5852 \times \ln (\mathrm{OCW})^{2 / 3}-10.2696$ & 0.9750 & 22.60 & 1.031 & 21.96 & 34.62 \\
\hline
\end{tabular}

Excluded datasets refer to analyses where groups with apomorphic occiput morphology (Monotremata, Cingulata, Dermoptera, Lagomorpha, Caviidae, Dinomyidae, and Dipodomys) were removed from the calculation. All abbreviations follow Table 3

a straightforward linear correlation between sample size and the absolute value of the residuals. Low sample sizes do not necessarily produce higher error rates, but higher sample sizes generally reduce error.

On an ordinal scale (treating the four suborders of rodents separately due to their large sample size in the present data and high overall diversity and morphological disparity), residuals are high $(>|0.5|$, negative values representing overestimates of body mass and positive values underestimates) in Castorimorpha (0.535, primarily driven by Dipodomys spp. and Geomyidae), Dermoptera (1.040), Lagomorpha (0.664), Macroscelidea (- 0.533), Monotremata (- 1.157), Paucituberculata $(-0.721)$, and Scandentia $(-0.560)$ (see Table 5). Cingulata also exhibits high average residuals $(-0.495)$, though not greater than -0.5 . Most of these groups exhibited occiput morphology that significantly deviates from the mammalian average with the exception of Macroscelidea, Paucituberculata, and Scandentia. The high residuals in these taxa cannot be attributed to small sample size, as all three are represented by at least three species and most species are represented by six or more specimens each.

A major concern of using species averages as the unit of observation in studies of body mass estimation is that it impedes the ability of the resulting regression models to make predictions about individual organisms. It is often assumed that using species average values will improve the overall accuracy of regression models by removing noise created by individual variation and body condition (e.g., underweight and overweight animals "offsetting" each other), but this may in turn inhibit the ability of such equations to identify intraspecific patterns
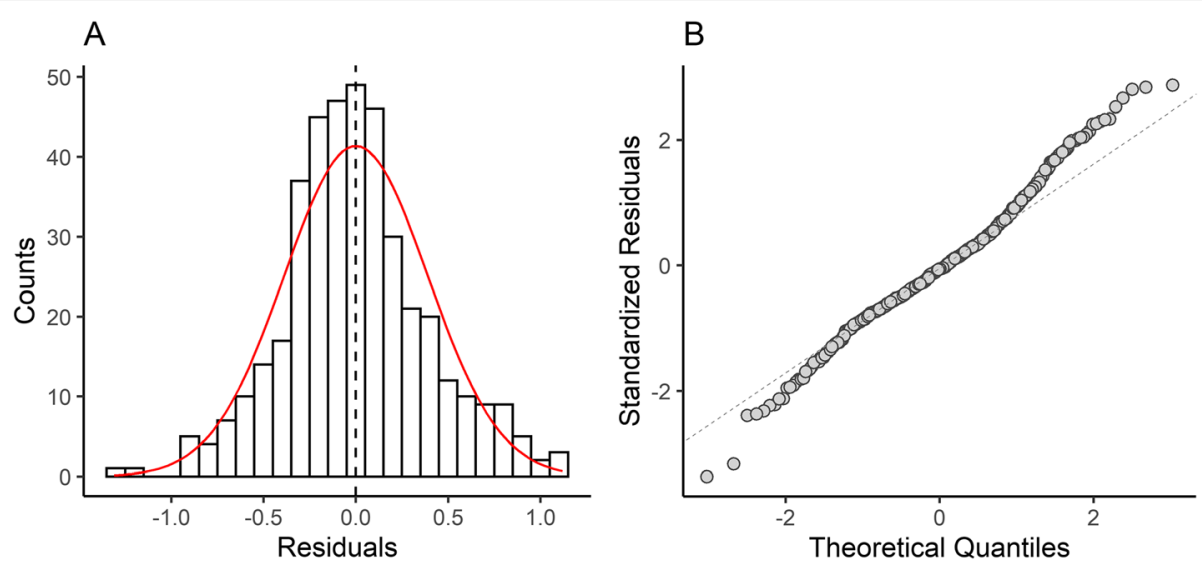

Fig. 5 Histogram (A) and Q-Q plot (B) of the residuals of the total species regression analysis between natural log OCW and natural log body mass, showing the approximately normal distribution of the residuals 

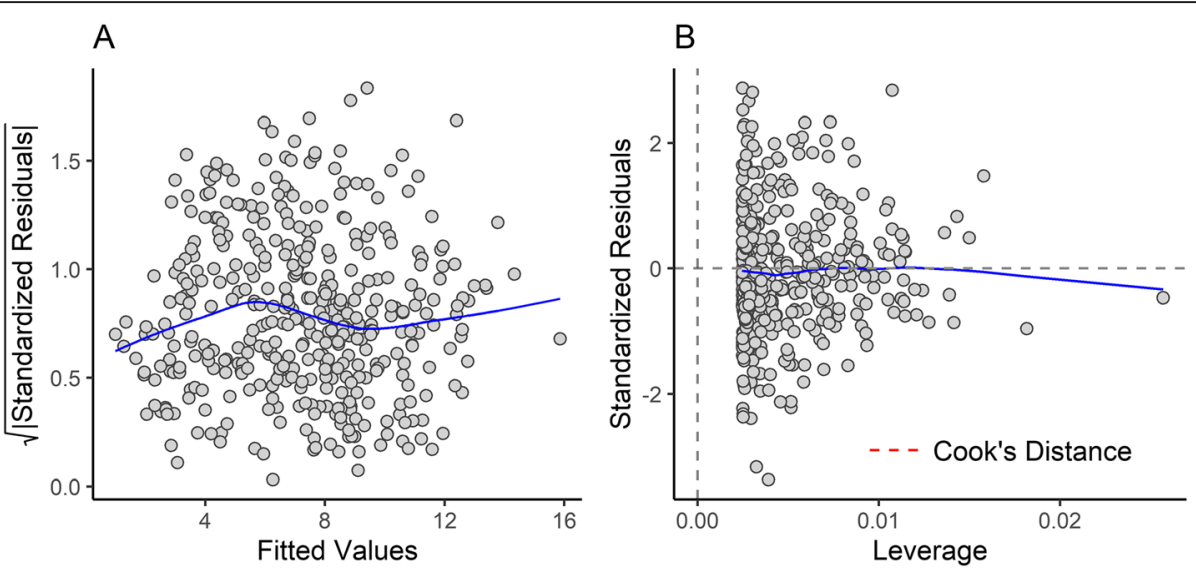

Fig. 6 Diagnostic plots of the total species regression between natural log OCW and natural log body mass, showing the scale-location plot (A) and the residuals versus leverage (B)

of body size variation such as sexual dimorphism, growth patterns, clinal variation, or differences in body size across geologic time [133, 135]. This is especially true for fossil mammals, where body mass estimations are often made on single specimens due to small sample sizes rather than species averages. A regression equation calculated using individual specimens as the observational unit, rather than species averages, produces comparable regression accuracies $\left(\% \mathrm{PE}=34.43, \% \mathrm{PE}_{\mathrm{cf}}=\right.$ $32.93, \% \mathrm{SEE}=50.60$; Table 6) to the all-species regression equation (Table 4). Additionally, the non-linear least squares fit treating all specimens independently producing a similar exponent to the species average equation (Table 3 ). This suggests that variation in OCW may not just correlate to species average body size, but the body size of the individual organism being measured.
Another concern is that differences in sexual dimorphism might influence the accuracy of regression models, which is why some studies have calculated regression equations treating the means for males and females as separate data points $[39,57]$. Treating the means of males and females as separate data points in the present study, filtering out individuals in which sex was unknown, resulted in a regression equation very similar to the all-species regression equation (Additional file 2) and differences between males and females were found to be non-significant $(t=0.552, p=0.581)$.

\section{Regression models considering condyle morphology}

Three specialized configurations of the occiput were observed in this study. Most mammals had rounded, reniform condyles that were located directly lateral to the

Table 5 Average residuals and \%PE $\mathrm{E}_{\mathrm{cf}}$ by order, along with the number of species sampled for each order

\begin{tabular}{|c|c|c|c|c|c|c|c|}
\hline Order & $N$ & Mean residual & Mean $\% \mathrm{PE}_{\mathrm{cf}}$ & Order & $N$ & Mean residual & Mean \%PE \\
\hline Afrosoricida & 3 & -0.009 & 58.10 & Macroscelidea & 4 & -0.533 & 43.74 \\
\hline Anomaluromorpha & 4 & 0.098 & 26.94 & Microbiotheria & 1 & -0.317 & 30.47 \\
\hline Artiodactyla & 51 & -0.015 & 28.85 & Monotremata & 3 & -1.157 & 69.54 \\
\hline Carnivora & 81 & -0.125 & 27.63 & Myomorpha & 35 & 0.059 & 25.76 \\
\hline Castorimorpha & 10 & 0.535 & 68.46 & Paucituberculata & 3 & -0.721 & 53.28 \\
\hline Cingulata & 6 & -0.495 & 39.62 & Peramelemorphia & 3 & 0.044 & 19.70 \\
\hline Dasyuromorphia & 9 & -0.123 & 25.18 & Perissodactyla & 6 & 0.039 & 23.01 \\
\hline Dermoptera & 1 & 1.04 & 170.10 & Pholidota & 1 & 0.099 & 10.40 \\
\hline Didelphimorphia & 27 & -0.062 & 27.39 & Pilosa & 4 & 0.141 & 25.69 \\
\hline Diprotodontia & 19 & 0.264 & 46.25 & Primates & 44 & -0.108 & 19.18 \\
\hline Eulipotyphla & 23 & 0.044 & 18.70 & Proboscidea & 1 & -0.178 & 20.09 \\
\hline Hyracoidea & 4 & 0.056 & 15.59 & Scandentia & 3 & -0.56 & 45.32 \\
\hline Hystricomorpha & 18 & 0.277 & 49.37 & Sciuromorpha & 29 & 0.067 & 18.82 \\
\hline Lagomorpha & 10 & 0.664 & 91.74 & Tubulidentata & 1 & 0.102 & 5.78 \\
\hline
\end{tabular}

Rodents categorized by suborder (i.e., Myomorpha, Sciuromorpha) due to large sample size $(N=95)$ and high intraordinal \%PE seen within this group 
Table 6 Regression equations for OCW under PGLS, using all individual specimens, using only wild-caught specimens, and including condyle shape or brain size as additional variables

\begin{tabular}{|c|c|c|c|c|c|c|c|c|}
\hline Analysis & $N$ & Equation & df & $r_{\text {adj }}^{2}$ & $\% \mathrm{PE}$ & CF & $\% \mathrm{PE}_{\mathrm{cf}}$ & $\%$ SEE \\
\hline \multicolumn{9}{|l|}{ PGLS } \\
\hline Brownian & 404 & $\ln ($ body mass $)=7.933560 \times \ln (\mathrm{OCW})^{2 / 3}-9.095213$ & 402 & - & 68.88 & 1.754 & 31.56 & 276.00 \\
\hline OU model & 404 & $\ln ($ body mass $)=7.691496 \times \ln (\text { OCW })^{2 / 3}-8.191059$ & 402 & - & 32.00 & 1.046 & 31.08 & 47.45 \\
\hline \multicolumn{9}{|c|}{ Using all specimens individually } \\
\hline OCW & 2127 & $\ln ($ body mass $)=7.68179 \times \operatorname{In}(\mathrm{OCW})^{2 / 3}-8.18617$ & 2125 & 0.9775 & 34.43 & 1.071 & 32.93 & 50.60 \\
\hline \multicolumn{9}{|c|}{ Using species average of wild-caught specimens only } \\
\hline OCW & 346 & $\ln ($ body mass $)=7.6249 \times \ln (\mathrm{OCW})^{2 / 3}-8.0759$ & 344 & 0.9764 & 32.09 & 1.071 & 30.91 & 48.51 \\
\hline \multicolumn{9}{|c|}{ Including "monotreme-like" and "rabbit-like" states as additional variables } \\
\hline OCW & 404 & $\begin{array}{l}\ln (\text { body mass })=0.71517 \times \text { rabbit }-1.14562 \times \text { monotreme }+7.75844 \times \\
\ln (\mathrm{OCW})^{2 / 3}-8.35284\end{array}$ & 400 & 0.9850 & 28.18 & 1.025 & 27.68 & 41.37 \\
\hline \multicolumn{9}{|c|}{ OCW + brain mass } \\
\hline $\begin{array}{l}\text { OCW }+ \text { brain } \\
\text { mass }\end{array}$ & 323 & $\ln ($ body mass $)=6.96789 \times \ln (\mathrm{OCW})^{2 / 3}+0.12473 \times \ln ($ brain mass $)-7.03109$ & 320 & 0.9807 & 31.51 & 1.063 & 30.48 & 46.36 \\
\hline OCW & 323 & $\ln ($ body mass $)=7.65044 \times \ln (\mathrm{OCW})^{2 / 3}-8.08812$ & 321 & 0.9803 & 31.54 & 1.050 & 30.56 & 46.88 \\
\hline
\end{tabular}

Abbreviations as for Table 3 and "Methods"

foramen magnum and closely followed the margins of this structure (Fig. 7a). However, several alternate states of occiput morphology could be observed, notably the mediolaterally narrow, pulley-like condyles of lagomorphs and caviids (Fig. 7b), the very wide occipital condyles of monotremes which do not follow the margins of the foramen magnum (Fig. 7c), and the rectangular, laterally projecting condyles of cingulates (Fig. 7d)
With regard to lagomorphs and taxa with lagomorphlike occipital condyles, which were the most heavily sampled group of mammals with a specialized condyle morphology $(N=19)$, a summary of slopes test found that the interaction between slope and the presence of lagomorph-like occipital condyles was non-significant $(t$ $=0.050, p=0.960)$. What this means rabbit-like and non-rabbit-like taxa have near-identical allometries, and
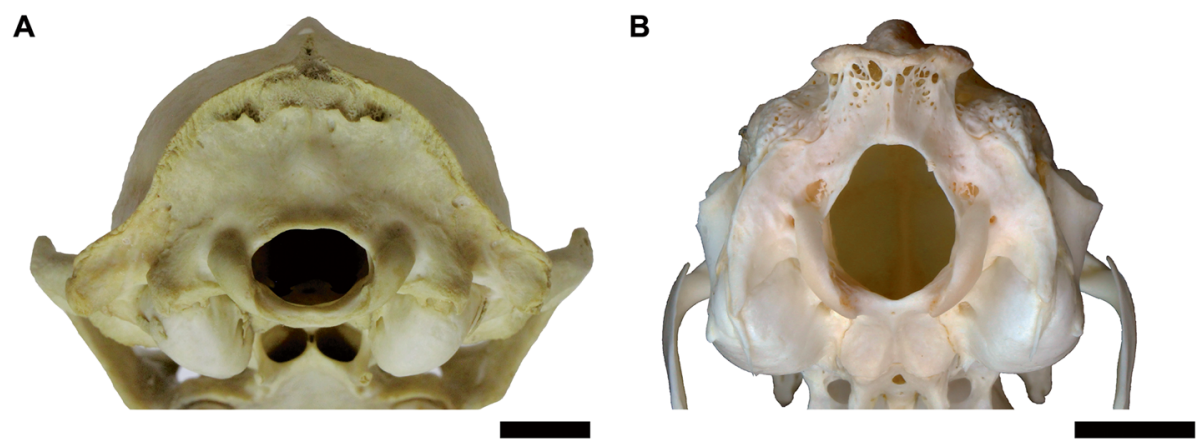

C
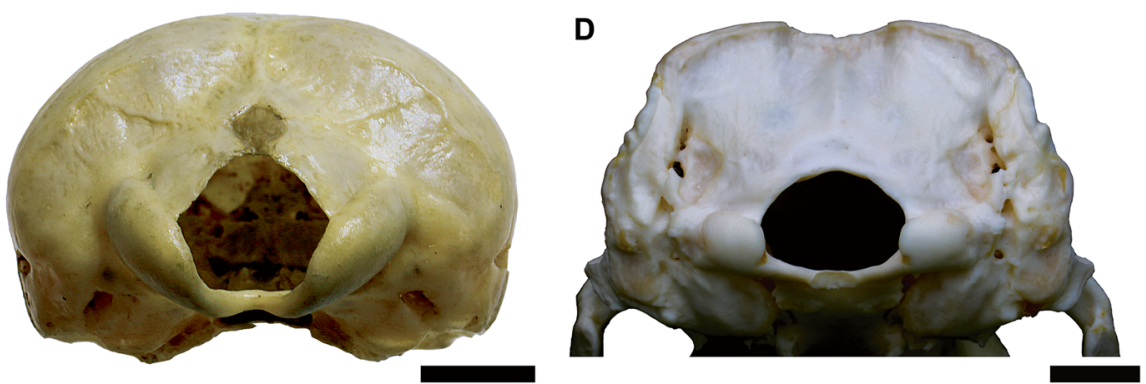

Fig. 7 Occipital region of a typical mammal (A; Procyon lotor, CMNH 22076), contrasting with the distinctive occiput morphology of lagomorphs (B; Lepus sp., R. Engelman pers. col.), monotremes (C; Tachyglossus aculeata, CMNH 18877), and cingulates (D; Euphractus sexcinctus, R. Engelman pers. col.). Scale $=1 \mathrm{~cm}$ 
the primary difference between these two groups driving the high residuals in taxa with rabbit-like condyles is a shift in the $y$-intercept. This, in turn can be related to the fact that the mediolaterally narrow condyles of lagomorphs and taxa with similar occiput morphology results in a lower OCW relative to other mammals. This observation is further supported by the fact that the slopes of the all-taxon regression line and a regression line calculated based solely on with lagomorph-like occipital condyles are nearly identical (see Tables 4 and 6 and Fig. 8). A regression line could not be calculated for Monotremata as only three monotreme taxa were included in this analysis and all extant monotremes span a very narrow range of body sizes $(2-3 \mathrm{~kg})$.

Adding two additional binary categorical variables to the model describing whether a taxon has a "lagomorph-like" or "monotreme-like" occipital morphology results in higher $r^{2}$ values and much lower \% $\mathrm{PE}$ and \%SEE (Table 6). The AIC (295), BIC (315), and $\log$ likelihood (-143) for the model considering additional variables for condyle shape are much lower than for any of the models only considering OCW and body mass (compare these values to the ones reported in Table 2). Both the state of having of a monotreme-like occiput morphology $(t=-5.702, p<$ $0.001)$ or a lagomorph-like occiput morphology $(t=$ 8.720, $p<0.001$ ) significantly correlated with body mass when considered as additional independent factor variables in the regression equation.

\section{Regression models by taxon}

Datasets excluding taxa with apomorphic occiput morphology (e.g., Monotremata, Lagomorpha) had lower values of $\% \mathrm{PE}_{\mathrm{cf}}$ and standard error of the estimate (\%SEE), with $\% \mathrm{PE}_{\mathrm{cf}}<30 \%$ for all analyses (Table 4). Even when excluding these data, the regression line of the log-power model still showed a $2 / 3$ power exponent (Table 3). Calculating the regression line based only on species with large sample sizes also resulted in lower error. However, the low error values for the equations only including species with more than 10 observations may also be due to decreased taxonomic and morphological breadth, as most species in these analyses pertain to a few taxonomic groups (Eulipotyphla, Rodentia, Carnivora) and only eight species in this analysis were larger than $10 \mathrm{~kg}$. The regression equation including only taxa for which body mass was greater than $1000 \mathrm{~g}$ produced results that were almost identical to the regression for the entire dataset (Table 4).

Examining the best-fit lines by order found that most species with sample sizes $>5$ produced lines with similar allometries to the all species best-fit line, though some groups had different intercept (Additional file 5). Testing for differences in intercept between mammalian orders (or suborders in the case of rodents) found nonsignificant differences for the majority of clades $(N=19$, Additional file 2). However, eight clades did show significant differences in intercept: Castorimorpha, Cingulata, Dermoptera, Lagomorpha, Macroscelidea,

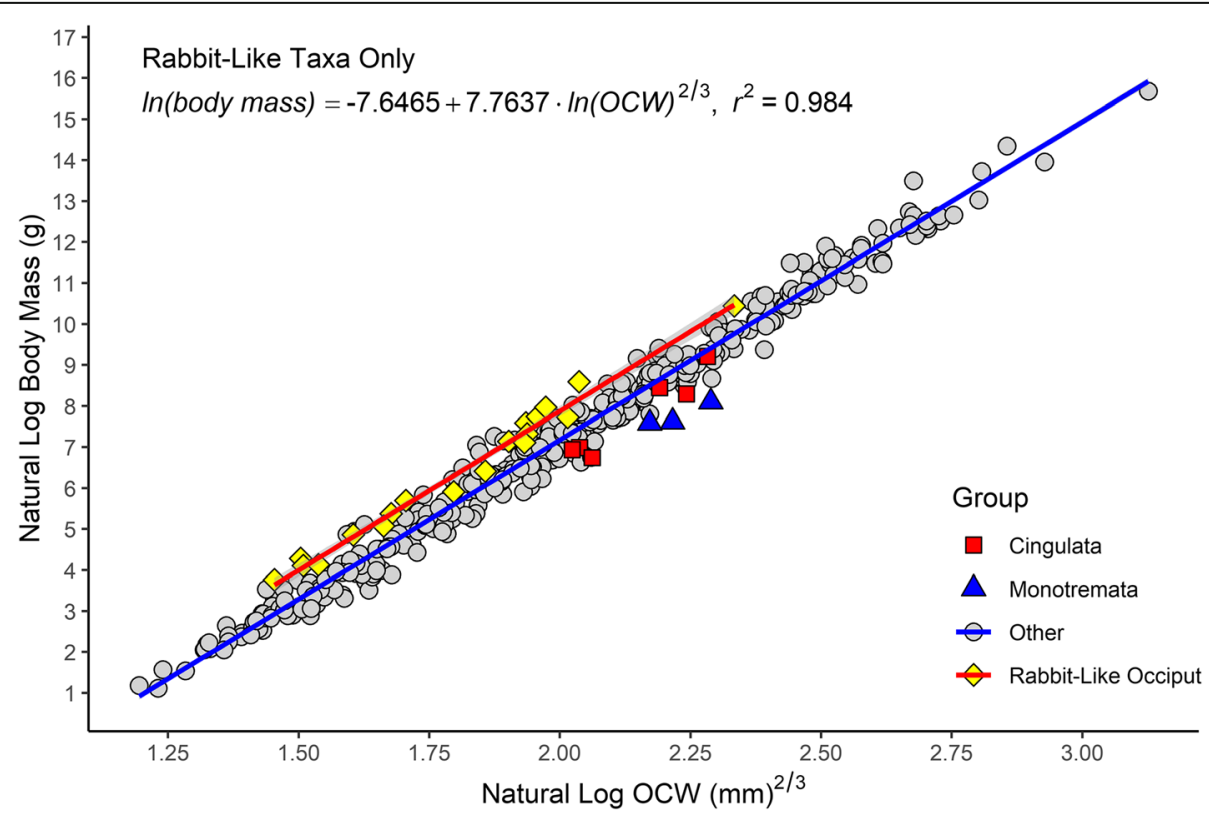

Fig. 8 Scatter plot of natural log of OCW raised to the 2/3 power against the natural log of body mass, showing groups that deviate from the main regression line (cingulates, monotremes, and taxa with rabbit-like occiputs) as well as the regression line formed by taxa with rabbit-like occiputs (in red) 
Monotremata, Paucituberculata, and Scandentia. These clades are all groups which are either characterized by specialized occiput morphology relative to other mammals (Castorimorpha, Cingulata, Dermoptera, Lagomorpha, Monotremata), or otherwise exhibit high residuals as a clade (Macroscelidea, Scandentia, Paucituberculata). Additionally, Macroscelidea, Scandentia, and Paucituberculata exhibit higher $p$ values $(0.05>p>0.01)$ than taxa with extreme occiput specializations $(p<0.01)$.

Examining differences in slope between clades by creating an interaction term between taxonomic group and OCW found that most of the differences between groups were non-significant. When setting Artiodactyla as the reference level (because of the low number of species in the alphabetically first taxon, Afrosoricida), the only groups to have significantly different slopes were Afrosoricida, Carnivora, Dasyuromorphia, Didelphimorphia, and Hystricomorpha. However, the 95\% confidence intervals for slopes all strongly overlap with one another and the slope for the all-species regression line except for Afrosoricida, which is composed of a small number of species spanning a narrow range of body sizes $(N=3$, $140-500 \mathrm{~g}$ ), and thus this result might be due to sampling error. Notably, the slope of Lagomorpha (which are exclusively composed of species with a specialized occiput morphology) did not differ significantly from the remaining sample, further supporting the idea that residuals in the present equation are driven by differences in occiput shape rather than clade-specific patterns of allometric scaling.

Accuracy of the taxonomically restricted regression equations were higher than those of the total species regression, as would be expected based on previous studies. The taxonomically narrowest dataset, the one including only sciuromorph rodents, produced the lowest error values, suggesting that taxonomic breadth is correlated with overall error rates. However, for the allrodent regression equation, residuals and $\% \mathrm{PE}_{\mathrm{cf}}$ for rodent taxa that were outliers in the total species regression (i.e., caviids, Dinomys, and Dipodomys) remain high even when rodents are considered by themselves. The QQ plot and histogram of the residuals of the rodentonly regression also show a strong departure from normality (compare Fig. 5 and Additional file 6), suggesting that all rodents may not conform to a single regression equation (though it is possible this departure from normality could disappear with a larger sample of rodents). Rodentia in general seems to show much higher variation in occiput proportions than most other groups, even after accounting for the high diversity of this clade.

Under a log-quadratic model, the best-fit regression curve was somewhat more variable than the best-fit lines under a log-power model. In particular, the curvature of the best-fit curve was not very well-resolved when trying to predict data beyond the upper and lower bounds of the data (see Additional file 2). This can be seen in the very wide confidence intervals for the best-fit curve beyond the distribution of measured species and the fact that the extrapolated curve for Australidelphia and Primates did not follow the general shape of the data for all mammals. Perhaps the most extreme example of this was the all-Sciuromorph equation, which produced a concave-up curve with an extremely wide confidence interval. This result seems to be the result of several species of Marmota spp., which are known to go through extreme annual variation in body mass [136], but in this case the presence of a few species is able to massively influence the shape of the loq-quadratic regression curve. Indeed, for Sciuromorpha, the second-order term did not have a statistical effect $(t=1.054, p=0.301)$.

Binning the data by superorder to increase sample size results in regression curves for the five therian superorders that are roughly comparable to the all-species model. Xenarthra shows slightly more variation than other therians, but this appears to be due to the low diversity within this clade and the presence of Cingulata (which exhibit specialized occiput morphology). When comparing intercepts between superorders, Euarchontoglires $(t=2.429, p=0.0156)$ has a significantly different intercept from other therians, but this result appears to be driven by the inclusion of species with a specialized lagomorph-like occiput (Lagomorpha, Caviidae) as including the presence of a lagomorph-like occiput as an additional explanatory variable reduces the statistical effect of this result $(t=1.779, p=0.073)$.

Overall, the results of the log-quadratic curves in this study agree with the results of Campione [137] and Müller et al. [138], who found that log-quadratic curves were very unpredictable when extrapolated beyond the range of values used to calculate them and the detection of non-linear allometry was heavily dependent on the range of body sizes included in the dataset, respectively.

\section{Phylogenetic signal and phylogenetic generalized least squares}

The residuals of the all-species regression equation show strong phylogenetic signal (mean $\lambda=0.901, p<0.001$ ). However, \%PE and \%SEE are much higher for under a Brownian model $(\% \mathrm{PE}=68.88 \%, \% \mathrm{SEE}=276 \%)$ than OLS (\%PE $=32.03 \%$, \%SEE = 47.59) (Table 6). Applying correction factors decreases this disparity $\left(\mathrm{PGLS} \% \mathrm{PE}_{\mathrm{c}}\right.$, 31.56; OLS $\left.\% \mathrm{PE}_{\mathrm{cf}}, 31.09\right)$, but at the same time, PGLS requires extremely large correction factors (1.754) that require increasing the fitted value by over $75 \%$ to produce a more accurate result, which suggests deeper methodological problems that are being obscured by the use of correction factors. The high \%SEE is likely due to the fact that PGLS does not remove the effects of phylogeny 
from the analysis nor adjust the predicted values based on phylogenetic position, rather it merely fits the best-fit line that minimizes the covariance between the residuals of the regression and the underlying phylogenetic correlation matrix [139]. Indeed, PGLS generally results in higher standard errors, weaker correlations between variables, and broader confidence intervals compared to OLS [139].

AIC, BIC, and log likelihood values for PGLS were extremely variable and depended entirely on which of the trees from the random sample were chosen for analysis. Despite all 100 trees producing similar regression lines with a relatively little variation in the coefficients (slope $=7.967 \pm 0.088$; $y$ intercept $=-9.160 \pm 0.179$, see Additional file 2), AIC and BIC values formed normal distributions with a range of over 150 and standard deviations of 50 (see Additional file 2), when differences of AIC more than 2 are considered statistically significant [140]. However, the mean and median values for both AIC $($ mean $=406$, median $=396)$ and BIC $($ mean $=418$, median $=408$ ) were higher than for OLS. This extreme variability in AIC values is noteworthy given that all of the PGLS analyses used the same dataset, the trees were similar enough in topology for each to be considered a reasonable approximation of mammalian phylogeny, and the resulting regression equations were near-identical. The high variability in AIC, BIC, and log likelihood values in potential most parsimonious trees makes it almost impossible to use these statistics to make model selection. Indeed, it is rather concerning that whether or not an OLS model is favored over a PGLS one is entirely driven by relatively minor differences in tree choice. Notably, this variation in AIC and BIC did not correlate with model prediction accuracy nor variation in model coefficients. That is, although PGLS under some trees produced an AIC lower than the OLS model, these models did not produce more accurate results. Excluding one model that produced unusually poor support values, \%PE ranged from 62.8 to $78.1 \%$ and \%SEE ranged from 219.9 to 452.6 across the 100 trees examined, at minimum producing error statistics twice as high as OLS. Because the goal of this study is predictive accuracy, rather than model fit, methods for PGLS as currently utilized are inappropriate here. Notably, the issues highlighted in this study are not driven by the data used, but are broader issues concerning PGLS. As the focus of this paper is on using OCW as a body mass estimator, addressing these issues is beyond the scope of the paper.

The PGLS model under Brownian motion produced a best-fit line that almost completely bypassed the distribution of the data (Fig. 9). This pattern is almost entirely driven by the apomorphic occiput of Monotremata (see "Discussion"), demonstrated by the fact that omitting monotremes results in a regression line very close to that produced by an OLS or OU model. Even excluding Monotremata phylogenetic signal in the dataset was still very high (mean $\lambda=0.884, p<0.001$ ), the resulting goodness-of-fit and the accuracy of PGLS (\%PE $=36.12$,

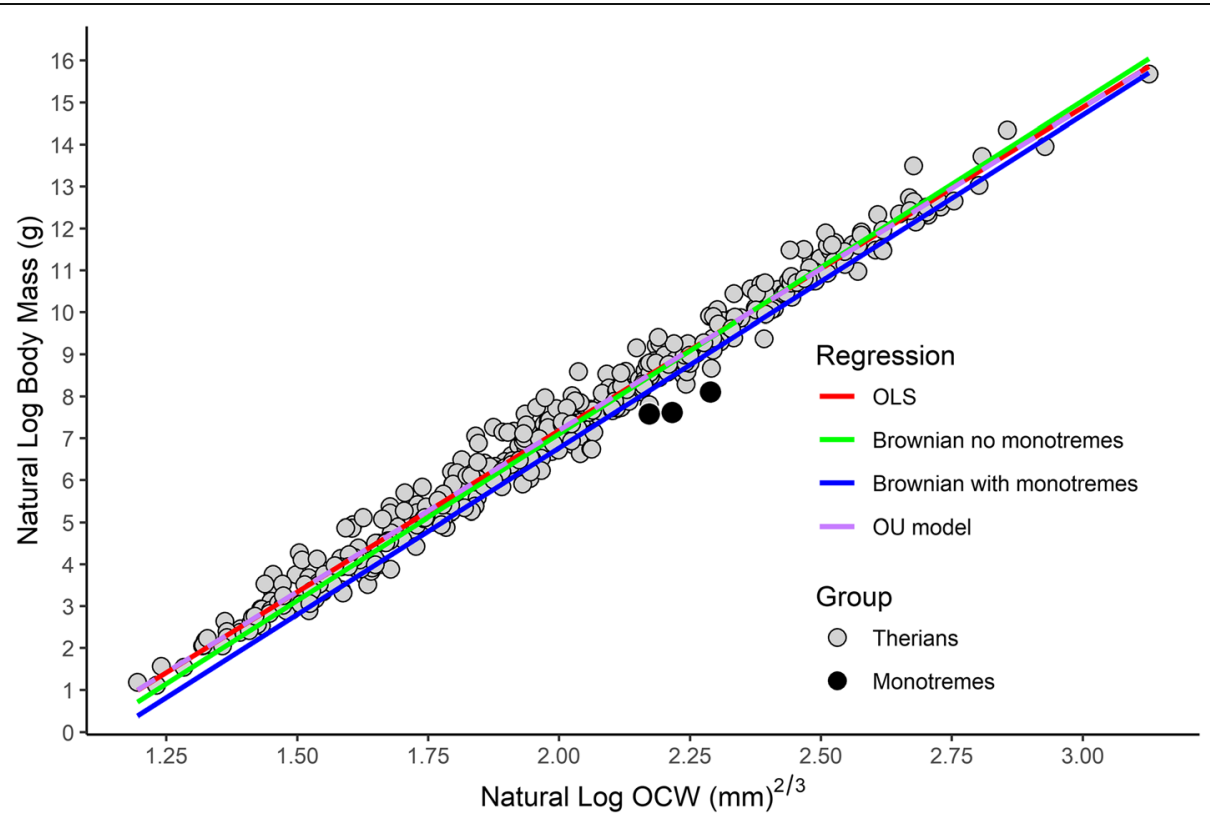

Fig. 9 Linear regression between log OCW and log body mass under OLS (in red), PGLS under a Brownian model (in blue), PGLS under a Brownian model excluding monotremes (in green), and PGLS under an OU model (in purple, dashed to not obscure the other lines), showing how the inclusion of monotreme taxa greatly biases the PGLS regression line under a Brownian model due to the deep divergence between Theria and Monotremata 
$\left.\% \mathrm{PE}_{\mathrm{CF}}=34.30, \% \mathrm{SEE}=277\right)$ was lower than for the therian-only model in OLS $\left(\% \mathrm{PE}=31.55, \% \mathrm{PE}_{\mathrm{CF}}=\right.$ $30.83, \% \mathrm{SEE}=45.9)$. This is a result of the fact that in the absence of phylogenetic information when predicting new values PGLS defaults to assuming the new taxa are located at the root of the entire tree [141]. This, again, is supported by the results of the current dataset: the best fit line under Brownian motion is roughly halfway between the lines formed by monotremes and therians, whereas the line under an Ornstein-Uhlenbeck (OU) model (which can better account for non-uniform rates of evolution) seemingly identified Monotremata as exhibiting a rate shift compared to other mammals. Phylogenetic information from the evolutionary model must be incorporated back into the model in order to produce accurate predictions, or else it will produce inaccurate results. This is an issue that is known in the specialist literature on phylogenetic comparative methods and has mathematical solutions [141], but is currently not implemented in available PGLS software (i.e., the fitted values reported by available PGLS R packages produce identical values to those manually calculated by treating the PGLS best-fit line as an OLS line). As this is a larger issue with the software presently available to perform PGLS, rather than unique to the present dataset, discussing and addressing this problem is beyond the scope of the present study. It seems likely that a PGLS model that includes signal in its predictions will outperform OLS given that signal apparently is present in the relationship between OCW and body mass, but presently available $\mathrm{R}$ packages do not allow for the consideration of signal when making predictions. As a result, the PGLS models produced here should not be used to estimate body mass over OLS.

Fitting a PGLS using an OU model instead of a Brownian model produces much lower error statistics with almost identical values to the OLS model (Table 2 ), though the AIC, BIC, and log likelihood are still much higher than under OLS. The PGLS under an OU model does not offer a significant improvement in error rates over OLS. The best-fit line produced by the OU model is nearly identical to that produced under OLS (Fig. 9).

The results of a PGLS using a log-quadratic model are very similar to those of a log-power model. The secondorder term is found to be significant under both a Brownian $(t=-8.528, p<0.001)$ and an OU model $(t=$ - 7.416, $p<0.001)$. The resulting best-fit line under a Brownian model shows significantly greater curvature than the OLS model, regardless of whether or not monotremes are excluded (see Additional file 2). By contrast, the PGLS fit under an OU model and logquadratic regression equation is nearly identical to that under OLS. As with the log-power model, the Brownian
PGLS without monotremes has a positive shift in the $y$ intercept compared to the model including monotremes. Overall, these results suggest that the curvilinear pattern between $\ln$ OCW and ln body mass is a real pattern and cannot be attributed to phylogenetic signal or different scaling patterns between clades.

Ancestral state reconstruction suggests that the relationship between OCW and body mass has remained relatively constant within Theria with pronounced shifts in covariance between the two variables occurring at several nodes, rather than covariance changing through random (=Brownian) drift across the entire tree (Additional file 7). The nodes that characterize abrupt shifts in OCW residuals almost always pertain to the most recent common ancestor of clades characterized by unusual occiput morphology. Negative shifts (i.e., OCW is smaller than expected for body size) are observed at the base of the clades Pseudocheiridae, Macropodini, Microtinae, Geomyidae, Dipodomyinae, Caviidae, Lagomorpha, and Camelidae. Positive shifts are observed at the bases of the clades Paucituberculata, Euphractinae, Macroscelidea, Scandentia, and Mustelidae (especially Mustela spp.). Monotremata also had strong positive residuals (and indeed, had the highest positive residuals of any clade), though due to its basal position it is not clear if this represents the ancestral state for the group or is another morphological shift. Several of these shifts (namely with Dipodomyinae, Caviidae, Lagomorpha, and Euphractinae) are associated with apomorphic occiput morphology compared to the rest of Theria.

\section{Effects of captivity status}

When fitting a multivariate ordinary least squares (OLS) regression of all individual specimens treating captivity status as an additional independent factor variable, captivity status is found to be significant $(t=-3.259, p=$ 0.00114 ), with specimens from zoological parks exhibiting slightly higher body mass. However, this difference is slight when examining the distribution of residuals in the two groups via a box plot (Additional file 8). Captivity status is non-randomly distributed with respect to order or body size in the dataset (Additional file 8), due to most data from zoological parks pertaining to megafauna (and vice versa, due to the logistic difficulty in obtaining body masses for wild megafauna). For example, $29.3 \%$ of all artiodactyl specimens (51/174), $12.7 \%$ of all carnivoran specimens $(55 / 432)$, and $71.4 \%$ of all perissodactyl specimens $(5 / 7)$ in this analysis came from zoological collections. By contrast, only $1.7 \%$ of rodents (11/636), $0.0 \%$ of didelphimorphian (0/168), and $0.6 \%$ of all eulipotyphlan specimens $(1 / 180)$ came from captivity. Due to this, captivity status is strongly correlated with body size $(t=-13.54, p<0.001)$. Hence, what appears to be a straightforward relationship between 
captivity status and the residuals could be confounded by the non-randomness of the data with respect to phylogeny.

The results of the phylogenetic generalized linear mixed model including both phylogenetic signal and captivity status found captivity status to be nonsignificant (0.325). Omitting all captive specimens and recalculating the regression equation using the species averages for all wild-caught specimens produced a slope (7.289) and exponent (0.663) comparable to that of the all-taxon species average regression equation. The values of this model were within the $95 \%$ confidence interval of the OLS model and the resulting regression line was not significantly different from the regression line using the average values for all specimens (ANOVA, $\mathrm{F}=0.791, p$ $=0.863)$.

\section{Covariance with brain size}

Plotting the residuals of the regression equation against relative brain size (measured as the residuals of a regression between brain mass and body mass) found the relationship between the two to be significant $(p<0.001)$ with a negative slope, but with a low correlation coefficient $\left(r^{2}\right.$ adj $=0.17$; Additional file 9). Brain size significantly correlated with body mass $(p=0.009)$ when treated as an additional independent variable but produced almost no change in model accuracy (Table 6). Comparing the residuals of the regression with brain mass as an additional independent variable against the equation where brain mass is not considered (Additional file 10) finds the residuals of the two regression equations to be highly correlated $\left(r^{2}=0.979, t=121.3, p<\right.$ 0.001 ) and the slope of this regression line is equal to 1 , suggesting that adding brain mass as an additional variable does not significantly reduce the residual variance in the regression between OCW and body mass. By contrast, if brain size significantly improved the regression model, it would be expected that the slope of the plot between the residuals of the two equations would be lower (due to residuals in the regression equation with brain size being lower residuals than the one without brain size), as well as exhibit a poorer fit on the extreme ends of the equation (due to the regression equation with brain size producing more accurate results and lower residuals). If natural log brain mass was included as an additional quantitative predictor variable, mass estimates from this model only differed from the model where brain mass was not considered by approximately $4.3 \%$. Ultimately, brain size had less of an effect on predicted body mass differences in occiput shape (i.e., excluding species with apomorphic occiput morphology or adding additional categorical variables to describe occiput shape, see Table 6).

\section{Comparisons with skull length and head-body length}

As with OCW, the relationship between skull length (as condylobasal length) and body size was not log-linear, but instead showed non-linear allometry. Specifically, larger mammals had disproportionately larger skulls relative to their body size compared to smaller mammals (Additional file 1). Comparing several models, the bestfitting model was a power model where ln condylobasal length was transformed by raising it to the $1 / 2$ power before regressing it against $\ln$ body mass (Additional file 2) and had better accuracy $\left(\% \mathrm{PE}_{\mathrm{cf}}=35.93, \mathrm{AIC}=544\right)$ than if skull length was assumed to scale with geometric similarity $\left(\% \mathrm{PE}_{\mathrm{cf}}=42.49, \mathrm{AIC}=597\right)$. A log-quadratic model had the second-lowest AIC and BIC values (Additional file 2) and the second-order term in this model was found to be statistically significant $(t=-7.604, p<$ 0.001).

A residuals versus fitted plot where skull length is not raised to the $1 / 2$ power reveals a distinctly non-linear pattern (Fig. 3c), which is supported by a Breusch-Pagel test of the function ( $\mathrm{BP}=9.0425, \mathrm{df}=1, p=0.003)$. This indicates it is not appropriate to treat the relationship between skull length and body mass as isometric. After raising skull length to the $1 / 2$ power, the residuals are more linear (Fig. 3d) but not completely homoscedastic (Breush-Pagan test; $\mathrm{BP}=8.0292, \mathrm{df}=1 p=0.004$ ). However, the scale-location plot shows little obvious signs of heteroskedasticity (see Additional file 2) and the data is much closer to homoscedasticity than the model where $\log$ skull length is not raised to the $1 / 2$ power. Examination of the data (see Additional file 2) suggests that the heteroskedasticity of the transformed dataset is driven by a few taxa such as the giant anteater (Myrmecophaga tridactyla) which have a very long skull relative to body size, or by taxa with fewer observations (which tend to be larger species), rather than by a significant heteroskedastic pattern across the entire dataset as in the untransformed variable. The regression equation between skull length (measured as condylobasal length) and body mass produces an equation with a $\% \mathrm{PE}_{\mathrm{cf}}$ of $35.93 \%$ and an SEE of $60.32 \%$ (Table 7), which is much higher than the same values for the same taxa under OCW. Even if excluding primates, which are characterized by a short rostrum and thus may not be comparable to other mammals, OCW still outperformed skull length (Table 7).

In contrast to OCW and skull length, HBL scaled isometrically with body mass (Table 7 ). The regression equation of head-body length (HBL) versus body mass produces an equation with a $\% \mathrm{PE}$ of $35.79 \%\left(\mathrm{PE}_{\mathrm{cf}}=\right.$ 34.38) and SEE of 52.91\%. Again, this is much higher than the same accuracy statistics under OCW.

Error values when regressing OCW against skull length or HBL were much lower than that produced when any of these variables were regressed against body 
Table 7 Body mass regression equations using condylobasal length (CBL) and head-body length (HBL)

\begin{tabular}{|c|c|c|c|c|c|c|c|c|}
\hline Analysis & $N$ & Equation & df & $r_{\text {adj }}^{2}$ & \%PE & $\mathrm{CF}$ & $\% \mathrm{PE}_{\mathrm{cf}}$ & \%SEE \\
\hline \multicolumn{9}{|c|}{ Condylobasal length (CBL) } \\
\hline CBL & 404 & $\ln ($ body mass $)=14.2241 \times \ln (C B L)^{1 / 2}-22.4349$ & 402 & 0.9722 & 39.96 & 1.182 & 35.93 & 60.32 \\
\hline CBL no primates & 360 & $\ln ($ body mass $)=14.1665 \times \ln (C B L)^{1 / 2}-22.3646$ & 358 & 0.9753 & 38.80 & 1.211 & 35.06 & 58.65 \\
\hline \multicolumn{9}{|l|}{$\mathrm{HBL}$} \\
\hline $\mathrm{HBL}$ & 404 & $\ln ($ body mass $)=2.9749 \times \ln (\mathrm{HBL})-10.3386$ & 402 & 0.9775 & 35.79 & 1.195 & 34.38 & 52.91 \\
\hline \multicolumn{9}{|c|}{$\mathrm{OCW}$ versus $\mathrm{CBL}$ and $\mathrm{HBL}$} \\
\hline OCW versus $C B L$ & 404 & $\ln ($ body mass $)=1.04366 \times \ln (\mathrm{OCW})-1.38825$ & 402 & 0.9654 & 12.04 & 1.012 & 12.01 & 16.55 \\
\hline $\mathrm{OCW}$ versus $\mathrm{HBL}$ & 404 & $\ln ($ body mass $)=2.53378 \times \ln (\mathrm{OCW})^{2 / 3}-0.82550$ & 402 & 0.9634 & 13.92 & 1.015 & 13.77 & 19.70 \\
\hline \multicolumn{9}{|l|}{$\mathrm{OCW}+\mathrm{CBL}+\mathrm{HBL}$} \\
\hline $\begin{array}{l}\mathrm{OCW}+\mathrm{CBL}+ \\
\mathrm{HBL}\end{array}$ & 404 & $\begin{array}{l}\ln (\text { body mass })=3.8162 \times \ln (\mathrm{OCW})^{2 / 3}+1.1223 \times \ln (\mathrm{HBL})+1.9521 \times \ln (\mathrm{CBL})^{1 / 2}- \\
11.1212\end{array}$ & 402 & 0.9889 & 24.41 & 1.098 & 23.34 & 34.95 \\
\hline
\end{tabular}

Abbreviations as for Table 3 and "Methods". Condylobasal length approximately equivalent to skull length in this analysis

mass (Table 4). This suggests that these three linear metrics are all closely approximating a similar measure of overall size, but that much of the residual variation in body mass regression equations is being driven by factors that are not being captured by linear skeletal measurements. Residuals for the regression between $\mathrm{HBL}$ and OCW were high $(>|0.2|)$ in Dermoptera (0.329), Lagomorpha (0.261), and Monotremata $(-0.448)$, as well as Cingulata $(-0.192)$ to a lesser degree. This highlights how even under a different proxy for body size these animals had occipital condyles that were much narrower (Dermoptera, Lagomorpha) or wider (Cingulata, Monotremata) than would be predicted for a mammal of their size.

The covariance of the residuals of the regression for OCW and skull length (0.054), OCW and HBL (0.022), and HBL and skull length (0.091) are all very low. The residuals of $\mathrm{OCW}$ are significantly correlated with the residuals of both HBL $(t=2.638, p<0.001)$ and skull length $(t=6.146, p<0.001)$, but the $r^{2}$ value for these regressions is extremely low (OCW versus $\mathrm{HBL}, r^{2}=$ 0.02; OCW versus skull length, $r^{2}=0.09$ ). Plotting the residuals of the body mass regression equations for skull length and HBL (Additional file 11) against the residuals for OCW does not produce a strong pattern of correlation. Indeed, the covariance between HBL and skull length and the correlation coefficient between these two variables $\left(r^{2}=0.21\right)$ is higher than that for OCW and either HBL or skull length, which may be due to the nonindependence of $\mathrm{HBL}$ and skull length due to skull length contributing to HBL. The low covariance between the residuals of OCW and skull length suggests that OCW is not strongly influenced by relative head size, in contrast to skull length.

Finally, a multivariate regression equation was performed considering all three variables together as independent estimators. OCW, skull length, and HBL all significantly correlated with body mass as singular variables $(p<0.001$ in all cases), so the question remained whether error would be reduced if all three were considered together. In the multivariate regression equation all three variables were significantly correlated with body mass $(p<0.001)$, but skull length was less correlated with body mass $\left(\mathrm{F}=3.774, p=1.85 \times 10^{-4}\right)$ than OCW $\left(\mathrm{F}=15.632, p<2 \times 10^{-16}\right)$ or HBL $(\mathrm{F}=10.812, p<2 \times$ $\left.10^{-16}\right)$. Both \%PE $\left(24.41, \mathrm{PE}_{\mathrm{cf}}=23.34\right)$ and \%SEE (34.95) were much lower for the multivariate equation than for any of the univariate equations (Table 7). Notably, even when three extremely strong predictors of body mass were used together, it was still not possible to reduce percent estimation error to below $20 \%$.

\section{Discussion \\ Allometry of OCW}

The data here show that the scaling relationship between OCW and body mass is not log-linear, but instead exhibits non-linear allometry (and the same is true of skull length). There are four lines of statistical evidence which suggest that this non-linear relationship is not a statistical artifact. First, model support statistics such as $r^{2}$, $\% \mathrm{PE}_{\mathrm{cf}}, \log$ likelihood, AIC, and BIC are substantially better for non-linear models (primarily a $2 / 3$ power or logquadratic model for OCW) than a linear one (Table 2). Second, this pattern remains even under PGLS (Table 2) and is present in multiple clades of similar size, indicating that it cannot be attributed to phylogenetic signal within a particular clade biasing the regression model (e.g., as discussed in [142]). Third, the residuals versus fits plot of these data under a log-linear model indicates significant non-linearity, which is normalized under a non-linear model (Fig. 3). Fourth, the slope under models with log-linear data is slightly different between size classes, with the slope of the larger taxa being 
slightly lower (Fig. 4), which is what would be expected if the data scaled sublinearly after log-transformation.

In general, regressions of biological variables have been performed with the assumption that logtransformation sufficiently linearizes the data for further analysis. However, a number of studies have found that several biological variables of interest, including brain size [143], mammalian basal metabolic rate [138], limb bone dimensions [137, 144, 145], and (in the present study) skull length and OCW, retain significant curvilinearity even after log-transformation (i.e., non-linear allometry, sensu Knell [146]). Previous studies have tried to account for non-linear allometry by proposing differential allometry within distinct size classes $[130,145]$ or different clades [145]. However, this approach appears to be unjustifiable. When examining the distributions of the data (see OCW and skull size in this study and limb bone measurements in Bertram and Biewener [145]), there are no sharp changes in slope that might represent logical thresholds at which different scaling models might be applicable between size classes (e.g., the $20 \mathrm{~kg}$ threshold proposed by Economos [130]). Instead, there appears to be a gradual change in slope across the sample as a whole. Similarly, this curvilinear relationship does not appear to be attributable to clade-specific allometry patterns. For example, the limb bones of similar-sized bovids and carnivorans exhibit the same pattern of allometric scaling [137: Fig. 1]. This can also be seen in the present study where even under PGLS the relationship between OCW and body mass is curvilinear, indicating that the non-linear allometric pattern is not driven by a single clade. Instead, at least in OCW, variation in phylogeny or natural history seems to be primarily reflected in the intercept.

Other studies have attempted to model non-linear allometry by adding a second-order (quadratic) term to the model, but there are some difficulties with this approach. For one, log-quadratic and other models of nonlinear allometry have been less studied than log-linear ones, and no real biological justifications have been proposed as to how to model this relationship. In a loglinear equation, the slope of the line is converted to a power rule when the antilog is taken [29], which can then be compared to various theoretical models which have known coefficients (e.g., the square-cube law, elastic similarity). This cannot easily be done with a nonlog-linear model, particularly with the second-order term [147]. Similarly, while some studies have proposed possible reasons as to why non-linear allometry might occur (e.g., greater stresses on the skeleton at larger sizes [148];), they do not provide any biomechanical reasoning as to why this relationship is best modelled by a logquadratic model versus a log-exponential or log-power one beyond the log-transformed data having a nonlinear distribution.

Another issue is that log-quadratic models can be very sensitive to data distribution and taxon selection. Müller et al. [138] found that reliably identifying whether a loglinear and log-quadratic model more appropriately fit a set of biological data was heavily dependent on the range of body sizes included in the dataset, with those data that comprised a narrow range of body sizes often failing to detect non-linearity [138]. Additionally, quadratic models are very sensitive to the distribution of values at the extremes of the dataset, and this can produce unreliable predictions at their extreme ends or if extrapolating, as noted by Campione [137]. This is seen in the present study where the curvature of various groups can be strongly influenced by a few points and subsets of the data with smaller ranges of body sizes are often unable to identify non-linearity. Yet ignoring non-linear allometry and assuming log-linear models approximate the true relationship may not be possible due to producing systematic error in the estimate, especially if these methods are intended to be applied to extinct megafauna (which, at least among paleobiologists, is often the end goal of such analyses [58, 74, 121, 137, 149]). A good example of this can be seen in the present dataset with Loxodonta africana, in which a log-linear model utterly fails to accurately predict body mass.

One possible solution might be modelled as the following. Consider for a moment some linear skeletal measurement represented by $L$, and body size (represented by body mass, or $B M$ ). The traditional way allometric equations work is to linearize the distribution of the data by taking the log of both sides, resulting in:

$$
\ln L=m * \ln B M+b
$$

in which $m$ is the slope and $b$ is the intercept. As a result, when the antilog is taken, the slope is converted to an exponent, resulting in:

$$
L=B M^{m}+\exp (b)
$$

Usually, in these equations body mass is treated as the independent variable, because the primary focus of these studies is determining how the biological variable of interest scales with respect to body size. However, because in this case, the dependent variable of interest is body mass the equation can be modelled as:

$$
\ln B M=m \times \ln L+b
$$

such that when the equation is converted back to an arithmetic scale the result is:

$$
B M=L^{m}+\exp (b)
$$


The general assumption made in most allometric studies is that the exponent $m$ is constant across all body sizes. However, this is not the case. Weight-bearing elements of very small mammals (rodents and small carnivorans such as mustelids) generally scale close to geometric similarity $\left(\mathrm{L} \propto \mathrm{BM}^{0.33}\right)$, larger mammals such as large carnivorans (large felids, ursids) and most bovids scale according to elastic similarity $\left(\mathrm{L} \propto \mathrm{BM}^{0.25}\right)$, and the very largest mammals (ceratomorphs, large bovids) scale according to stress similarity $\left(\mathrm{L} \propto \mathrm{BM}^{0.125}\right)[145,148$, $150,151]$. This is likely a multiplicative effect due to the increasing stress placed on skeletal structures (e.g., articular surfaces, limb bone circumferences) at larger body masses. This means that the exponent in the model is not a constant integer across taxa but instead is proportional to some constant $Z$ such that:

$$
L=B M^{m \times Z}
$$

or, rewriting the equation such that body mass is the dependent variable results in...

$$
B M=L^{m \times Z}
$$

$Z$, in turn, is proportional to $\log$ body size $(Z \propto \ln B M)$. However, body mass (the dependent variable) cannot be used as a variable to calculate itself. However, assuming that the variable $L$ scales with isometry outside of this upscaling factor (i.e., the majority of the magnitude in values of $L$ correlate with size), then $Z \propto \ln B M \propto \ln L$.

Similarly, the distribution of the data and differences in exponent across scaling models suggests that simply adding a second order (quadratic term) is not appropriate, as the $\delta m$ is not constant but increases at greater values of $x$. This is more consistent with a power rule, with the value of $Z$ being close to zero at small body sizes (resulting in geometric similarity) but becomes increasingly influential at larger body sizes. Therefore, $Z \propto$ $\ln L^{r}$, where $r$ is some constant. This results in the allometric model being written as:

$$
\ln B M=m \times \ln L^{r} * \ln L+b
$$

which, due to the rules of multiplying exponents with the same base, can be rewritten as

$$
\ln B M=m \times \ln L^{1+r}+b
$$

The constant $r$ must then be solved for experimentally. In the present study the best-fit relationship is one of $\ln (\mathrm{BM}) \propto \ln (\mathrm{OCW})^{2 / 3}$, which suggests that $r$ has a value of $-1 / 3$. Thus, because OCW scales positively with respect to body size, it is necessary to downweight OCW at larger values in order to produce reliable estimates of body mass.

The slope of the regression line not considering the scaling factor is roughly $\mathrm{OCW} \propto \mathrm{BM}^{0.130}$. This is close to the exponent predicted by stress similarity, which might be expected given that the primary role of the occipital condyles is the stabilization of the occipitoatlantal joint, and scaling under elastic similarity for stresses produced by bending and torsion is predicted to $\mathrm{L} \propto \mathrm{BM}^{0.125}$ [148]. However, this should be treated with some caution as it is not clear how adding in a scaling factor affects predictions of model shape. The log-linear regression model suggests that in a broad sense OCW $\propto$ $\mathrm{BM}^{0.277}$, which might imply scaling according to elastic similarity $\left(\mathrm{L} \propto \mathrm{BM}^{0.25},[148]\right)$, but again making comparisons between a linear and non-linear allometric model is difficult.

There are several possible biological explanations for this non-linear allometry in OCW. One is that the nonlinear relationship between $\ln$ OCW and $\ln$ body size is correlated to the non-linear pattern for relationship between skull length and body size described here. If maintenance of a functional occipito-atlantal joint is a major selective factor on the dimensions of the occiput and if larger animals have proportionally larger heads, then it might be expected that larger animals might require proportionally larger condyles to support the weight of their heads. This would agree with previous observations that articular dimensions tend to scale with positively allometry $[152,153]$, and that in this study larger animals tend to have larger condyles relative to their body size. However, this would not explain why several animals with very large heads relative to their body size (e.g., the "creodonts" and sparassodonts mentioned in the "Background") have small occiputs relative to skull size, and the fact that the residuals for the regressions between OCW and body size and skull length and body size are not strongly correlated.

Another possibility is the non-linear allometry in occipital condyle dimensions is part of a broader phenomenon that occurs across articular dimensions more generally, given that non-linear allometry has been most frequently documented in reference to tetrapod weight-bearing structures [137, 144, 145, 148, 151]. Non-linear allometry in limb elements follows the same pattern as documented here for OCW: the rate of increase in skeletal measurements is greater at larger body sizes than smaller ones [148]. Bertram and Biewener [145] and Biewener [154] suggested that non-linear allometry in mammalian limb bones was related to limb posture: at smaller sizes mammals compensate for increased stress on weight-bearing structures by adopting an increasingly erect limb posture, whereas at larger sizes the limbs are virtually columnar and the only functional solution is to dramatically increase limb bone thickness. However, the fact that this pattern also occurs in OCW, which is an axial articular surface and thus not affected by changes in limb posture, as well as skull 
length, suggests this phenomenon may be more broadly applicable across the skeleton.

Despite exhibiting non-linear allometry, the correlation between $\ln$ OCW and $\ln$ body mass is extremely strong once non-linear scaling is accounted for. A $2 / 3$ power model is also robust to differences between size classes and phylogeny, given it occurs even under PGLS and most clades exhibit similar slopes under the $2 / 3$ power model. That is, the non-linear allometry of the best-fit model is not driven by one very large or very small clade exhibiting differential allometry relative to other taxa but occurs across all clades. Because the goal of this study is to use OCW to predict body mass, this empirically determined model seems reasonably practical for further use even though the biological mechanisms that produce non-linear allometry across skeletal dimensions more generally are poorly understood.

On a similar note, one of the more noteworthy findings of this study is that skull length does not scale isometrically to body mass but also exhibits non-linear allometry, with ln body mass scaling to ln condylobasal length raised to the $1 / 2$ power. The $95 \%$ confidence interval for the empirically fitted curve rules out the possibility of skull length scaling isometrically to body mass (Table 3), the plot of the residuals versus fitted values (Fig. 3) suggests the relationship cannot be modelled linearly, and a log-quadratic model finds the secondorder term to be significant. This result is rather concerning given the large number of studies have used skull length to estimate body mass in fossil mammals $[39,64,149,155]$, all of which have assumed either explicitly or implicitly that this measurement scales loglinearly with body size. This pattern may occur for the same reasons as non-linear allometry in limb bone measurements and OCW, but another possibility is that it is due to craniofacial evolutionary allometry (CREA [156, 157];). This result shows that non-linear allometry is widely distributed in mammalian skeletal measurements and that the influence of this phenomenon may have been underestimated on previous studies of mammalian biology.

\section{Utility of OCW in body mass estimation}

OCW is a good predictor of body mass in mammals, with a \%PE of about $31 \%(\sim 27.5 \%$ if outlier taxa with apomorphic occiput morphology are excluded). This agrees with some previous studies $[117,119,120]$ which found $\mathrm{OCW}$ to strongly correlate with body mass. A percent error of $31 \%$ by itself may seem high, but it must be kept in mind that much of this error arises from small differences between predicted and actual values on a logarithmic scale being magnified when backtransformed to an arithmetic scale (\%PE for logtransformed values is only $\pm 5 \%$, compared to $\pm 31 \%$ for detransformed ones). In general, regression models with errors of less than 33\% are considered "good" in body mass estimation, particularly if not restricting comparisons to taxonomically narrow datasets $[39,57,58,64]$.

Despite the great phylogenetic breadth of the present sample, OCW actually produces lower \% $\mathrm{PE}$ and \%SEE many regression equations of previous studies based on more restrictive taxonomic groups (Table 8). These include all of the total species regression equations for carnivorans in Van Valkenburgh [39], most of the total species craniodental regression equations for ungulates in Janis [64], all but two of the equations for Australian marsupials in Myers [158], all but one of the cranial or postcranial equations produced by Aiello and Wood [160], and all but one of the regression equations based on linear measurements of the astragalus calculated by Tsubamoto [58]. Compared to the limb bone equations of Campione and Evans [87] (subsetted to only include mammals in order to allow for direct comparisons), in which the authors found limb bone dimensions to be highly correlated with body mass across tetrapods, OCW outperformed both humeral length and femoral length and produced values comparable to femoral circumference. If occiput shape is controlled for, humeral circumference and OCW produce similar accuracy rates. Similarly, within the present study OCW performs much better than skull length in estimating body mass and produces results comparable to that achieved through the regression of HBL on the same sample. The high accuracy of OCW despite the wide phylogenetic breadth of the present sample is especially notable given that accuracy and taxonomic breath are often inversely correlated in regression equations of body mass [134].

OCW has several advantages over other regression equations (Table 9). OCW is relatively easy to measure and can be unambiguously recognized by different observers. Previous studies have found that OCW is an extremely replicable measurement, at least among features of the occiput, and shows low inter-observer bias [163]. Furthermore, because OCW is a cranial measurement, it does not require associated postcrania to estimate mass (as is the case for limb bones) or a relatively complete specimen with undistorted skull and spinal column (as is the case for HBL). This allows it to be applied to a wider range of specimens, including taxa known only from the skull (e.g., Andrewsarchus [164], Josephoartigasia [149]). Additionally, because OCW scales with the size of the postcranium and is relatively consistent across Theria, it avoids many of the common pitfalls of estimating body mass based on craniodental measurements such as taxa having a disproportionately large skull [39] or teeth and limbs that are not comparable across taxa [64, 66]. Indeed, in the present dataset, OCW even accurately estimates body mass in many taxa which have skulls and 
Table 8 Accuracy of OCW-based regressions compared to those of other studies

\begin{tabular}{|c|c|c|c|c|c|c|c|c|c|c|}
\hline \multirow[t]{2}{*}{ Taxonomic scope } & \multicolumn{4}{|c|}{ OCW } & \multicolumn{6}{|c|}{ Other regression equations } \\
\hline & $\bar{N}$ & $r^{2}$ & \%PE & \%SEE & $\bar{N}$ & $r^{2}$ & $\% \mathrm{PE}$ & $\%$ SEE & Variable & Ref. \\
\hline \multirow[t]{3}{*}{ All Therians } & 401 & 0.982 & 31.55 & 45.92 & $80^{*}$ & 0.985 & 28.83 & 41.98 & Astragalus (Li1) & [58] \\
\hline & & & & & $80^{*}$ & 0.980 & 34.01 & 49.68 & Astragalus (Li7) & [58] \\
\hline & & & & & $80^{*}$ & 0.980 & 37.17 & 55.53 & Astragalus (Li4) & [58] \\
\hline \multirow[t]{7}{*}{ All Therians (controlling for shape) } & 404 & 0.985 & 28.18 & 41.37 & $69^{*}$ & 0.979 & 32.36 & 47.21 & Calcaneus (CA2) & [93] \\
\hline & & & & & $69^{*}$ & 0.973 & 38.67 & 55.46 & Calcaneus (CA5) & [93] \\
\hline & & & & & $69^{*}$ & 0.973 & 38.92 & 55.42 & Calcaneus (CA10) & [93] \\
\hline & & & & & 187 & 0.955 & 50.60 & 84.78 & Humerus length & [87] \\
\hline & & & & & 200 & 0.982 & 27.73 & 47.86 & Humerus circum. & [87] \\
\hline & & & & & 188 & 0.944 & 66.77 & 98.01 & Femur length & {$[87]$} \\
\hline & & & & & 200 & 0.983 & 31.16 & 45.93 & Femur circum. & {$[87]$} \\
\hline \multirow[t]{3}{*}{ Australidelphian Marsupials } & 32 & 0.972 & 30.54 & 47.44 & 38 & 0.980 & 27 & 39 & Total jaw length & [158] \\
\hline & & & & & 38 & 0.979 & 28 & 40 & CBL & [158] \\
\hline & & & & & 38 & 0.967 & 35 & 51 & M1-4 length & [158] \\
\hline \multirow[t]{3}{*}{ Carnivora + Large Dasyuromorphia } & 86 & 0.973 & 23.59 & 34.74 & 72 & 0.96 & 36 & 53 & $\mathrm{HBL}$ & [39] \\
\hline & & & & & 72 & 0.95 & 47 & 66 & CBL & [39] \\
\hline & & & & & 72 & 0.95 & 42 & 61 & Occiput-orbit length & [39] \\
\hline \multirow[t]{3}{*}{ Ungulates (except proboscideans) } & 61 & 0.962 & 27.47 & 39.95 & 91 & 0.975 & 31.42 & 45.54 & $\mathrm{HBL}$ & {$[66]$} \\
\hline & & & & & 94 & 0.967 & 34.51 & 53.02 & p4-m3 length & {$[66]$} \\
\hline & & & & & 94 & 0.963 & 36.34 & 55.82 & m1-3 length & {$[66]$} \\
\hline \multirow[t]{3}{*}{ Rodents } & 96 & 0.971 & 29.35 & 40.80 & 36 & 0.940 & 30.65 & 15.70 & CBL & {$[31]$} \\
\hline & & & & & 36 & 0.890 & 43.36 & 21.50 & P4-M3 length & [31] \\
\hline & & & & & 34 & 0.890 & 44.62 & 21.80 & m1 length & {$[31]$} \\
\hline \multirow[t]{4}{*}{ Rodentst } & 58 & 0.953 & 10.21 & 13.50 & 36 & 0.880 & 39.42 & 21.70 & Humerus diameter & [31] \\
\hline & & & & & $203^{*}$ & 0.964 & 29.55 & 43.33 & $C B L$ & [155] \\
\hline & & & & & 93 & 0.948 & 34.55 & 50.14 & CBL & [155] \\
\hline & & & & & 75 & 0.920 & 40.10 & 64.45 & p4-m3 length & [159] \\
\hline \multirow[t]{4}{*}{ Anthropoid primates } & 43 & 0.965 & 18.49 & 28.41 & 46 & 0.98 & 24 & - & Biorbital breadth & [160] \\
\hline & & & & & 46 & 0.97 & 25 & - & Foramen magnum area & [160] \\
\hline & & & & & 38 & 0.98 & 18 & - & Humeral length & [160] \\
\hline & & & & & 38 & 0.99 & 20 & - & Anteroposterior diameter of femoral head & [160] \\
\hline
\end{tabular}

Only linear variables are considered here as models with multiple independent anatomical variables tend to produce lower errors regardless of what measurements are considered [58, 86, 159]. When large numbers of regression equations were calculated in a given study, only the equations with the lowest $\% \mathrm{PE}$ were used for comparison. \%PE was reported for this study instead of \% $\mathrm{PE}_{\mathrm{cf}}$ as many of the studies considered here did not use correction factors. ${ }^{*}=$ regression equation calculated using individual specimens, instead of species averages. $\dagger=$ results of Moncunill-Solé et al. [119]

teeth that cannot easily be compared to other mammals such as anteaters, sloths, and aardvarks $\left(\% \mathrm{PE}_{\mathrm{cf}}\right.$ for Orycteropus afer $=5.78 \%$, see below for discussion of $\% \mathrm{PE}_{\mathrm{cf}}$ in Pilosa).

OCW accurately predicts body mass in mammals regardless of variables such as body proportions (i.e., most mammals had their weight accurately estimated despite differences in head size, neck length, limb proportions) or phylogeny (very distantly related taxa fell along the same regression line, unless occiput specializations were present). The lowest error values in the present dataset were primarily for mammals with generalized postcrania (e.g., didelphids, hyracoids, procyonids, many sciuromorphs, and cricetids) regardless of their phylogenetic position. This gives further evidence that OCW may work well for many wholly extinct groups of Paleogene or South American mammals, which tend to have generalized postcrania [44]. OCW accurately estimated body mass in the extant large-headed dasyuromorphians Dasyurus viverrinus $\left(\% \mathrm{PE}_{\mathrm{cf}}=4.7 \%\right)$, Dasyurus maculatus $\left(\% \mathrm{PE}_{\mathrm{cf}}=\right.$ $28.05 \%)$, Sarcophilus $\left(\% \mathrm{PE}_{\mathrm{cf}}=27.19 \%\right)$, and Thylacinus cynocephalus $\left(\% \mathrm{PE}_{\mathrm{cf}}=14.48 \%\right)$, suggesting it should be a strong predictor of body mass in extinct 
Table 9 Pros and cons of various methods of body mass estimation discussed in this paper

\begin{tabular}{|c|c|c|}
\hline Variable & Pros & Cons \\
\hline \multicolumn{3}{|c|}{ Pros and cons of various methods of body mass estimation discussed in this paper } \\
\hline $\begin{array}{l}\text { Dental } \\
\text { variables } \\
\text { (e.g., molar } \\
\text { row length) }\end{array}$ & $\begin{array}{l}\text { 1. Abundant in the fossil record and known for almost } \\
\text { every fossil mammalian taxon } \\
\text { 2. Easy to obtain large sample sizes } \\
\text { 3. Dimensions of permanent teeth in mammals always } \\
\text { reflect adult size rather than growth stage due to } \\
\text { diphyodonty }\end{array}$ & $\begin{array}{l}\text { 1. Extremely morphologically variable and often cannot be applied across } \\
\text { taxa (e.g., edentulous taxa) } \\
\text { 2. Little reason to believe they necessarily correlate better with mass than } \\
\text { other variables } \\
\text { 3. Cannot be used to reconstruct growth patterns in fossil mammals } \\
\text { 4. May be biased by head size }\end{array}$ \\
\hline $\begin{array}{l}\text { Cranial } \\
\text { variables } \\
\text { (e.g., skull } \\
\text { length) }\end{array}$ & $\begin{array}{l}\text { 1. Does not require associated postcrania } \\
2 \text {. Slightly less biased by dietary habits than dental } \\
\text { variables }\end{array}$ & $\begin{array}{l}\text { 1. Can be highly influenced by ecology and non-isometric allometry (e.g., } \\
\text { rostrum length) } \\
\text { 2. Often fails to produce accurate estimates if head is disproportionately } \\
\text { large/small relative to body size }\end{array}$ \\
\hline OCW & $\begin{array}{l}\text { 1. Highly conserved across Mammalia } \\
\text { 2. Strong theoretical reasons to believe OCW correlates } \\
\text { with spine size, and therefore body size } \\
\text { 3. Unlike other craniodental variables is not biased by skull } \\
\text { size } \\
\text { 4. Only requires skull rather than partial skeleton }\end{array}$ & $\begin{array}{l}\text { 1. Not as well studied, so potential confounding factors and interspecific } \\
\text { variation less understood } \\
\text { 2. Sample sizes can be small because skulls may have damaged occiputs } \\
\text { 3. Potential concerns with covariation with brain size }\end{array}$ \\
\hline $\begin{array}{l}\text { Head-body } \\
\text { length }\end{array}$ & $\begin{array}{l}\text { 1. Probably the strongest theoretical reasoning as to why } \\
\text { this variable should most closely approximate mass [66, } \\
\text { 161] } \\
\text { 2. Extremely large sample of published extant comparative } \\
\text { data with associated mass }\end{array}$ & $\begin{array}{l}\text { 1. Requires rare, nearly-complete specimens, much less tolerant of missing } \\
\text { data than any other method } \\
\text { 2. Head-body length highly subject to subjective decisions and almost al- } \\
\text { ways requires some degree of estimation, even near-complete specimens } \\
\text { are often missing vertebrae that must be filled in from close relatives }\end{array}$ \\
\hline $\begin{array}{l}\text { Limb } \\
\text { elements }\end{array}$ & $\begin{array}{l}\text { 1. Strong biomechanical reason to believe they correlate } \\
\text { with body mass }[87,162]\end{array}$ & $\begin{array}{l}\text { 1. Limb bones rarely associated with diagnostic specimens } \\
\text { 2. Can be biased when phylogenetic/paleoecological signal overrides size- } \\
\text { based signal (e.g., fossoriality or differences in weight distribution between } \\
\text { clades }[31,87] ; \text { ) }\end{array}$ \\
\hline
\end{tabular}

large-headed carnivorous mammals like sparassodonts and "creodonts."

Because OCW correlates with body mass in nearly all therians regardless of phylogenetic position or body size, it can be used to estimate the body mass of taxa that belong to groups that are now totally extinct (e.g., South American ungulates, sparassodonts, "creodonts"), are only represented by a few morphologically similar living species (e.g., perissodactyls, proboscideans, and hyracoids), or are outside the range of body masses spanned by extant members of the group (e.g., the lagomorph Nuralagus, the giant caviomorph rodents Josephoartigasia or Phoberomys, or dwarf island proboscideans) without concerns about a lack of phylogenetic bracketing by extant species [83] or extrapolation of the data (except possibly in some of the most extreme cases, like Paraceratherium and some of the largest fossil proboscideans $[165,166])$. However, representation for the upper end of the body size spectrum $(>500 \mathrm{~kg})$ in the current dataset is very sparse, with only five specimens each represented by a single captive specimen, and this is an area where the present dataset could use improvement.

Applications of OCW to particular extinct mammal groups (e.g., the large-headed extinct mammal groups mentioned in the "Background") is beyond the scope of the present study and is planned for future analyses currently in preparation by the author. However, as a case study, OCW was used to estimate the body mass of two large-headed extinct mammals for which previous body mass estimates based on craniodental variables have been considered dubious: the early Oligocene North American hyaenodont "creodonts" Hyaenodon horridus and Hyaenodon crucians. Hyaenodon is used as a case study because this genus is known from several nearly complete skeletons (see Fig. 1) and thus its body mass has been estimated using a number of both craniodental and postcranial proxies [32, 39, 58]. OCW produces an estimated body mass of $32.2 \mathrm{~kg}$ for Hyaenodon horridus $(\mathrm{OCW}=42 \mathrm{~mm})$ and $13.0 \mathrm{~kg}$ for $\mathrm{H}$. crucians $(\mathrm{OCW}=$ $32 \mathrm{~mm}$ ), comparable to estimates in previous analyses (Table 10). 95\% confidence intervals for $H$. horridus and H. crucians are very large (Table 10), but this is related to log-transformation issues (i.e., if the data are logdistributed, the confidence intervals will be on a logarithmic scale as well and thus be very large when backtransformed into arithmetic units $[39,57,58])$. This is a problem present in nearly all body mass regression models, rather than unique to OCW. Indeed, confidence intervals for $\mathrm{HBL}$, limb bone dimensions, and astragalar dimensions are very large and comparable to $\mathrm{OCW}$ (Table 10). Body mass estimates of Hyaenodon spp. using $\mathrm{OCW}$ agree with mass estimates produced with HBL or postcranial variables, but do not agree with the extremely high body mass estimates produced by skull length, demonstrating that $\mathrm{OCW}$ scales with postcranial variables and is not biased by the disproportionately large heads seen in hyaenodonts. 
Table 10 Body mass estimates (in $\mathrm{kg}$ ) and 95\% confidence interval for Hyaenodon spp. in this study, compared to estimates in previous studies

\begin{tabular}{|c|c|c|c|c|c|c|c|}
\hline \multicolumn{3}{|c|}{ Hyaenodon horridus } & \multicolumn{3}{|c|}{ Hyaenodon crucians } & \multirow[b]{2}{*}{ Measurement } & \multirow[b]{2}{*}{ Reference } \\
\hline Mean & Lower & Upper & Mean & Lower & Upper & & \\
\hline 32.2 & 14.9 & 69.3 & 13.0 & 6.0 & 27.9 & OCW (all taxa) & Present Study \\
\hline 31.5 & 15.9 & 62.4 & 12.6 & 6.4 & 24.9 & OCW (all taxa with condyle shape) & Present study \\
\hline 34.1 & 19.0 & 61.2 & 12.4 & 6.9 & 22.1 & OCW (Carnivora-only) & Present Study \\
\hline 30.2 & 12.9 & 71.0 & 8.8 & 3.8 & 20.7 & $\mathrm{HBL}$ & {$[39,167]$} \\
\hline 130.6 & 47.5 & 359.3 & 30.5 & 11.2 & 83.2 & Skull length & {$[39,167]$} \\
\hline 38.4 & 28.1 & 52.6 & - & - & - & Humeral trochlea area & {$[168]$} \\
\hline 41.4 & 24.9 & 43.3 & 15.0 & 9.1 & 24.8 & "Limb bones" & {$[32]$} \\
\hline 25.8 & 12.8 & 51.8 & 10.6 & 5.3 & 21.3 & Li1 (Astragalus) & {$[58]$} \\
\hline 29.2 & 13.9 & 61.1 & 11.0 & 5.3 & 23.1 & Ar1 (Astragalus) & [58] \\
\hline
\end{tabular}

The equations of Morlo [78] were not used because this study estimated body mass in hyaenodonts by regressing molar row/average molar length against body mass estimates created using other proxies (done at least in part to avoid the issue of hyaenodonts having large heads), rather than directly estimating body mass from skeletal proxies in a sample of living taxa. The measurement from Egi [32] is listed as "limb bones" because Egi [32] does not detail which of the equations they produced were used to estimate the reported body mass. Note that body mass estimates reported here are not all drawn from the same individuals

The present study also highlights the importance of including $\mathrm{OCW}$ and other occiput measurements in multivariate analyses of craniodental morphology or geometric morphometric analyses. Even in cases where the primary objective of the study are interspecific shape differences rather than body mass, it is often of interest to distinguish shape differences that are driven by isometric size or allometric scaling (often measured by correlation with PC1 or centroid size [169]) from non-sizerelated differences in shape. Despite the strong correlation between OCW and body mass recovered here, a survey of the paleontological and zoological literature finds OCW (and occiput measurements more generally) to be one of the most rarely recorded morphological measurements in morphometric studies. Similarly, most morphometric analyses using traditional or geometric morphometrics do not record dimensions or landmarks of the occiput. For example, Mendoza et al. [86] and Figueirido et al. [41] considered a large number of craniodental variables ( $N=25$ and 39 , respectively) in their multivariate regression equations of body mass in ungulates and carnivorans, respectively, but included almost no measurements of the occiput or foramen magnum. Mendoza et al. [86] did include occiput height, but there is reason to believe that this variable is less correlated with body size than other occiput dimensions and is influenced by dietary habits or paleobiology [64].

This issue is especially pertinent if there is reason to suspect that the taxon of interest has a disproportionately large head compared to extant taxa. This is because estimating body mass in extinct mammals using a dataset of craniodental data and body mass for extant species implicitly assumes that the extinct taxon of interest has a head that is the same size relative to its body as the taxa in the sample dataset. As a result, the dependent variable in a multivariate analysis of craniodental data (or centroid size in a geometric morphometric analysis) will implicitly correlate to the size of the head, not the size of the actual animal. Thus, increasing the number of craniodental variables in a body mass regression model may increase precision in the estimate, but will not increase accuracy. Because occiput dimensions (especially $\mathrm{OCW})$ are shown here to correlate with the size of the entire body and not the cranium, the inclusion of occiput dimensions in multivariate or geometric morphometric analyses may help properly weigh variables to produce a more accurate relationship between craniodental features and body size.

\section{Limitations of OCW}

The majority of mammals exhibit a similar occiput morphology, in which there are a pair of reniform condyles positioned laterally on either side of the foramen magnum (Fig. 7a). However, a few groups of mammals exhibit specialized occiput morphology that differs from the general mammalian condition, most of which can be groups into three distinct morphotypes (Fig. 7b-d). These morphotypes appear to differ on an almost categorial level, rather than representing an arbitrary extreme in a morphological shape gradient. However, it seems likely that intermediate states could exist in the fossil record. This may be because of the predicted high stabilizing selection on the occipito-atlantal joint in mammals: under most circumstances, there is strong selective pressure for the occiput to retain a consistent shape, but if a lineage enters an adaptive zone that puts different selective pressures on the occiput, there is extremely strong selection to a new local optimum because 
maintaining a stable occipito-atlantal joint is critical for Darwinian fitness. Because these taxa violate the assumption of that their occiput morphology is comparable to the general mammalian condition, OCW unsurprisingly failed to estimate body mass in these species. However, because of these morphotypes are highly distinctive fossil taxa that exhibit them can be identified as unsuitable for body mass estimation via OCW a priori, and thus are detailed further here.

The most common of these alternative occiput morphotypes are seen in lagomorphs (both leporids and ochotonids), caviids, and Dipodomys spp., hereafter called a "rabbit or lagomorph-like" occiput given it is most prevalent in this clade. These taxa have opisthobasally long, mediolaterally narrow condyles that are almost pulley-like in appearance (Fig. 7b). Because these condyles are narrower than would be expected in a mammal of their size, OCW consistently underestimates mass in these taxa. It is tempting to suggest this condition might be correlated with saltatorial/richochetal habits, but this condition is not exclusively correlated with this lifestyle. Some non-hopping mammals such as pikas or caviids have a lagomorph-like occiput morphology, whereas some ricochetal taxa (i.e., Pedetes) have a typical therian occiput morphology. The deviation from the Q-Q plot for normality is driven by these rabbit-like taxa.

However, taxa with a rabbit-like occiput form a regression line that is parallel to that of other therians (Fig. 8). Taxa with rabbit-like occiputs primarily differ from other mammals in terms of their $y$-intercept, with differences in slope between these taxa and the rest of the sample being non-significantly different. This indicates that the scaling relationship between OCW and body mass remains constant in rabbit-like taxa, and these taxa differ from other mammals in terms of occiput shape (i.e., narrow condyles) but not overall occiput size. This, in turn, means that it is possible to use OCW to estimate body mass in taxa with rabbit-like occiputs (and possibly other alternate morphotypes) provided corrections for morphological differences are made (i.e., including condyle morphotype as an additional categorical predictor variable, see "Results"). This agrees with previous studies that found $\mathrm{OCW}$ to be a good predictor of body mass within Lagomorpha [120].

The second major alternate occiput morphotype was found in monotremes, in which the condyles are low, mediolaterally long, and strongly diverge laterally from the borders of the foramen magnum (Fig. 7c), in contrast to most therians where the occipital condyles generally follow the border of the foramen magnum (Fig. $7 \mathrm{a})$. This resulted in OCW being wider than expected, and thus OCW significantly overestimated body mass in the monotremes Ornithorhynchus $\left(\% \mathrm{PE}_{\mathrm{cf}}=72.1 \%\right)$,
Tachyglossus (62.2\%), and Zaglossus (74.2\%). This alternative occiput morphology also occurs in the extinct ornithorhynchid Obdurodon [170]. It is not clear whether the unusual morphology of the condyles seen in monotremes is plesiomorphic for mammals or represents an autapomorphy of Monotremata. The occipital condyles of the mammaliamorph Adelobasileus cromptoni [171], the multituberculates Tombataar sabuli [172] and Kryptobaatar dashzevegi [173], the non-therian zatherian Vincelestes neuquenianus [174: fig. 37b], and the gondwanatherian Vintana sertichi [175: Fig. 6] are all more similar to those of therians than monotremes. This suggests that the morphology seen in extant monotremes is an autapomorphy of Montremata, whereas therians represent the plesiomorphic condition. Nevertheless, because there are no living non-monotreme, non-therian mammals with known body masses to act as independent data points that can be used to verify if multituberculates and other extinct non-therian mammals follow the same regression line as extant therians, the regression equations in this study should be applied to non-therians with caution.

The third alternative morphotype was seen in cingulates, which have occipital condyles that are typically very robust, almost cylindrical in lateral view and rectangular in occipital view (Fig. 7d). This feature is also present in extant cingulates such as pampatheres and glyptodonts and is considered a synapomorphy of Cingulata [176]. As with monotremes, this resulted in greater than expected OCW, resulting in body mass being overestimated in taxa like Euphractus sexcinctus $\left(\% \mathrm{PE}_{\mathrm{cf}}=55 \%\right)$ and Zaedyus pichiy $\left(\% \mathrm{PE}_{\mathrm{cf}}=62 \%\right)$. The current sample size of Cingulata is too small $(N=6)$ to determine if these taxa form a distinct regression line parallel to that of other therians, similar to taxa with rabbit-like occiputs. By contrast, error in body mass estimates for most pilosans (specifically Myrmecophaga tridactyla $\left[\% \mathrm{PE}_{\mathrm{cf}}=9.65 \%\right]$, Tamandua tetradactyla [5.86\%], and Choloepus hoffmanni [5.42\%]; Bradypus variegatus showed high underestimates of body mass $\left.\left[\% \mathrm{PE}_{\mathrm{cf}}=81.8 \%\right]\right)$, the sister taxon to Cingulata, were closer to other therians. Unusually, most specimens of Dasypus novemcinctus, one specimen of $D$. sabanicola, and one specimen of Tolypeutes matacus showed comparatively lower error values $\left(\% \mathrm{PE}_{\mathrm{cf}}<50 \%\right)$. It is possible that the robustness of the occipital condyles could vary within Cingulata, with more fossorial species (such as Euphractus) having more robust condyles and less fossorial ones (such as Tolypeutes) having less robust condyles, but the present sample size was too small to test this idea.

The sole species of Dermoptera included in this analysis, Galeopterus variegatus, consistently showed an extreme underestimation of body mass $\left(\% \mathrm{PE}_{\mathrm{cf}}=170 \%\right.$, 
estimated body mass $=529 \mathrm{~g}$, actual mass $1429 \mathrm{~g}$ ) representing the highest error for any taxon in which $N>1$. A priori observations of specimens of Galeopterus in this study almost immediately noticed this taxon had an unusually small occiput relative to skull size. The high error in G. variegatus cannot be attributed to the gliding habits of this species, as other gliding mammals (Idiurus macrotis, Petaurus breviceps, Glaucomys volans) showed much lower degrees of error $\left(\% \mathrm{PE}_{\mathrm{cf}}\right.$ for I. macrotis = 34.8\%; Petaurus breviceps, 2.9\%; G. volans, 14.8\%). Exactly why Galeopterus has such a small occiput is unclear. The small occiput in Galeopterus does not appear to be the result of this taxon having a large head relative to body size; indeed, it actually has one of the smallest skull lengths relative to both head-body length and body mass in the present dataset. That is, Galeopterus has a smaller occiput than would be expected based on its already small skull length. The broader significance of this is unclear given only a single dermopteran species could be included in this analysis. Regardless of the reasons why this occurs, Galeopterus represents a clear outlier relative to other mammalian taxa.

The sole living representative of Dinomyidae, Dinomys branickii, has a unique occiput morphology among living mammals with distinct laterally projecting accessory condyles or paracondyles [177]. D. branickii shows a very high \%PE (120.3\%), but allometric comparisons beyond this are difficult given this is the only living taxon with such an arrangement.

A few other taxa exhibited relatively high \%PE in the regression equation, including camelids, pseudocheirids, Geocapromyx ingrahmi (Capromyidae), geomyids, most arvicolines, and the sigmodontines Sigmodon hispidus and Nectomys squamipes. These taxa do not exhibit distinctive occiput morphology, but some of them have been described as having small brains relative to their body size $[12,178,179]$. Similarly, several taxa with high positive residuals have been described as having large brains relative to body size, including macroscelideans [180] and paucituberculatans [178]. This suggests that encephalization quotient may have some effect on OCW-based body mass estimates, which is a concern given that many extinct Paleogene and South American mammal groups are often described as having low encephalization quotients [11]. However, including brain mass as an additional independent variable did not greatly affect model accuracy, differences between mass estimates including and excluding brain mass were low, and the correlation between encephalization quotient and the residuals of the regression equation has a low $r^{2}$ value, suggesting if bias does exist it is minor. Additionally, encephalization quotients did not always correlate with high residuals. Some species known to have very low encephalization quotients, including Marmota spp.,
Eulipotyphla, and Peramelemorphia [12, 181], had their body mass accurately estimated using OCW (Mean $\% \mathrm{PE}_{\mathrm{cf}}=0.38$ for Marmota spp., see Table 5 for \% $\mathrm{PE}$ for Eulipotyphla and Peremelemorphia). Future multivariate methods of estimating body mass including multiple basicranial measurements (compare with [182, 183]) may be able to produce more accurate results.

Overall, OCW shows a very strong correlation with body mass in most mammal groups assuming a generalized occiput morphology. Most groups that show high residuals also violate the assumption of geometric similarity; they show alternate states of occiput morphology that deviates radically in shape from the generalized mammalian condition and thus cannot be directly compared. These taxa with specialized occiputs can be readily identified in osteological specimens, which suggests they should also be readily recognizable in the fossil record (e.g., comparable states can be seen in Nuralagus [184] and Obdurodon [170]). However, intra-group comparisons between taxa with similar condylar morphology (i.e., lagomorphs and similar taxa) show a similar scaling relationship, suggesting that differences between taxa are primarily ones of shape rather than different allometric relationships and that there is a common allometry between all species. Other taxa show high residuals for unclear reasons, identifying particular biological or metric reasons for this pattern or further sampling to determine if these patterns are real or potentially due to individual variation in body condition, especially given that the functional morphology of the occiput is poorly studied.

The fact that OCW, HBL, and skull length all more accurately predict one another than any of these linear measurements predicted body mass suggests that much of the residual variation in this study and error in the regression equation is driven by individual variation in body condition. Namely, it implies that all three of these measurements broadly agree with one another when it comes to describing the geometric size of an organism, but lack key information that prevents them from accurately predicting individual body mass. This is reminiscent of the results of Sarko et al. [69] and Churchill et al. [126], who also found OCW to more accurately predict body length than body mass in sirenians and pinnipeds, respectively, and also attributed this to individual variability in body mass. There are many potential sources of individual variation in body mass that would not be expected to be reflected in skeletal morphology, including sexual dimorphism (males in many mammal species are more massive than females of the same size due to higher lean muscle mass [185-187]), age (most mammals typically achieve adult linear dimensions by the time of sexual maturity but continue to "fill out" and gain mass afterwards, and then mass may be lost as part of senescence [188-191]), seasonality (e.g., fat reserves 
in hibernating species), reproductive status (i.e., pregnancy), individual body condition, and the weight of the gut contents [39]. Additionally, there are also significant sources of interspecific error in mass due to soft tissue distribution, such as species-specific differences in fat reserves or muscle mass $[102,108,111,192]$. Decomposition and fluid loss can be other significant sources of error in recorded body masses [126, 193], especially in large taxa which often have to be weighed piecemeal (fluid loss may account for 3-7\% live body mass in large animals such as rhinoceroses and elephants [193];). By contrast, osteological or body measurements like OCW, HBL, or skull length are much less susceptible to individual variation due to environmental conditions, and cannot easily increase or decrease in adults the way body mass can.

The idea that much of the residual variation and error in the $\mathrm{OCW}$ regression equation is driven by variation in body condition is supported by the general observation that when it was possible to select from large sample sizes of specimens the absolute value of the residuals for these taxa was generally lower (Welch two sample $t$ test; $t=3.3755, \mathrm{df}=168.51, p<0.001$; Additional file 8). This is likely because in these species it was possible to select "optimal" individuals that were close to the mean value for the entire population and avoid extremes in body condition, rather than simply measuring whatever individuals happened to have body mass recorded. However, it is also plausible that the lower error values for these taxa are a consequence of larger sample size, as most of these taxa had $N>10$. Indeed, this is the exact reason why most studies of body mass use the average value of several individuals in the first place, in the hopes that differences between individuals will average out and hopefully produce a truer estimate of the relationship between skeletal proxy and body mass in the species as a whole $[53,129,133]$.

\section{Applying occipital condyles beyond mammals}

OCW also has potential applications beyond just mammals. Indeed, Anderson [194] used occipital condyle dimensions as a proxy for body size in Triceratops. Nevertheless, there are several potential issues with using $\mathrm{OCW}$ to estimate mass in non-mammals that are not present in therian mammals. First, extinct nonmammalian amniotes span a much greater range of body sizes than extant amniotes. The largest non-mammalian amniote is the saltwater crocodile (Crocodylus porosus), whereas many extinct sauropsids greatly exceed living crocodylians in size (e.g., many non-avian dinosaurs). This means that estimating body mass using occipital condyles in these groups requires significant extrapolation beyond extant taxa $[137,195]$. By contrast, most extinct mammals are within the range of body sizes spanned by living taxa $[165,166,196]$.

Secondly, a large number of extinct amniote groups are not well-bracketed by living representatives. These include non-mammalian synapsids, which are bracketed by sauropsids and extant mammals. Sauropsids and extant mammals share a non-analogous occiput morphology, with sauropsids having a singular median condyle ventral to the foramen magnum and extant mammals having paired condyles positioned lateral to this foramen [197]. Paired occipital condyles seem to have originated at the base of Cynodontia [198], but Rowe [199] noted that non-mammaliaform cynodonts exhibit a transitional morphology where the condyles are positioned more ventrally than in modern mammals. Rowe [199] considered non-mammalian mammaliaformes (i.e., Morganucodontidae) to also exhibit this condition, but the condyles of Morganucodon [200] and Adelobasileus [171] show a condition similar to extant therians. Occipital condyle morphology varies greatly in noncynodontian synapsids, with stem ("pelycosaurs") exhibiting a single, sauropsid-like occiput [201, 202]; biarmosuchians exhibiting a strange condition where the exoccipital forms paired structures lateral to the foramen magnum distinct from the condyle that may contribute to occiput function [203, 204]; gorgonopsians exhibiting an unusual "kidney-shaped" occipital condyle [201]; and dinocephalians, anomodonts, and therocephalians exhibiting a tripartite occiput $[201,205,206]$ unlike either mammals or sauropsids (with the condyle of therocephalians sometimes being notched as in gorgonopsians [206];). Similarly, non-avian archosaurs are bracketed by extant crocodilians and neornithe birds, but given the extreme differences in body shape between these two groups, it is unlikely that a regression equation based on both groups would produce accurate results.

Third, extinct non-amniotes exhibit much more diversity in body shape than terrestrial mammals. Most terrestrial mammals have a relatively conservative quadrupedal body plan, and it is for this reason that differences in body shape between mammal species are assumed to contribute little to the relationship between OCW and body mass. By contrast, body shape in other amniotes can involve significant differences in head size (e.g., the very large heads of ceratopsians or the very small heads of stegosaurs and sauropods), neck length (e.g., sauropodomorphs and sauropterygians), presacral vertebral count [207], limb posture (sprawling versus erect limbs), tail length [22, 113], and limb proportions (e.g., bipedalism versus quadrupedalism [112]) that would be expected to increase error in the correlation between occiput dimensions and body mass. Overall, it is possible that the results found here for mammals could be applied to other amniotes like sauropsids, but 
there are other considerations that suggest the correlation between occiput dimensions and body mass might not be as straightforward in non-mammalian groups.

\section{Conclusions}

Occipital condyle width (OCW) is found to be a strong predictor of body mass in mammals, especially given the constraints of the present dataset (high phylogenetic breadth, extreme range of body sizes, no phylogenetic correction or separate regression lines for species of different diets or locomotor habits). Although there are groups for which OCW does not accurately predict body mass, these groups are characterized by highly recognizable, specialized occiput morphology and can be identified as unsuitable for this method a priori, in contrast to other size proxies which require nearly complete remains to identify the discrepancy (e.g., craniodental features in hyaenodontsors skull length and femoral cross-section in large caviomorphs). The low interordinal variability seen in most species makes OCW a particularly useful method for estimating mass in extinct species for which dental or postcranial remains are either unknown or are considered to be poor correlates of body mass. Additionally, it provides another method of estimating body mass partially independent of the biases seen in traditional metrics (cranio-dental dimensions, HBL, limb bone dimensions). Along with recent studies on the scapula, astragalus, and calcaneus, the present study illustrates the value of utilizing variables from other regions of the body in addition to traditionally preferred metrics of the dentition and long bones when estimating body mass in extinct mammals.

\section{Methods}

\section{Data collection}

Occipital condyle width (OCW) and body mass were collected from 2127 specimens of mammals with associated body mass representing 404 species and 91 families of non-volant terrestrial mammals, including all extant terrestrial mammal orders except Notoryctemorphia. These specimens come from the collections of the American Museum of Natural History (AMNH), Carnegie Museum of Natural History (CM), Cleveland $\mathrm{Mu}-$ seum of Natural History (CMNH), Cornell University Museum of Vertebrates (CUMV), University of California Museum of Vertebrate Zoology (MVZ), Núcleo de Pesquisa em Ecologia e Desenvolvimento Sócio-Ambiental de Macaé (NPM), Sam Noble Museum of Natural History (OMNH), University of Florida/Florida Museum of Natural History (UF), University of Michigan $\mathrm{Mu}-$ seum of Zoology (UMMZ), Smithsonian Museum of Natural History (USNM), Burke Museum of Natural History and Culture (UWBM), University of Wyoming Museum of Vertebrates (UWYMV), and the Yellowstone
National Park Archives (YELL). This sample (including the additional specimens listed below) represents approximately $71.6 \%$ of all currently recognized recent terrestrial mammal families [208].

Data for seven additional specimens (see Additional file 12) were obtained from photographs of specimens housed at the University of Alaska Museum (UAM) on ARCTOS (arctos.database.museum) and the Harvard Museum of Comparative Zoology (MCZ) from the MCZ database (https://mcz.harvard.edu/database). With regard to primates, data for 205 specimens from the USNM were measured from X-ray images provided by Terry Ritzman to the USNM Collections Database (https://collections.nmnh.si.edu/search/mammals/). Data for the sole proboscidean specimen used in this analysis (Loxodonta africana, ROM R6000/96185) was taken from Jukar et al. [121], data for Lagidium ahucaense was taken from photographs in Ledesma et al. [209], and data for Ichthyomys stolzmanni and I. tweedii were taken from Brito et al. [210] and Ramírez-Fernández et al. [211], respectively. Data for the specimen of Zaglossus bruijni (AMNH 157072) and Hydromys chrysogaster (MVZ 175330) were measured from CT scans from MorphoSource (https://www.morphosource.org).

The primary purpose of this study was to examine scaling relationships of OCW across generalized terrestrial mammals. Part of this is based on the theoretical assumption that because most mammals have a roughly similar body plan their proportions are relatively consistent (primarily differing in limb length) and thus axial dimensions would be expected to be correlated to body mass. Marine mammals (Cetacea, Pinnipedia, and Sirenia), bats, and subterranean talpids were not considered because their body plan deviates radically from this generalized body plan and thus might violate assumptions that postcranial morphology is comparable among examined taxa. Although subterranean talpids (e.g., Talpa, Condylura) were not considered; the lessspecialized [212] American shrew-mole Neurotrichus gibbsii was included given it has a body plan similar to other eulipotyphlans. Chrysochlorids and notoryctemorphians were also not considered due to lack of available specimens with associated body mass.

OCW was measured as the greatest transverse width across the occipital condyles (Fig. 10) to the nearest $0.01 \mathrm{~mm}$ using a Mitutoyo Digimatic caliper. All body mass data used in this study (in g) represent tag data directly associated with each specimen. Average OCW and body mass for each species can be found in Additional file 12 , and individual values for each specimen are listed in Additional file 13. Few body mass estimations in extinct mammals are based on models where mass and measurement data are drawn from the same individuals due to availability of data [213]. Instead, body mass data 


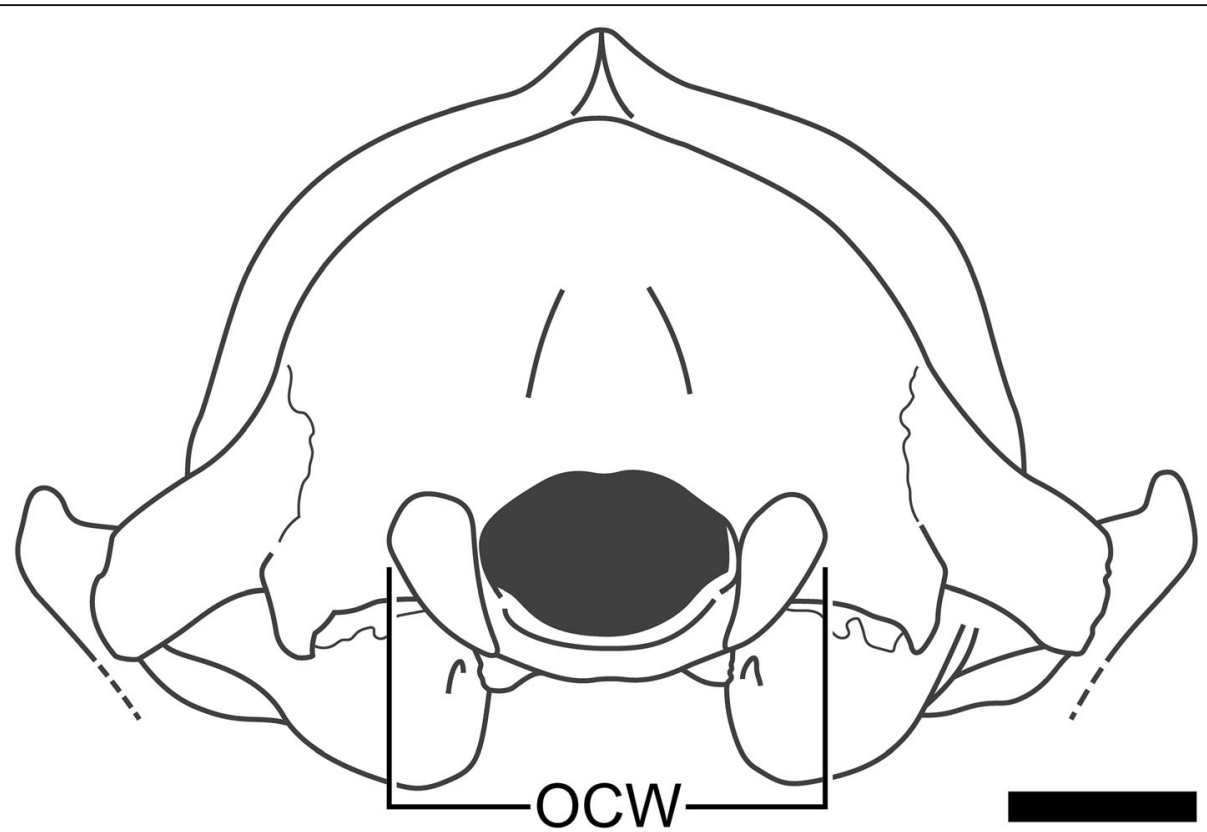

Fig. 10 Line drawing of skull of Procyon lotor (CMNH 22076) in occipital view illustrating how occipital condylar width (OCW) was measured in this analysis. Scale $=1 \mathrm{~cm}$

in these studies are typically mean values for the species reported in the previously published literature. However, this can lead to errors in body mass estimations as bone and weight measurements do not correspond to the same sample of individuals (see [214]).

When not constrained by availability of specimens, at least ten individuals were measured for each species, ideally consisting of five male and five female individuals to account for sexual dimorphism in a given taxon. Specimens from adult, wild-caught individuals were used whenever possible. However, for many large-bodied species, no mass data were available for wild individuals. Most collectors only began regularly recording body mass data for mammalian specimens in the 1980s (S. McLaren pers. comm., 2015, J. Martin pers. comm., 2015), and even afterwards associated weights for large mammals are rare due to ogistical difficulties. As a result, specimens from zoological parks are often the only option to get associated weight and skeletal measurement data for many taxa. Domesticated or feral animals were not considered due to artificial selection or anthropogenic food provisioning potentially biasing the relationship between OCW and body mass.

Body mass and OCW for each specimen were crossreferenced with other measured specimens of the same species in the present study and/or reported body masses for the species in the previously published literature to ensure each specimen was representative of the species. Specimens were only excluded if the recorded body mass was outside of the range of reported adult body masses in the literature, suggesting the specimen was not a reasonable representative of the species (or that some form of lapsus arose during the original measurement, such as recording "eviscerated" weight as live weight, which is a common issue for tag weights of game animals). For some species, hundreds or even thousands of specimens with body mass were available (e.g., many rodents), and it was not feasible to measure every available individual. In these cases intraspecific regression equations were created by regressing HBL against body mass of available specimens as an index of body condition $[215,216]$, and individuals with the lowest residuals were used.

\section{Analysis}

All analyses and statistical calculations were performed in $\mathrm{R}$ 4.1.1 [217]. $\mathrm{R}$ code used to perform this analysis can be found in Additional file 14, and a knitted .html document showing the direct results of all analyses performed in this study can be found in Additional file 2 . Regression models were created using the average, natural log-transformed body mass and OCW for each species. Species averages were used as is standard in comparisons of interspecific data (see [129] for more information). Curve fitting was performed with the nls function and the package nlstools [218]. The relative strength of the best-fit model against several alternate models (linear, power, quadratic/cubic equations) was evaluated using an Akaike Information Criterion (AIC [219]) and a Bayesian Information Criterion (BIC [220]). 
For both criteria, more negative numbers generally mean better fits.

Most mammals exhibited a roughly comparable occiput morphology across all taxa (Fig. 7a), in which the condyles are reniform and follow the margins of the foramen magnum. However, several taxa, specifically monotremes, dermopterans, lagomorphs, certain hystricomorphs (Caviidae and Dinomyidae), and ricochetal heteromyids (i.e., Dipodomys) exhibited one of several highly distinctive alternate states of occipital condyle morphology (see Fig. 7b-b and "Discussion" for more details) that might violate assumptions of morphological similarity. These alternate states of occiput morphology are readily recognizable in osteological specimens (i.e., they can be recognized in extinct taxa), and thus regression equations were also calculated excluding these groups to determine the accuracy of the correlation including only specimens with a generalized mammalian morphology. Regression equations were also calculated using a sample of all species for which large numbers of individuals ( $\geq 6$ and $\geq 10$ ) could be measured.

Taxon-specific regression equations were calculated for Australidelphia, Carnivora, all rodents, Sciuromorpha, and "ungulates" (i.e., Artiodactyla, Perissodactyla, and Hyracoidea), given their large sample size (Table 4) and observed range of body sizes and the fact that taxonomically restricted datasets are generally said to have better predictive power $[66,86,134]$. Sciuromorpha were examined both separately and as part of the all rodent dataset in order to test if narrower taxonomic selectivity produced improved accuracy rates, as has been suggested by some authors [134]. Sciuromorphs were ideal for this purpose, as a large number of sciuromorph taxa $(N=29)$ spanning a wide range of body sizes $(\sim 50-5000 \mathrm{~g})$ could be measured, reducing concerns that taxonomic regression lines might be biased by a limited range of body sizes.

One concern with the present dataset is that error rates in the regression equation might be biased by oversampling of small mammals. Even if OCW produces a low \%PE in extant mammals as a whole, if the sample dataset is biased by large numbers of small mammals such as rodents (which represent roughly half of all living mammals [208]), it might not produce an accurate estimate of how well the equation performs in larger mammals. Small mammals tend to be generalized and postcranially conservative [221], whereas larger mammals tend to exhibit more postcranial diversity and more extreme anatomical modifications for the same lifestyles [13], possibly due to physical demands on the postcranium increase with increasing body size. This is a concern because most of the specimens OCW can be applied towards are larger mammals, cranial morphology being rarely preserved in fossil micromammals. As a result, I performed an additional analysis including all taxa for which body mass was $>1 \mathrm{~kg}$.

To correct for log-transformation bias [222, 223], three correction factors were calculated: the quasi-maximum likelihood estimator [222, 223], smearing estimate [222$224]$, and ratio estimator [222, 223, 225].

$$
\text { Quasi-maximum likelihood estimator }=\exp \left(\frac{s^{2}}{2}\right)
$$

where $s^{2}=$ residual mean square of the regression equation,

$$
\text { smearing estimate }=\frac{\sum \exp \left(\log \left(r_{i}\right)\right)}{N}
$$

where $N=$ number of observations and $r_{i}=$ residual of data point $i$, and

$$
\text { ratio estimator }=\frac{y}{\hat{y}}
$$

where $y=$ the mean of the observed values for the dependent variable and $\hat{y}=$ the mean of the predicted value for this variable without correction. These corrections factors were averaged to calculate a mean correction factor following the methodology of Tsubamoto [58], and corrected estimates were calculated by multiplying the uncorrected body mass estimates by the correction factor.

Accuracy of the correlation between OCW and body mass was primarily examined using mean percentage prediction error (\%PE) and percent standard error of the estimate (\%SEE). As mentioned in previous studies [39, 226], the correlation coefficient $\left(r^{2}\right)$ is not a good measure of the accuracy of a $\log$-log regression as $r^{2}$ is very sensitive to the range of the data. Data with high logscaled ranges produce high $r^{2}$ values even when the actual predicting power of variables is low. \%PE was calculated as

$$
\% \mathrm{PE}=\frac{\text { observed value-estimated value }}{\text { estimated value }} \times 100
$$

following previous studies. Mean \%PE was calculated as

$$
\% \mathrm{PE}=\frac{\sum|\% \mathrm{PE}|}{\mathrm{N}}
$$

\%PE has been suggested to be an suboptimal metric to gauge accuracy in regression equations [134] as it may overpenalize underestimates of body mass due to using the predicted value as a denominator (similar to how another estimate of accuracy, mean absolute percentage error, penalizes overestimates [227]). However, \%PE was used in this study in order to compare the results of this analysis with previous studies, which also used \%PE. 
\%SEE for natural log transformed variables was calculated following Ruff [57], in which

$$
\% \mathrm{SEE}=\exp (\mathrm{SEE}+4.6052)-100
$$

where SEE = standard error of the estimate.

To test for phylogenetic signal in the present dataset OCW was regressed against body mass using phylogenetic generalized least squares regression (PGLS) via the $\mathrm{R}$ packages ape [228], phytools [229], sensiPhy [230], nlme [231], and geiger [232], and a pruned mammal phylogeny from Upham et al. [233] downloaded from vertlife.org (Additional file 15). The strength of phylogenetic signal was measured using Pagel's $\lambda$ [234].

The accuracy of OCW was compared to two other commonly used estimators of body mass: skull length (measured as condylobasal or condyloincisive length, $\mathrm{CBL}$ ), and head-body length (HBL). Skull length has been considered to be one of the best estimators of body mass in certain groups of mammals [155, 158], though in some groups such as carnivorans other metrics are considered more accurate predictors of body mass [39]. HBL, on the other hand, has often been considered to be one of the most accurate estimators of body mass when available $[39,52,66]$. Skull length was mostly compiled for the taxa using previously published values. HBL was calculated based on a mix of literature data and actual tag data associated with the specimens (see Additional file 12 for more details). Regression equations were calculated for both variables using the body mass from the present dataset and methodologies described above.

In order to test for potential bias in the dataset due to mixing data from both captive and wild individuals and the tendency of most species to become obese while in captivity [235, 236], a phylogenetic multivariate generalized linear mixed model using Markov chain Monte Carlo techniques was fit using the MCMCglmm package [237] in R. OCW and captivity status were treated as fixed effects, whereas phylogenetic signal was calculated using the dataset of Upham et al. [233].

Relative brain size was identified as a potentially confounding variable during the course of the study. To examine the effects of brain size on the regression equations, I compiled a list of published brain masses available for 280 of the examined species (roughly $78.2 \%$ of the dataset) primarily from Burger et al. [12] with a few additions from other sources (see Additional file 12 for more details), and ran analyses treating brain mass as an additional independent factor variable. In order to avoid bias by comparing results from different samples, the results of this analysis were compared to a single-variate regression using only those 280 taxa for which brain mass could be obtained.
As a case study in the use of OCW for estimating body mass in fossil taxa, body mass was estimated using $\mathrm{OCW}$ in the early Oligocene North American hyaenodont "creodonts" Hyaenodon cruciens and H. horridus. $\mathrm{OCW}$ was measured from the figures of the occiput of $H$. cruciens and H. horridus in Lange-Badré [238]. $H y$ aenodon cruciens and $H$. horridus were chosen specifically because these species are known from nearly complete remains and have had their body mass estimated by different authors using a variety of skeletal proxies $[32,39,58]$.

\section{Abbreviations}

AMNH: American Museum of Natural History, New York, USA; CM: Carnegie Museum of Natural History, Pittsburgh, USA; CMNH: Cleveland Museum of Natural History, Cleveland, USA; CUMV: Cornell University Museum of Vertebrates, Ithaca, USA; MECN: Museo Ecuatoriano de Ciencias Naturales; MCZ: Harvard Museum of Comparative Zoology, Cambridge, USA; MNPN: Escuela Politécnica Nacional, Ecuador; MNCR: Museo Nacional de Costa Rica, San José, Costa Rica; MVZ: University of California Museum of Vertebrate Zoology, Berkeley, USA; NPM: Núcleo de Pesquisa em Ecologia e Desenvolvimento Sócio-Ambiental de Macaé, Macaé, Brazil; OMNH: Sam Noble Museum of Natural History, Norman, USA; ROM: Royal Ontario Museum, Toronto, Canada; UAM: University of Alaska Museum, Fairbanks, USA; UF: University of Florida/Florida Museum of Natural History, Gainesville, USA; UMMZ: University of Michigan Museum of Zoology, Ann Arbor, USA; USNM: Smithsonian Museum of Natural History, Washington D.C., USA; UWBM: Burke Museum of Natural History and Culture, Seattle, USA; UWYMV: University of Wyoming Museum of Vertebrates, Laramie, USA; YELL: Yellowstone National Park Archives, Gardiner, USA; AIC: Akaike Information Criterion; BIC: Bayesian Information Criterion; CBL: Condylobasal length of skull; CF: Averaged correction factor (see Methods); HBL: Headbody length; OCW: Occipital condyle width; PE: Prediction error;

PGLS: Phylogenetic generalized least squares regression; SEE: Standard error of estimate

\section{Supplementary Information}

The online version contains supplementary material available at https://doi. org/10.1186/s12915-021-01224-9.

Additional file 1: Figure S1. Plots of variables examined versus body mass. A, OCW versus body mass assuming isometry. B, OCW versus body mass with OCW raised to the $2 / 3$ power. $\mathbf{C}$, condylobasal length versus body mass assuming isometry. $\mathbf{D}$, skull length versus body mass raised to the $1 / 2$ power. E, HBL versus body mass. No power transformation for $\mathrm{HBL}$ is included as the non-linear fit indicates that the relationship between natural $\log \mathrm{HBL}$ and natural $\log$ body mass is linear. For $\mathbf{A}$ and $\mathbf{C}$, blue lines are linear regression lines and red dashed lines are loess fit lines. Note how the linear regression lines in $\mathbf{A}$ and $\mathbf{C}$ do not precisely follow the trend of the data, overestimating body mass at the extremes and underestimating it in the middle ranges of the data set (.tiff).

Additional file 2. Knitted html report showing the raw results of the analyses performed in this study (.html).

Additional file 3: Figure S2. Scatterplot of natural log of OCW versus natural log of body mass, comparing the best fit curve between a linear (in red), 2/3 power (in blue) and quadratic model (in green). Dashed lines represent the $95 \%$ prediction intervals (.tiff).

Additional file 4: Figure S3. Scatter plot (A) and boxplot (B) of sample size versus absolute value of the residuals of the regression equation between log OCW and log body mass (.tiff).

Additional file 5: Figure S4. Ordinal-level regression equations of log OCW and log body mass for various orders of mammals (and suborders of rodents) for which $\geq 5$ species are sampled. The dashed black line represents the best fit line of the total dataset. Data points which pertain to clades for which $\mathrm{N}<5$ are denoted in gray (.tiff). 
Additional file 6: Figure S5. Histogram (A) and Q-Q plot (B) of the residuals for the rodent regression equation between log OCW and log body mass (.tiff).

Additional file 7: Figure S6. Residuals of the all-species regression equation of log OCW versus log body mass plotted onto a phylogeny of the examined taxa. Higher than expected body masses are shown in reds and yellows and lower than expected body masses are shown in cyans and blues. There is very little variation in the residuals across most of the model, suggesting a lack of Brownian motion in the evolution of this trait, but there are extreme shifts in residual values at the base of several clades such as Lagomorpha and Monotremata (.pdf).

Additional file 8: Figure S7. A, box plot of residuals versus captivity status for all specimens. B, box plot of residuals versus natural log of body mass (in g) for all specimens. C, box plot comparing species average residuals for species in which it was possible to be selective about what specimens were chosen versus species in which it was not possible to be selective (.tiff).

Additional file 9: Figure S8. Plot of the residuals of the regression of OCW and body mass against the residuals of the regression between brain mass (scaled to the $3 / 4$ power) and body mass, showing that the residuals in relative brain size are not strongly correlated with residuals in OCW (.tiff).

Additional file 10: Figure S9. Plot of the residuals of the regression equation including brain mass as an independent variable and the residuals of the regression of the same data where brain mass is not included. Red line represents a line with intercept of 0 and slope of 1 , blue line represents OLS fit. If including brain size significantly improved estimates, it would be expected that the slope would be much shallower than 1 due to residuals for extreme values being lower (.tiff).

Additional file 11: Figure S10. Plot of the residuals for the regression of OCW and body mass against the residuals for the regressions of headbody length (A) and skull length (B) against body mass (.tiff).

Additional file 12: Table S1. Database of average OCW and body mass in all specimens measured, as well as skull length (measured as condylobasal or condyloincisive length when available), HBL, and brain mass for each species compiled from the previously published literature (.csv) $[12,136,180,209-211,239-564]$.

Additional file 13: Table S2. Database of the individual specimens measured in this analysis, including their raw measurements, gender, and captivity status (.csv)

Additional file 14. $R$ code used to perform the analyses in this study, in Rmarkdown format (.Rmd).

Additional file 15. Phylogenetic tree used to perform the tests for phylogenetic signal and PGLS, in NEXUS format (.nex).

\section{Acknowledgements}

I thank S. McLaren and J. Wible (CM), R. Muehlheim and T. Matson (CMNH), C. Dardia (CUMV), C. Thompson and R. Nagesan (MSU/UMMZ), C. Spenser (MVZ), M. Xavier, P. Gonçalves, and F. Khaled (NPM), B. Coyner, S. Burridge, E. Freitas (OMNH), B. Lim and K. Seymour (ROM), V. Mathis and I. Quitmyer (UF), D. Lunde and J. Ososky (USNM), J. Bradley (UWBM), E. Wommack (UWYMV), and C. Curry, D. Smith, E. Stahler, and M. Watson (YELL) for facilitating access to specimens in their care and assisting me in locating specimens with body mass data; J. Maisano and C. Thompson for providing access to CT scans through MorphoSource, C. Engelman, K. Engelman, and T. Hull for aiding in travel and assisting in taking photographs and measurements; J. R. Burger, G. McDonald, J. Martin, and I. Quitmyer for helpful discussions and advice in locating specimens; M. Benard, J. Burger, J. Burns, T. Guillerme, S.S.B. Hopkins, R. Martin, F.J. Rohlf, N. Upham, and the r-sig-phylo mailing list for discussions regarding $R$ and the statistical aspects of the analysis; $R$. Rose for access to their original field notes; R. Beck, M. Benard, D. Croft, N. Gardner, and S. Simpson for helpful comments on earlier versions of this manuscript, and $\mathrm{N}$. Campione, B. Moncunill-Solé, and two anonymous reviewers for their comments and criticism.

\section{Author's contributions}

The author confirms sole responsibility for the following: study conception and design, data collection, analysis and interpretation of results, and manuscript preparation. All authors read and approved the final manuscript.

\section{Funding}

The author has no funding to declare for this study.

\section{Availability of data and materials}

All data generated or analyzed during this study are included in this published article (and its supplementary information files).

\section{Declarations}

Ethics approval and consent to participate

Not applicable.

\section{Consent for publication}

Not applicable.

\section{Competing interests}

The author declares no competing interests.

Received: 1 September 2020 Accepted: 26 December 2021

Published online: 07 February 2022

References

1. Kay RF, Hylander WL. The dental structure of mammalian folivores with special reference to Primates and Phalangeroidea. In: The Ecology of Arboreal Folivores. Edited by Montgomery GG. Washington, D.C.: Smithsonian Institution Press; 1978. p. 173-91.

2. Clauss M, Frey R, Kiefer B, Lechner-Doll M, Loehlein W, Polster C, et al. The maximum attainable body size of herbivorous mammals: morphophysiological constraints on foregut, and adaptations of hindgut fermenters. Oecol. 2003;136(1):14-27. https://doi.org/10.1007/s00442-003-12 54-z.

3. Carbone C, Mace GM, Roberts SC, Macdonald DW. Energetic constraints on the diet of terrestrial carnivores. Nature. 1999;402(6759):286-8. https://doi. org/10.1038/46266.

4. Cork SJ, Foley WJ. Digestive and metabolic strategies of arboreal folivores in relation to chemical defenses in temperate and tropical forests. In: Palo RT, Robbins CT, editors. Plant Defenses Against Mammalian Herbivory. Boca Raton: CRC Press; 1991. p. 166-75.

5. McNab BK. Uniformity in the basal metabolic rate of marsupials: its causes and consequences. Rev Chil de Hist Nat. 2005;78:183-98.

6. Robinson JG, Redford KH. Body size, diet, and population density of Neotropical forest mammals. Am Nat. 1986;128(5):665-80. https://doi.org/1 $0.2307 / 2461950$

7. Speakman JR. Body size, energy metabolism and lifespan. J Exp Biol. 2005; 208(9):1717. https://doi.org/10.1242/jeb.01556.

8. Blueweiss L, Fox H, Kudzma V, Nakashima D, Peters R, Sams S. Relationships between body size and some life history parameters. Oecol. 1978;37(2):25772. https://doi.org/10.1007/BF00344996.

9. Reiss M. Scaling of home range size: body size, metabolic needs and ecology. Trends Ecol Evol. 1988;3(3):85-6. https://doi.org/10.1016/0169-534 7(88)90025-0.

10. Weckerly FW. Sexual-size dimorphism: influence of mass and mating systems in the most dimorphic mammals. J Mammal. 1998;79(1):33-52.

11. Jerison HJ. Evolution of the brain and intelligence. New York: Academic Press; 1973.

12. Burger JR, George MA Jr, Leadbetter C, Shaikh F. The allometry of brain size in mammals. J Mammal. 2019;100(2):276-83. https://doi.org/10.1093/jma $\mathrm{mmal} / \mathrm{gyz0} 33$.

13. Shockey BJ, Croft DA, Anaya F. Analysis of function in the absence of extant functional analogs: a case study of mesotheriid notoungulates. Paleobiology. 2007;33(2):227-47.

14. Geist V. On the relationship of social evolution and ecology in ungulates. Am Zool. 1974;14(1):205-20. https://doi.org/10.2307/3881984.

15. Ercoli MD, Prevosti FJ, Forasiepi AM. The structure of the mammalian predator guild in the Santa Cruz Formation (late early Miocene). J Mammal Evol. 2014;21(4):369-81. https://doi.org/10.1007/s10914-013-9243-4. 
16. Dayan T, Simberloff D. Character displacement, sexual dimorphism, and morphological variation among British and Irish Mustelids. Ecology. 1994; 75(4):1063-73. https://doi.org/10.2307/1939430.

17. Tejada-Lara JV, MacFadden BJ, Bermudez L, Rojas G, Salas-Gismondi R, Flynn JJ. Body mass predicts isotope enrichment in herbivorous mammals. Proc $R$ Soc B. 2018;285(1881). https://doi.org/10.1098/rspb.2018.1020.

18. Cardillo M, Mace GM, Jones KE, Bielby J, Bininda-Emonds ORP, Sechrest W, et al. Multiple causes of high extinction risk in large mammal species. Science. 2005;309(5738):1239-41. https://doi.org/10.1126/science.1116030.

19. Calder WA. Size, function, and life history. Cambridge: Harvard University Press; 1984.

20. Peters $\mathrm{RH}$. The ecological implications of body size. Cambridge: Cambridge University Press; 1983.

21. Damuth J. MacFadden BJ (eds.): Body size in mammalian paleobiology: estimation and biological implications. Cambridge: Cambridge University Press; 1990.

22. Hone DWE. Variation in the tail length of non-avian dinosaurs. J Vertebr Paleontol. 2012;32(5):1082-9. https://doi.org/10.1080/02724634.2012. 680998.

23. Murray PF, Vickers-Rich P. Magnificent Mihirungs. The colossal flightless birds of the Australian dreamtime. Bloomington: Indiana University Press; 2004.

24. McGill BJ, Enquist BJ, Weiher E, Westoby M. Rebuilding community ecology from functional traits. Trends Ecol Evol. 2006;21(4):178-85. https://doi.org/1 0.1016/j.tree.2006.02.002.

25. Gingerich PD, Smith BH. Allometric scaling in the dentition of primates and insectivores. In: Jungers WL, editor. Size and Scaling in Primate Biology. Boston: Springer US; 1985. p. 257-72.

26. McNab BK. Complications inherent in scaling the basal rate of metabolism in mammals. Q Rev Biol. 1988;63(1):25-54. https://doi.org/1 $0.1086 / 415715$.

27. Damuth J, MacFadden BJ. Introduction: body size and its estimation. In: Damuth J, BJ MF, editors. Body Size in Mammalian Paleobiology: Estimation and Biological Implications. Cambridge: Cambridge University Press; 1990. p. $1-10$.

28. Bartholomew GA. A matter of size: an examination of endothermy in insects and terrestrial vertebrates. In: Henrich B, editor. Insect Thermoregulation. New York: Wiley; 1981. p. 45-78.

29. Schmidt-Nielsen K. Scaling: why is animal size so important? Cambridge: Cambridge University Press; 1984

30. Rose KD. The beginning of the age of mammals. Baltimore: The John Hopkins University Press; 2006.

31. Millien $\mathrm{V}$, Bovy $\mathrm{H}$. When teeth and bones disagree: body mass estimation of a giant extinct rodent. J Mammal. 2010;91(1):11-8. https://doi.org/10.1644/ 08-mamm-a-347r1.1.

32. Egi N. Body mass estimates in extinct mammals from limb bone dimensions: the case of North American Hyaenodontids. Palaeontology. 2001;44(3):497-528. https://doi.org/10.1111/1475-4983.00189.

33. Sinclair WJ. Mammalia of the Santa Cruz Beds. Marsupialia. In: Scott WB, editor. vol. IV, Part III Reports of the Princeton University Expeditions to Patagonia, 1896-1899. Stuttgart: Princeton University, E. Schweizerbart'sche Verlagshandlung (E. Nägele); 1906. p. 333-460

34. Scott WB, Jepsen GL. The Mammalian fauna of the White River Oligocene: Part I. Insectivora and Carnivora. Trans Am Phil Soc. 1936;28(1):1-153. https://doi.org/10.2307/1005507.

35. Sinclair WJ. The marsupial fauna of the Santa Cruz Beds. Proc Am Philos Soc. 1906:44(179):73-81.

36. Argot C. Postcranial functional adaptations in the South American Miocene borhyaenoids (Mammalia, Metatheria): Cladosictis, Pseudonotictis and Sipalocyon. Alcheringa. 2003;27(3-4):303-56.

37. Zhou X, Sanders WJ, Gingerich PD. Functional and behavioral implications of vertebral structure in Pachyaena ossifraga (Mammalia, Mesonychia). Contrib Mus Paleontol Univ Mich. 1992;28(12):289-312.

38. Wortman JL. Osteology of Patriofelis, a middle Eocene creodont. Bull Am Mus Nat Hist. 1894;6:129-64.

39. Van Valkenburgh B. Skeletal and dental predictors of body mass in carnivores. In: Damuth J, BJ MF, editors. Body Size in Mammalian Paleobiology: Estimation and Biological Implications. Cambridge: Cambridge University Press; 1990. p. 181-205.

40. Hunt RM Jr. Amphicyonidae. In: Janis CM, Scott KM, Jacobs LL, editors. vol. 1: Terrestrial carnivores, ungulates, and ungulate-like mammals Evolution of
Tertiary Mammals of North America. Cambridge: Cambridge University Press; 1998. p. 196-227.

41. Figueirido B, Pérez-Claros JA, Hunt RM, Palmqvist P. Body mass estimation in amphicyonid carnivoran mammals: a multiple regression approach from the skull and skeleton. Acta Palaeontol Pol. 2011;56(2):225-46. https://doi. org/10.4202/app.2010.0005.

42. Simons EL. The Paleocene Pantodonta. Trans Am Phil Soc. 1960;50(6):3-99.

43. Osborn HF. A complete skeleton of Coryphodon radians. Notes upon the locomotion of this animal. Bull Am Mus Nat Hist. 1898;10(6):81-91.

44. Argot C. Postcranial analysis of a carnivoran-like archaic ungulate: the case of Arctocyon primaevus (Arctocyonidae, Mammalia) from the late Paleocene of France. J Mammal Evol. 2013;20(2):83-114. https://doi.org/10.1 007/s10914-012-9198-X.

45. Schoch RM. Systematics, functional morphology, and macroevolution of the extinct mammalian order Taeniodonta. Peabody Mus Bull. 1986:42:1-307.

46. Joeckel RM. A functional interpretation of the masticatory system and paleoecology of entelodonts. Paleobiology. 1990;16(4):459-82.

47. Sharp AC. A quantitative comparative analysis of the size of the frontoparietal sinuses and brain in vombatiform marsupials. Mem Mus Vic 2016;74:331-42.

48. Riggs ES. A skeleton of Astrapotherium. Field Mus Nat Hist, Geol ser. 1935; 6(13):167-76.

49. Sinclair WJ. The Santa Cruz Typotheria. Proc Am Philos Soc. 1908:47(188):6478.

50. Carrillo JD, Asher RJ. An exceptionally well-preserved skeleton of Thomashuxleya externa (Mammalia, Notoungulata), from the Eocene of Patagonia, Argentina. Palaeontol Electron. 2017;20.2.34A:1-33.

51. Simpson GG. A Deseado hegetothere from Patagonia. Am J Sci. 1945; 243(10):550-64.

52. Croft DA, Gelfo JN, López GM. Splendid innovation: the extinct South American native ungulates. Ann Rev Earth Planet Sci. 2020;48(1):259-90. https://doi.org/10.1146/annurev-earth-072619-060126.

53. Millien $\mathrm{V}$. The largest among the smallest: the body mass of the giant rodent Josephoartigasia monesi. Proc R Soc B. 2008;275(1646):1953-5.

54. Reynolds PS. How big is a giant? The importance of method in estimating body size of extinct mammals. J Mammal. 2002;83(2):321-32. https://doi. org/10.1644/1545-1542(2002)083<0321:HBIAGT>2.0.CO;2.

55. Jungers WL. Problems and methods in reconstructing body size in fossil primates. In: Damuth J, BJ MF, editors. Body Size in Mammalian Paleobiology: Estimation and Biological Implications. Cambridge: Cambridge University Press; 1990. p. 103-18.

56. Van Valkenburgh B. Skeletal indicators of locomotor behavior in living and extinct carnivores. J Vertebr Paleontol. 1987;7:162-82.

57. Ruff CB. Long bone articular and diaphyseal structure in Old World monkeys and apes. Il: estimation of body mass. Am J Phys Anthropol. 2003;120(1):1637. https://doi.org/10.1002/ajpa.10118.

58. Tsubamoto T. Estimating body mass from the astragalus in mammals. Acta Palaeontol Pol. 2014;59(2):259-65. https://doi.org/10.4202/app.2011.0067.

59. Moncunill-Solé B, Tuveri C, Arca M, Angelone C. Tooth and long bone scaling in Sardinian ochotonids (Early Pleistocene-Holocene): evidence for megalodontia and its palaeoecological implications. Palaeogeogr Palaeoclimatol Palaeoecol. 2021;582:110645. https://doi.org/10.1016/j.pala eo.2021.110645.

60. Croft DA, Bond M, Flynn JJ, Reguero MA, Wyss AR. Large archaeohyracids (Typotheria, Notoungulata) from central Chile and Patagonia including a revision of Archaeotypotherium. Fieldiana: Geology (New Series). 2003;49:138.

61. Shockey BJ, Anaya F. Postcranial osteology of mammals from Salla, Bolivia (late Oligocene): form, function, and phylogenetic implications. In: Sargis EJ, Dagosto M, editors. Mammalian Evolutionary Morphology: A Tribute to Frederick S Szalay. New York: Springer; 2008. p. 135-57.

62. Davis $E B$, Calède JJM. Extending the utility of artiodactyl postcrania for species-level identifications using multivariate morphometric analyses. Palaeontol Electron. 2012:15.1.1A:1-22.

63. Davis EB, Pyenson ND. Diversity biases in terrestrial mammalian assemblages and quantifying the differences between museum collections and published accounts: a case study from the Miocene of Nevada. Palaeogeogr Palaeoclimatol Palaeoecol. 2007;250(1):139-49. https://doi.org/1 0.1016/j.palaeo.2007.03.006

64. Janis CM. Correlation of cranial and dental variables with body size in ungulates and macropodids. In: Damuth J, BJ MF, editors. Body Size in 
Mammalian Paleobiology: Estimation and Biological Implications. Cambridge: Cambridge University Press; 1990. p. 255-300.

65. MacFadden BJ, Hulbert RCJ. Body size estimates and size distribution of ungulate mammals from the late Miocene Love Bone Bed of Florida. In: Damuth J, BJ MF, editors. Body Size in Mammalian Paleobiology: Estimation and Biological Implications. Cambridge: Cambridge University Press; 1990. p. 337-63.

66. Damuth J. Problems in estimating body masses of archaic ungulates using dental measurements. In: Damuth J, BJ MF, editors. Body Size in Mammalian Paleobiology: Estimation and Biological Implications. Cambridge: Cambridge University Press; 1990. p. 229-53.

67. MacFadden BJ. Fossil horses from "Eohippus" (Hyracotherium) to Equus: scaling, Cope's law, and the evolution of body size. Paleobiology. 1986;12(4): 355-69. https://doi.org/10.2307/2400511.

68. Palmqvist P, Arribas A, Martínez-Navarro B. Ecomorphological study of large canids from the lower Pleistocene of southeastern Spain. Lethaia. 1999;32(1): 75-88. https://doi.org/10.1111/j.1502-3931.1999.tb00583.x

69. Sarko DK, Domning DP, Marino L, Reep RL. Estimating body size of fossil sirenians. Mar Mam Sci. 2010;26(4):937-59. https://doi.org/10.1111/j.17487692.2010.00384.x

70. Argot C. Functional adaptations of the postcranial skeleton of two Miocene borhyaenoids (Mammalia, Metatheria), Borhyaena and Prothylacinus, from South America. Palaeontology. 2003;46(6):1213-67.

71. Vizcaíno SF, Blanco RE, Bender JB, Milne N. Proportions and function of the limbs of glyptodonts. Lethaia. 2011;44(1):93-101. https://doi.org/10.1111/j.1 502-3931.2010.00228.x

72. Biknevicius AR. Body mass estimation in armoured mammals: cautions and encouragements for the use of parameters from the appendicular skeleton. J Zool (London). 1999;248(2):179-87.

73. Biknevicius AR. Biomechanical scaling of limb bones and differential limb use in caviomorph rodents. J Mammal. 1993;74(1):95-107.

74. Fariña RA, Vizcaíno SF, Bargo MS. Body mass estimation in Lujanian (late Pleistocene-early Holocene of South America) mammal megafauna. Mastozool Neotrop. 1998;5(2):87-108.

75. Sánchez-Villagra MR, Aguilera O, Horovitz I. The anatomy of the world's largest extinct rodent. Science. 2003;301:1708-10. https://doi.org/10.1126/ science.1089332.

76. Etienne C, Mallet C, Cornette R, Houssaye A. Influence of mass on tarsus shape variation: a morphometrical investigation among Rhinocerotidae (Mammalia: Perissodactyla). Biol J Linn Soc. 2020;129(4):950-74. https://doi. org/10.1093/biolinnean/blaa005.

77. Mallet C, Cornette R, Billet G, Houssaye A. Interspecific variation in the limb long bones among modern rhinoceroses-extent and drivers. PeerJ. 2019;7: e7647. https://doi.org/10.7717/peerj.7647.

78. Morlo M. Niche structure and evolution in creodont (Mammalia) faunas of the European and North American Eocene. Geobios. 1999;32(2):297-305. https://doi.org/10.1016/s0016-6995(99)80043-6.

79. Sorkin B. A biomechanical constraint on body mass in terrestrial mammalian predators. Lethaia. 2008;41(4):333-47. https://doi.org/10.1111/j.1502-3931.2 007.00091.x

80. Gingerich PD. Prediction of body mass in mammalian species from long bone lengths and diameters. Contrib Mus Paleontol Univ Mich. 1990;28(4):79-92.

81. McGrath AJ, Anaya F, Croft DA. Two new macraucheniids (Mammalia: Litopterna) from the late middle Miocene (Laventan South American Land Mammal Age) of Quebrada Honda, Bolivia. J Vertebr Paleontol. 2018;38(3): e1461632. https://doi.org/10.1080/02724634.2018.1461632.

82. Croft DA. Cenozoic environmental change in South American as indicated by mammalian body size distributions (cenograms). Divers Distrib. 2001;7: 271-87.

83. Witmer LM. The Extant Phylogenetic Bracket and the importance of reconstructing soft tissues in fossils. In: Thomason JJ, editor. Functional Morphology in Vertebrate Paleontology. New York: Cambridge University Press; 1995. p. 19-33.

84. Prevosti FJ, Forasiepi A, Zimicz N. The evolution of the Cenozoic terrestrial mammal guild in South America: competition or replacement? J Mammal Evol. 2013;20(1):3-21. https://doi.org/10.1007/s10914-011-9175-9.

85. Schwartz GT, Rasmussen DT, Smith RJ. Body-size diversity and community structure of fossil hyracoids. J Mammal. 1995;76(4):1088-99.

86. Mendoza M, Janis CM, Palmqvist P. Estimating the body mass of extinct ungulates: a study on the use of multiple regression. J Zool. 2006;270(1):90101. https://doi.org/10.1111/j.1469-7998.2006.00094.x
87. Campione NE, Evans DC. A universal scaling relationship between body mass and proximal limb bone dimensions in quadrupedal terrestrial tetrapods. BMC Biol. 2012;10(1):60. https://doi.org/10.1186/1741-7007-10-60.

88. De Esteban-Trivigno S, Mendoza M, De Renzi M. Body mass estimation in xenarthra: a predictive equation suitable for all quadrupedal terrestrial placentals? J Morphol. 2008;269(10):1276-93. https://doi.org/10.1002/jmor.1 0659

89. Westbury M, Baleka S, Barlow A, Hartmann S, Paijmans JLA, Kramarz A, et al. A mitogenomic timetree for Darwin's enigmatic South American mammal Macrauchenia patachonica. Nat Commun. 2017:8:15951. https://doi.org/10.1 038/ncomms15951.

90. Welker F, Collins MJ, Thomas JA, Wadsley M, Brace S, Cappellini E, et al. Ancient proteins resolve the evolutionary history of Darwin's South American ungulates. Nature. 2015;522:81. https://doi.org/10.1038/nature1424 9.

91. Alroy J. Simple equations for estimating body mass in mammals (and dinosaurs). In: 72nd Annual Meeting Society of Vertebrate Paleontology. North Carolina: Raleigh; 2012. p. 55-6.

92. Tsubamoto T, Egi N, Takai M, Thaung H. Zin Maung Maung T: Body mass estimation from the talus in primates and its application to the Pondaung fossil amphipithecid primates. Hist Biol. 2016;28(1-2):27-34. https://doi.org/1 0.1080/08912963.2014.971783.

93. Tsubamoto T. Relationship between the calcaneal size and body mass in primates and land mammals. Anthropological Science. 2019;127(1):73-80. https://doi.org/10.1537/ase.190221.

94. Argot C, Babot J. Postcranial morphology, functional adaptations and palaeobiology of Callistoe vincei, a predaceous metatherian from the Eocene of Salta, north-western Argentina. Palaeontology. 2011;54(2):447-80. https://doi.org/10.1111/j.1475-4983.2011.01036.x.

95. Maddin HC, Piekarski N, Reisz RR, Hanken J. Development and evolution of the tetrapod skull-neck boundary. Biol Rev Camb Philos Soc. 2020;95(3):57391. https://doi.org/10.1111/brv.12578.

96. Romer AS. Osteology of the reptiles. Chicago: University of Chicago Press; 1956.

97. Radinsky L. Relative brain size: a new measure. Science. 1967;155(3764):8368. https://doi.org/10.1126/science.155.3764.836.

98. MacLarnon A. The evolution of the spinal cord in primates: evidence from the foramen magnum and the vertebral canal. J Human Evol. 1996;30(2): 121-38. https://doi.org/10.1006/jhev.1996.0009.

99. Williams SA, Spear JK, Petrullo L, Goldstein DM, Lee AB, Peterson AL, et al. Increased variation in numbers of presacral vertebrae in suspensory mammals. Nat Ecol Evol. 2019;3(6):949-56. https://doi.org/10.1038/s41559-01 9-0894-2.

100. Persons WS, Currie PJ. The tail of Tyrannosaurus: Reassessing the size and locomotive importance of the M. caudofemoralis in non-avian theropods. Anat Record. 2011;294(1):119-31. https://doi.org/10.1002/ar.21290.

101. Morton SR. Ecological correlates of caudal fat storage in small mammals. Aust Mamm. 1980;3:81-6.

102. Grand TI. Adaptation of tissue and limb segments to facilitate moving and feeding in Arboreal folivores. In: Montgomery GG, editor. The Ecology of Arboreal Folivores. Washington D.C: Smithsonian Institute Press; 1978. p. 231-41.

103. Organ CL. Biomechanics of ossified tendons in ornithopod dinosaurs. Paleobiology. 2006;32(4):652-65. https://doi.org/10.1666/05039.1.

104. Willey JS, Biknevicius AR, Reilly SM, Earls KD. The tale of the tail: limb function and locomotor mechanics in Alligator mississippiensis. J Exp Biol. 2004;207(3):553-63. https://doi.org/10.1242/jeb.00774.

105. Daniels CB, Flaherty SP, Simbotwe MP. Tail size and effectiveness of autotomy in a lizard. J Herpetol. 1986;20(1):93-6. https://doi.org/10.2307/1 564134.

106. Jagnandan K, Russell AP, Higham TE. Tail autotomy and subsequent regeneration alter the mechanics of locomotion in lizards. J Exp Biol. 2014; 217(21):3891-7. https://doi.org/10.1242/jeb.110916.

107. Arnold SJ. A quantitative approach to antipredator performance: salamander defense against snake attack. Copeia. 1982;1982(2):247-53. https://doi.org/10.2307/1444602.

108. Grand TI. Body weight: Its relation to tissue composition, segment distribution, and motor function. I. Interspecific comparisons. Am J Phys Anthropol. 1977;47(2):211-39. https://doi.org/10.1002/ajpa.1330470204.

109. Grand TI, Eisenberg JF. On the affinities of the Dinomyidae. Saugetierkundliche Mitteilungen. 1982;30:151-7. 
110. Hager ER, Hoekstra HE. Tail length evolution in deer mice: linking morphology, behavior, and function. Integr Comp Biol. 2021;61(2):385-97. https://doi.org/10.1093/icb/icab030.

111. Grand TI. Body composition and the evolution of the Macropodidae (Potorous, Dendrolagus, and Macropus). Anat Embryol. 1990;182(1):85-92. https://doi.org/10.1007/BF00187530.

112. Campione NE, Evans DC, Brown CM, Carrano MT. Body mass estimation in non-avian bipeds using a theoretical conversion to quadruped stylopodial proportions. Methods Ecol Evol. 2014;5(9):913-23. https://doi.org/10.1111/2 041-210X.12226.

113. Font E, García-Roa R, Pincheira-Donoso D, Carazo P. Rethinking the effects of body size on the study of brain size evolution. Brain Behav Evol. 2019; 93(4):182-95. https://doi.org/10.1159/000501161.

114. Hall GC, Kinsman MJ, Nazar RG, Hruska RT, Mansfield KJ, Boakye M, et al. Atlanto-occipital dislocation. World J Orthop. 2015;6(2):236-43. https://doi. org/10.5312/wjo.v6.i2.236.

115. Danowitz M, Domalski R, Solounias N. A new species of Prolibytherium (Ruminantia, Mammalia) from Pakistan, and the functional implications of an atypical atlanto-occipital morphology. J Mammal Evol. 2016;23(2):201-7. https://doi.org/10.1007/s10914-015-9307-8.

116. Martin RA. Body mass and basal metabolism of extinct mammals. Comp Biochem Physiol Part A Physiol. 1980;66(2):307-14. https://doi.org/10.1016/ 0300-9629(80)90167-X.

117. Köhler M, Moyà-Solà S. Reduction of brain and sense organs in the fossil insular bovid Myotragus. Brain Behav Evol. 2004;63(3):125-40.

118. Moncunill-Solé $B$, Jordana $X$, Köhler M. How common is gigantism in insular fossil shrews? Examining the 'Island Rule' in soricids (Mammalia: Soricomorpha) from Mediterranean Islands using new body mass estimation models. Zool J Linn Soc. 2016;178(1):163-82. https://doi.org/1 $0.1111 /$ zoj.12399.

119. Moncunill-Solé B, Jordana X, Marín-Moratalla N, Moyà-Solà S, Köhler M. How large are the extinct giant insular rodents? New body mass estimations from teeth and bones. Integr Zool. 2014;9(2):197-212. https://doi.org/1 $0.1111 / 1749-4877.12063$

120. Moncunill-Solé B, Quintana J, Jordana X, Engelbrektsson P, Köhler M. The weight of fossil leporids and ochotonids: body mass estimation models for the order Lagomorpha. J Zool. 2015;295(4):269-78. https://doi.org/10.1111/ jzo.12209.

121. Jukar AM, Lyons SK, Uhen MD. A cranial correlate of body mass in proboscideans. Zool J Linn Soc. 2018;184(3):919-31. https://doi.org/10.1093/ zoolinnean/zlx108.

122. Marino $L$, Uhen MD, Pyenson ND, Frohlich B. Reconstructing cetacean brain evolution using computed tomography. Anat Rec B New Anat. 2003; 272B(1):107-17. https://doi.org/10.1002/ar.b.10018.

123. Marino L, McShea DW, Uhen MD. Origin and evolution of large brains in toothed whales. Anat Rec A Discov Mol Cell Evol Biol. 2004;281A(2):1247-55. https://doi.org/10.1002/ar.a.20128.

124. Nummela S, Hussain ST, Thewissen JGM. Cranial anatomy of Pakicetidae (Cetacea, Mammalia). J Vertebr Paleontol. 2006;26(3):746-59. https://doi. org/10.1671/0272-4634(2006)26[746:caopcm]2.0.co;2.

125. Castelblanco-Martínez DN, Morales-Vela B, Padilla-Saldívar JA. Using craniometrical practices to infer body size of Antillean manatees. Mammalia. 2014;78(1):109-15.

126. Churchill M, Clementz MT, Kohno N. Predictive equations for the estimation of body size in seals and sea lions (Carnivora: Pinnipedia). J Anat. 2014; 225(2):232-45. https://doi.org/10.1111/joa.12199.

127. Debey LB, Pyenson ND. Osteological correlates and phylogenetic analysis of deep diving in living and extinct pinnipeds: what good are big eyes? Mar Mam Sci. 2013;29(1):48-83. https://doi.org/10.1111/j.1748-7692.2011.00545.x.

128. Cassini GH, Vizcaíno SF, Bargo MS. Body mass estimation in early Miocene native South American ungulates: a predictive equation based on 3D landmarks. J Zool. 2012;287(1):53-64. https://doi.org/10.1111/j.1469-7998.2 011.00886.x

129. SSB H. Estimation of body size in fossil mammals. In: Croft DA, Su DF, Simpson SW, editors. Methods in Paleoecology: Reconstructing Cenozoic Terrestrial Environments and Ecological Communities. Cham: Springer Nature; 2018. p. 7-22.

130. Economos AC. Elastic and/or geometric similarity in mammalian design. J Theor Biol. 1983;103:167-72.

131. Norman GR, Streiner DL. Biostatistics: the bare essentials. Shelton: People's Medical Publishing House; 2008.
132. Ghasemi A, Zahediasl S. Normality tests for statistical analysis: a guide for non-statisticians. Int J Endocrinol Metab. 2012;10(2):486-9. https://doi.org/10. 5812/ijem.3505

133. Sears KE, Finarelli JA, Flynn JJ, Wyss AR. Estimating body mass in New World "monkeys" (Platyrrhini, Primates), with a consideration of the Miocene platyrrhine, Chilecebus carrascoensis. Am Mus Novitates. 2008;3617:1-29.

134. Yapuncich GS, Gladman JT, Boyer DM. Predicting euarchontan body mass: a comparison of tarsal and dental variables. Am J Phys Anthropol. 2015;157(3): 472-506. https://doi.org/10.1002/ajpa.22735.

135. Smith RJ. Estimation of body mass in Paleontology. J Human Evol. 2002 43(2):271-87. https://doi.org/10.1006/jhev.2002.0573.

136. Kwiecinski GG. Marmota monax. Mamm Spec. 1998:591:1-8.

137. Campione NE. Extrapolating body masses in large terrestrial vertebrates. Paleobiology. 2017;43(4):693-9. https://doi.org/10.1017/pab.2017.9.

138. Müller DWH, Codron D, Werner J, Fritz J, Hummel J, Griebeler EM, et al. Dichotomy of eutherian reproduction and metabolism. Oikos. 2012;121(1): 102-15. https://doi.org/10.1111/j.1600-0706.2011.19505.x.

139. Rohlf FJ. A comment on phylogenetic correction. Evolution. 2006;60(7): 1509-15.

140. Burnham KP, Anderson DR. Model selection and multimodel inference. Springer New York: New York; 2002.

141. Garland T Jr, Ives AR. Using the past to predict the present: confidence intervals for regression equations in phylogenetic comparative methods. Am Nat. 2000;155(3):346-64. https://doi.org/10.1086/303327.

142. Kerkhoff AJ, Enquist BJ. Multiplicative by nature: why logarithmic transformation is necessary in allometry. J Theor Biol. 2009;257:519-21.

143. Albrecht GH, Gelvin BR, Miller JMA. Complex curvilinear allometry of brain size scaling in mammals. FASEB J. 2010;24(S1):642.641. https://doi.org/10.1 096/fasebj.24.1_supplement.642.1.

144. Chan NR. Phylogenetic variation in hind-limb bone scaling of flightless theropods. Paleobiology. 2017;43(1):129-43. https://doi.org/10.1017/pab.2016.32.

145. Bertram JEA, Biewener AA. Differential scaling of the long bones in the terrestrial Carnivora and other mammals. J Morphol. 1990;204:157-69.

146. Knell RJ. On the analysis of non-linear allometries. Ecol Entomol. 2009;34(1): 1-11. https://doi.org/10.1111/j.1365-2311.2008.01022.x.

147. Packard GC. Is non-loglinear allometry a statistical artifact? Biol J Linn Soc. 2012;107(4):764-73. https://doi.org/10.1111/j.1095-8312.2012.01995.x.

148. Biewener AA. Biomechanical consequences of scaling. J Exp Biol. 2005; 208(9):1665-76. https://doi.org/10.1242/jeb.01520.

149. Rinderknecht A, Blanco RE. The largest fossil rodent. Proc R Soc B. 2008; 275(1637):923-8. https://doi.org/10.1098/rspb.2007.1645.

150. Bou J, Casinos A, Ocaña J. Allometry of the limb long bones of insectivores and rodents. J Morphol. 1987;192(2):113-23. https://doi.org/10.1002/jmor.1 051920204.

151. Christiansen P. Scaling of mammalian long bones: small and large mammals compared. J Zool. 1999;247(3):333-48. https://doi.org/10.1111/j.1469-7998.1 999.tb00996.x

152. Perry JMG, Cooke SB, Runestad Connour JA, Burgess ML, Ruff CB. Articular scaling and body mass estimation in platyrrhines and catarrhines: Modern variation and application to fossil anthropoids. J Human Evol. 2018;115:2035. https://doi.org/10.1016/j.jhevol.2017.10.008

153. Doube M, Conroy AW, Christiansen P, Hutchinson JR, Shefelbine S. Threedimensional geometric analysis of felid limb bone allometry. PLoS ONE. 2009;4(3):e4742. https://doi.org/10.1371/journal.pone.0004742.

154. Biewener AA. Biomechanics of mammalian terrestrial locomotion. Science. 1990;250(4984):1097-103. https://doi.org/10.1126/science.2251499.

155. Bertrand OC, Schillaci MA, Silcox MT. Cranial dimensions as estimators of body mass and locomotor habits in extant and fossil rodents. J Vertebr Paleontol. 2016;36(1):e1014905. https://doi.org/10.1080/02724634.2015.1014 905.

156. Cardini A. Craniofacial allometry is a rule in evolutionary radiations of placentals. Evolutionary Biology. 2019;46(3):239-48. https://doi.org/10.1007/ s11692-019-09477-7.

157. Cardini A, Polly D, Dawson R, Milne N. Why the long face? Kangaroos and Wallabies follow the same 'rule' of Cranial Evolutionary Allometry (CREA) as placentals. Evol Biol. 2015;42(2):169-76. https://doi.org/10.1007/s11692-0159308-9.

158. Myers TJ. Prediction of marsupial body mass. Aust J Zool. 2001:49(2):99-118.

159. Hopkins SSB. Reassessing the mass of exceptionally large rodents using toothrow length and area as proxies for body mass. J Mammal. 2008;89(1): 232-43. 
160. Aiello LC, Wood BA. Cranial variables as predictors of hominine body mass Am J Phys Anthropol. 1994;95(4):409-26. https://doi.org/10.1002/ajpa.133 0950405.

161. Prothero J. Scaling of bodily proportions in adult terrestrial mammals. Am J Physiology-Regulatory Integr Comp Physiol. 1992;262(3):R492-503. https:// doi.org/10.1152/ajpregu.1992.262.3.R492.

162. Scott KM. Postcranial dimensions of ungulates as predictors of body mass. In: Damuth J, BJ MF, editors. Body Size in Mammalian Paleobiology: Estimation and Biological Implications. Cambridge: Cambridge University Press; 1990. p. 301-35

163. Gapert R, Last J. The adult human occipital bone: measurement variance and observer error. In: Proceedings of the Fifth Annual Conference of the British Association for Biological Anthropology and Osteoarchaeology. Oxford: Archaeopress; 2005. p. 119-22.

164. Osborn HF. Andrewsarchus, giant mesonychid of Mongolia. Am Mus Novitates. 1924;146:1-5.

165. Fortelius $M$, Kappelman J. The largest land mammal ever imagined. Zool J Linn Soc. 1993;108(1):85-101. https://doi.org/10.1111/j.1096-3642.1993.tb02 560.x.

166. Larramendi A. Shoulder height, body mass, and shape of Proboscideans. Acta Palaeontol Pol. 2015;61(3):537-74. https://doi.org/10.4202/app.00136.2 014.

167. Van Valkenburgh B. Locomotor diversity within past and present guilds of large predatory mammals. Paleobiology. 1985;11(4):406-28. https://doi.org/1 $0.1017 /$ S0094837300011702.

168. Andersson K. Predicting carnivoran body mass from a weight-bearing joint. J Zool. 2004;262(2):161-72. https://doi.org/10.1017/S0952836903004564.

169. Klingenberg CP. Size, shape, and form: concepts of allometry in geometric morphometrics. Dev Genes Evol. 2016;226(3):113-37. https://doi.org/10.1 007/s00427-016-0539-2.

170. Macrini TE, Rowe T, Archer M. Obdurodon dicksoni. Dig Morphol. 2006; [http://digimorph.org/specimens/Obdurodon_dicksoni/]. Accessed 28 Jan 2021.

171. Lucas SG, Luo Z. Adelobasileus from the Upper Triassic of West Texas: the oldest mammal. J Vertebr Paleontol. 1993;13(3):309-34. https://doi.org/10.1 080/02724634.1993.10011512

172. Macrini TE. Tombaatar sabuli. Dig Morphol. 2001; [http://digimorph.org/ specimens/Tombaatar_sabuli/]. Accessed 23 Dec 2019.

173. Macrini TE. Kryptobaatar dashzevegi. Dig Morphol. 2001; [http://digimorph. org/specimens/Kryptobaatar_dashzevegi/]. Accessed 23 Dec 2019.

174. Rougier GW. Vincelestes neuquenianus Bonaparte (Mammalia, Theria) un primitivo mamífero del Cretacico inferior de la cuenca Neuquina. Buenos Aires: Universidad Nacional de Buenos Aires; 1993.

175. Krause DW, Wible JR, Hoffmann S, Groenke JR, O'Connor PM, Holloway WL, et al. Craniofacial morphology of Vintana sertichi (Mammalia, Gondwanatheria) from the late Cretaceous of Madagascar. J Vertebr Paleontol. 2014;34(sup1):14-109. https://doi.org/10.1080/02724634.2014. 976129.

176. Gaudin TJ, Wible JR. The phylogeny of living and extinct armadillos (Mammalia, Xenarthra, Cingulata): a craniodental approach. In: Carrano MT Gaudin TJ, Blob RW, Wible JR, editors. Amniote Paleobiology: Perspectives on the Evolution of Mammals, Birds, and Reptiles. Chicago: University of Chicago Press; 2006. p. 153-96.

177. Álvarez A, Ercoli MD. Why pacaranas never say no: analysis of the unique occipitocervical configuration of †Tetrastylus intermedius Rovereto, 1914, and other dinomyids (Caviomorpha; Dinomyidae). J Vertebr Paleontol. 2017; 37(6):e1385476. https://doi.org/10.1080/02724634.2017.1385476.

178. Weisbecker V, Ashwell K, Fisher D. An improved body mass dataset for the study of marsupial brain size evolution. Brain Behav Evol. 2013;82(2):81-2. https://doi.org/10.1159/000348647.

179. Borroto-Páez R. Relative brain size in capromyid rodents. In: Borroto-Páez R, Woods CA, Sergile FE, editors. Terrestrial Mammals of the West Indies: Contributions. Gainesville: University of Florida Press; 2012. p. 165-77.

180. Kaufman JA, Turner GH, Holroyd PA, Rovero F, Grossman A. Brain volume of the newly-discovered species Rhynchocyon udzungwensis (Mammalia: Afrotheria: Macroscelidea): implications for encephalization in sengis. PLoS ONE. 2013;8(3):e58667. https://doi.org/10.1371/journal.pone.0058667.

181. Weisbecker V, Goswami A. Brain size, life history, and metabolism at the marsupial/placental dichotomy. Proc Natl Acad Sci USA. 2010;107(37): 16216-21. https://doi.org/10.1073/pnas.0906486107.
182. Wroe S, Myers T, Seebacher F, Kear B, Gillespie A, Crowther M, et al. An alternative method for predicting body mass: the case of the Pleistocene marsupial lion. Paleobiology. 2003;29(3):403-11. https://doi.org/10.1666/ 0094-8373(2003)029<0403:aamfpb>2.0.co;2.

183. Soul LC, Benson RBJ, Weisbecker V. Multiple regression modeling for estimating endocranial volume in extinct Mammalia. Paleobiology. 2012; 39(1):149-62. https://doi.org/10.1666/0094-8373-39.1.149.

184. Quintana J, Köhler M, Moyà-Solà S. Nuralagus rex gen. et sp. nov., an endemic insular giant rabbit from the Neogene of Minorca (Balearic Islands, Spain). J Vertebr Paleontol. 2011;31(2):231-40. https://doi.org/10.1080/02724 634.2011 .550367$.

185. Schulte-Hostedde Al, Millar JS, Hickling GJ. Sexual dimorphism in body composition of small mammals. Can J Earth Sci. 2001;79:1016-20. https:// doi.org/10.1139/cjz-79-6-1016.

186. Higgins PB, Rodriguez PJ, Voruganti VS, Mattern V, Bastarrachea RA, Rice K, et al. Body composition and cardiometabolic disease risk factors in captive baboons (Papio hamadryas sp.): sexual dimorphism. Am J Phys Anthropol. 2014;153(1):9-14. https://doi.org/10.1002/ajpa.22357.

187. Wells JCK. Sexual dimorphism of body composition. Best Pract Res Clin Endocrinol Metab. 2007;21(3):415-30. https://doi.org/10.1016/j.beem.2007.04. 007.

188. Reimers E. Growth in Domestic and Wild Reindeer in Norway. J Wildl Manag. 1972;36(2):612-9. https://doi.org/10.2307/3799094.

189. Steyn D, Hanks J. Age determination and growth in the hyrax Procavia capensis (Mammalia: Procaviidae). J Zool. 1983;201(2):247-57. https://doi. org/10.1111/j.1469-7998.1983.tb04274.x.

190. Roseberry JL, Klimstra WD. Some morphological characteristics of the Crab Orchard Deer Herd. J Wildl Manag. 1975;39(1):48-58. https://doi.org/10.23 07/3800465.

191. Prestrud P, Nilssen K. Growth, size, and sexual dimorphism in arctic foxes. J Mammal. 1995;76(2):522-30. https://doi.org/10.2307/1382360.

192. Grand TI. The functional anatomy of body size. In: Damuth J, BJ MF, editors. Body Size in Mammalian Paleobiology: Estimation and Biological Implications. Cambridge: Cambridge University Press; 1990. p. 39-48.

193. Roth VL. Insular dwarf elephants: a case study in body mass estimation and ecological inference. In: Damuth J, BJ MF, editors. Body Size in Mammalian Paleobiology: Estimation and Biological Implications. Cambridge: Cambridge University Press; 1990. p. 151-79.

194. Anderson JS. Occipital condyle in the ceratopsian dinosaur Triceratops, with comments on body size variation. Contrib Mus Paleontol Univ Mich. 1999: 30(8):215-31.

195. Brassey CA, Maidment SCR, Barrett PM. Body mass estimates of an exceptionally complete Stegosaurus (Ornithischia: Thyreophora): comparing volumetric and linear bivariate mass estimation methods. Biol Lett. 2015; 11(3):20140984. https://doi.org/10.1098/rsbl.2014.0984.

196. Bloch Jl, Rose KD, Gingerich PD. New species of Batodonoides (Lipotyphla, Geolabididae) from the early Eocene of Wyoming: smallest known mammal? J Mammal. 1998;79(3):804-27.

197. Osborn HF. Origin of the Mammalia, III. Occipital condyles of the reptilian tri-partite type. Am Nat. 1900;34:943-7.

198. Botha J, Abdala F, Smith R. The oldest cynodont: new clues on the origin and early diversification of the Cynodontia. Zool J Linn Soc. 2007;149(3): 477-92. https://doi.org/10.1111/j.1096-3642.2007.00268.x.

199. Rowe T. Definition, diagnosis, and origin of Mammalia. J Vertebr Paleontol. 1988:8(3):241-64. https://doi.org/10.1080/02724634.1988.10011708.

200. Kermack KA, Mussett F, Rigney HW. The skull of Morganucodon. Zool J Linn Soc. 1981;71(1):1-158. https://doi.org/10.1111/j.1096-3642.1981.tb01127.x.

201. Kemp TS. The atlas-axis complex of the mammal-like reptiles. J Zool. 1969; 159(2):223-48. https://doi.org/10.1111/j.1469-7998.1969.tb03079.x.

202. Romer AS, Price LI. Review of the Pelycosauria. Geol Soc Am Spec Publ. 1940;28:1-538.

203. Rubidge BS, Sidor CA. On the cranial morphology of the basal therapsids Burnetia and Proburnetia (Therapsida: Burnetiidae). J Vertebr Paleontol. 2002;22(2):257-67. https://doi.org/10.1671/0272-4634(2002)022[0257: OTCMOT]2.0.CO;2

204. Sidor CA, Rubidge BS. Herpetoskylax hopsoni, a new biarmosuchian (Therapsida: Biarmosuchia) from the Beaufort Group of Africa. In: Carrano MT, Gaudin TJ, Blob RW, Wible JR, editors. Amniote Paleobiology: Perspectives on the Evolution of Mammals, Birds, and Reptiles. Chicago: University of Chicago Press; 2006. p. 76-113. 
205. Güven S, Rubidge BS, Abdala F. Cranial morphology and taxonomy of South African Tapinocephalidae (Therapsida: Dinocephalia): the case of Avenantia and Riebeeckosaurus. Palaeontol Afr. 2013;48:24-33.

206. Huttenlocker AK, Sidor CA, Smith RMH. A new specimen of Promoschorhynchus (Therapsida: Therocephalia: Akidnognathidae) from the Lower Triassic of South Africa and its implications for theriodont survivorship across the Permo-Triassic boundary. J Vertebr Paleontol. 2011; 31(2):405-21. https://doi.org/10.1080/02724634.2011.546720.

207. Müller J, Scheyer TM, Head JJ, Barrett PM, Werneburg I, Ericson PGP, et al. Homeotic effects, somitogenesis and the evolution of vertebral numbers in recent and fossil amniotes. Proc Natl Acad Sci USA. 2010;107(5):2118. https://doi.org/10.1073/pnas.0912622107.

208. Burgin CJ, Colella JP, Kahn PL, Upham NS. How many species of mammals are there? J Mammal. 2018;99(1):1-14. https://doi.org/10.1093/jmammal/ gyx 147 .

209. Ledesma K, Werner F, Spotorno A, Albuja Viteri LH. A new species of mountain viscacha (Chinchillidae: Lagidium Meyen) from the Ecuadorean Andes. Zootaxa. 2009;2126:41-57.

210. Brito J, Tenecota GM. P-ZG: New record of Stolzmann's crab-eating rat Ichthyomys stolzmanni (Rodentia: Cricetidae) in Ecuador. Therya. 2016;7(3): 491-8.

211. Ramírez-Fernández JD, Durán AFJ, Fernández-Vargas M. First record of Tweedy's Crab-eating Rat, Ichthyomys tweedii Anthony, 1921 (Rodentia, Cricetidae, Sigmodontinae), for Costa Rica. Check List. 2020;16(2):435-40.

212. Dalquest WW, Orcutt DR. The Biology of the Least Shrew-Mole, Neurotrichus gibbsii Minor. Am Midl Nat. 1942;27(2):387-401. https://doi.org/10.2307/2421 007.

213. Martin RA. Estimating body mass and correlated variables in extinct mammals: travels in the fourth dimension. In: Damuth J, BJ MF, editors. Body Size in Mammalian Paleobiology: Estimation and Biological Implications. Cambridge: Cambridge University Press; 1990. p. 49-68.

214. Esteban-Trivigno S. de, Köhler M: New equations for body mass estimation in bovids: testing some procedures when constructing regression functions. Z Saugetierkd. 2011;76(6):755-61. https://doi.org/10.1016/j.mambio.2011.07. 004.

215. Labocha MK, Schutz $H$, Hayes JP. Which body condition index is best? Oikos. 2014;123(1):111-9. https://doi.org/10.1111/j.1600-0706.2013.00755.x.

216. Huot J, Poulle M-L, Crête M. Evaluation of several indices for assessment of coyote (Canis latrans) body composition. Can J Zool. 1995;73(9):1620-4. https://doi.org/10.1139/z95-192.

217. Core Team R. R: a language and environment for statistical computing. In: vol. 4.0.3. Vienna: R Foundation for Statistical Computing; 2020.

218. Baty F, Ritz C, Charles S, Brutsche M, Flandrois J-P, Delignette-Muller M-L. A toolbox for nonlinear regression in R: the package nlstools. J Stat Softw. 2015;1(Issue 5). https://doi.org/10.18637/jss.v066.i05.

219. Akaike $H$. A new look at the statistical model identification. IEEE T Automat Contr. 1974;19(6):716-23. https://doi.org/10.1109/tac.1974.1100705.

220. Schwarz G. Estimating the dimension of a model. Ann Statist. 1978;6(2):4614. https://doi.org/10.1214/aos/1176344136

221. Janis CM, Martín-Serra A. Postcranial elements of small mammals as indicators of locomotion and habitat. PeerJ. 2020:e9634. https://doi.org/10. 7717/peerj.9634

222. Smith RJ. Bias in equations used to estimate fossil primate body mass. J Human Evol. 1993;25:31-41.

223. Smith RJ. Logarithmic transformation bias in allometry. Am J Phys Anthropol. 1993;90:215-28.

224. Duan N. Smearing estimate: a nonparametric retransformation method. J Am Stat Assoc. 1983;78(383):605-10. https://doi.org/10.1080/01621459.1 983.10478017

225. Snowdon P. A ratio estimator for bias correction in logarithmic regressions. Can J For Res. 1991;21(5):720-4. https://doi.org/10.1139/×91-101.

226. Smith RJ. Allometric scaling in comparative biology: problems of concept and method. Am J Physiol. 1984;246:R152-60. https://doi.org/10.1152/a jpregu.1984.246.2.R152.

227. Armstrong JS. Long-range forecasting: from crystal ball to computer. 2nd ed. New York: Wiley; 1985.

228. Paradis E, Schliep K. ape 5.0: an environment for modern phylogenetics and evolutionary analyses in R. Bioinformatics. 2018;35:526-8.

229. Revell $L$. phytools: an R package for phylogenetic comparative biology (and other things). Methods Ecol Evol. 2012;3(2):217-23. https://doi.org/1 0.1111/j.2041-210X.2011.00169.x.
230. Paterno GB, Penone C, GDA W. sensiPhy: an r-package for sensitivity analysis in phylogenetic comparative methods. Methods Ecol Evol. 2018;9(6):1461-7. https://doi.org/10.1111/2041-210X.12990.

231. Pinheiro J, Bates D, DebRoy S, Sarkar D, Team RC. nlme: linear and nonlinear mixed effects models. In: vol. R package version 3; 2019. p. 1-143.

232. Harmon LJ, Weir JT, Brock CD, Glor RE, Challenger W. GEIGER: investigating evolutionary radiations. Bioinformatics. 2007;24(1):129-31. https://doi.org/1 0.1093/bioinformatics/btm538.

233. Upham NS, Esselstyn JA, Jetz W. Inferring the mammal tree: species-level sets of phylogenies for questions in ecology, evolution, and conservation. PLOS Biol. 2019;17(12):e3000494. https://doi.org/10.1371/journal.pbio.30004 94.

234. Pagel M. Inferring the historical patterns of biological evolution. Nature. 1999;401(6756):877-84. https://doi.org/10.1038/44766.

235. Goodchild S, Schwitzer C. The problem of obesity in captive lemurs. Int Zoo News. 2008;55(6):353-7.

236. Morfeld KA, Meehan CL, Hogan JN, Brown JL. Assessment of body condition in African (Loxodonta africana) and Asian (Elephas maximus) elephants in North American zoos and management practices associated with high body condition scores. PLoS ONE. 2016;11(7):e0155146. https://doi.org/10.13 71/journal.pone.0155146.

237. Hadfield JD. MCMC methods for multi-response generalized linear mixed models: the MCMCglmm R Package. J Stat Softw. 2010;33(2):1-22.

238. Lange-Badré B. Les Créodontes (Mammalia) d’Europe occidentale de I' Éocéne supérieur à l'Oligocéne supérieur. Mémoires du muséum national d’histoire naturelle, Série C, Sciences de la terre. 1979;42:1-249.

239. Abramov AV, Baryshnikov GF. Geographic variation and intraspecific taxonomy of weasel Mustela nivalis (Carnivora, Mustelidae). Zoosystematica Rossica. 2000;8(2):365-402.

240. Abramov AV, Puzachenko AY. Sexual dimorphism of craniological characters in Eurasian badgers, Meles spp. (Carnivora, Mustelidae). Zoologischer Anzeiger - A J Comp Zool. 2005;244(1):11-29. https://doi.org/10.1016/j.jcz.2 004.12.002.

241. Akbarirad S, Darvish J, Aliabadian M. Increased species diversity of brushtailed mice, genus Calomyscus (Calomyscidae, Rodentia), in the Zagros Mountains, western Iran. Mammalia. 2016;80(5):549-61. https://doi.org/10.1 515/mammalia-2014-0162.

242. Allen GM. The mammals of China and Mongolia. In: Granger W, editor. Natural History of Central Asia, vol. 11. New York: American Museum of Natural History; 1940. p. 621-1350.

243. Allen JA. Mammals from the states of Sinaloa and Jalisco, Mexico, collected by J. H. Batty during 1904 and 1905. Bull Am Mus Nat Hist. 1906;22:191-262.

244. Allen JA. Ontogenetic and Other Variations in Muskoxen, With a Systematic Review of the Muskox Group, Recent and Extinct. Mem Am Mus Nat Hist. 1913;1(4):1-126.

245. Allen JA. Mammals collected on the Roosevelt Brazilian Expedition, with field notes by Leo E. Miller. Bull Am Mus Nat Hist. 1916;35:559-610.

246. Allen JA. Carnivora collected by the American Museum Congo Expedition. Bull Am Mus Nat Hist. 1924:47:73-281.

247. Allen JA. Primates collected by the American Museum Congo Expedition. Bull Am Mus Nat Hist. 1925;47(4):283-524.

248. Allen JA, Lang H, Chapin JP. The American Museum Congo Expedition collection of Insectivora. Bull Am Mus Nat Hist. 1922:47:1-38.

249. Anderson S. Mammals of Bolivia: taxonomy and distribution. Bull Am Mus Nat Hist 1997:231:1-652.

250. Angelici FM, Capizzi D, Amori G, Luiselli L. Morphometric variation in the skulls of the crested porcupine Hystrix cristata from mainland Italy, Sicily, and northern Africa. Mamm Biol. 2003;68(3):165-73. https://doi.org/10.1 078/1616-5047-00078

251. Antunes VZ, Delciellos AC, Vieira MV. Postural climbing behaviour of didelphid marsupials: parallels with primates. Oecologia Australis. 2016; 20(03):375-90. https://doi.org/10.4257/oeco.2016.2003.07.

252. Aplin KP, Helgen KM, Lunde DP. A review of Peroryctes broadbenti, the giant bandicoot of Papua New Guinea. Am Mus Novitates. 2010;3696:1-41.

253. Asahara M, Koizumi M, Macrini TE, Hand SJ, Archer M. Comparative cranial morphology in living and extinct platypuses: feeding behavior, electroreception, and loss of teeth. Sci Adv. 2016;2(10):e1601329. https://doi. org/10.1126/sciadv.1601329.

254. Asher RJ, McKenna MC, Emry RJ, Tabrum AR, Kron DG. Morphology and relationships of Apternodus and other extinct, zalambdadont, placental mammals. Bull Am Mus Nat Hist. 2002;273:1-117. 
255. Bärmann EV, Schikora T. The polyphyly of Neotragus - results from genetic and morphometric analyses. Mamm Biol. 2014;79(4):283-6. https://doi.org/1 0.1016/j.mambio.2014.01.001

256. Barry RE, Shoshani J. Heterohyrax brucei. Mamm Species. 2000;645:1-7. https://doi.org/10.1644/1545-1410(2000)645<0001:HB>2.0.CO;2.

257. Beisiegel BM, Zuercher GL. Speothos venaticus. Mamm Species. 2005;783:16. https://doi.org/10.1644/783.1.

258. Beneski JT Jr, Stinson DW. Sorex palustris. Mamm Species. 1987;296:1-6. https://doi.org/10.2307/3503968.

259. Bennett D, Hoffmann RS. Equus caballus. Mamm Species. 1999;628:1-14. https://doi.org/10.2307/3504442.

260. Berta A. Cerdocyon thous. Mamm Species. 1982;186:1-4.

261. Best TL. Lepus californicus. Mamm Species. 1996;530:1-10.

262. Biswas B, Ghose RK. Taxonomic notes on the Indian pale hedgehogs of the genus Paraechinus Trouessart, with descriptions of a new species and subspecies. Mammalia. 1970;34(3):467-77.

263. Blanchard BM. Size and growth patterns of the Yellowstone grizzly bear Bears. Biol Manag. 1987;7:99-107. https://doi.org/10.2307/3872615.

264. Bodmer RE. Strategies of seed dispersal and seed predation in Amazonian ungulates. Biotropica. 1991;23(3):255-61.

265. Braun JK, Eaton TS Jr, Mares MA. Marmota caligata (Rodentia: Sciuridae). Mamm Species. 2011;884:155-71. https://doi.org/10.1644/884.1.

266. Braun JK, Mares MA. Neotoma micropus. Mamm Species. 1989;330:1-9.

267. Braun JK, Pratt NL, Mares MA. Thylamys pallidior (Didelphimorphia: Didelphidae). Mamm Species. 2010;42(1):90-8. https://doi.org/10.1644/856.1.

268. Burton RW. Weights and measurements of game animals. J Bombay Nat Hist Soc. 1915;186:24-36.

269. Caldara V Jr, Leite YLR. Geographic variation in hairy dwarf porcupines of Coendou from eastern Brazil (Mammalia: Erethizontidae). Zoologia (Curitiba). 2012;29:318-36.

270. Carleton MD, Arroyo-Cabrales J. Review of the Oryzomys couesi Complex (Rodentia: Cricetidae: Sigmodontinae) in Western Mexico. Bull Am Mus Nat Hist. 2009;2009(331):94-127. https://doi.org/10.1206/582-3.1

271. Carmignotto AP, Monfort T. Taxonomy and distribution of the Brazilian species of Thylamys (Didelphimorphia: Didelphidae). Mammalia. 2006;70(12):126-44. https://doi.org/10.1515/MAMM.2006.013.

272. Carraway LN. Sorex pacificus. Mamm Species. 1985;231:1-5. https://doi.org/1 $0.2307 / 3504065$

273. Ceballos G. Mammals of Mexico. Baltimore: John Hopkins University Press; 2014.

274. Cerqueira R, Lemos B. Morphometric differentiation between Neotropical black-eared opossums, Didelphis marsupialis and D. aurita (Didelphimorphia, Didelphidae). Mammalia. 2000;64(3). https://doi.org/10.1515/mamm.2000. 64.3.319.

275. Chakraborty S. Contributions to the knowledge of the mammalian fauna of Jammu and Kashmir, India. Rec Zool Soc India. 1983;38:1-129.

276. Chapman JA, Hockman JG, Ojeda CMM. Sylvilagus floridanus. Mamm Species. 1980;136:1-8. https://doi.org/10.2307/3504055.

277. Chapman JA, Willner GR. Sylvilagus palustris. Mamm Species. 1981;153:1-3. https://doi.org/10.2307/3503947.

278. Choudhary OP, Singh I. Morphmetrical studies on the skull of Indian Blackbuck (Antilope cervicapra). Int J Morphol. 2015;33(3):868-76.

279. Christiansen P. Species distinction and evolutionary differences in the Clouded Leopard (Neofelis nebulosa) and Diard's Clouded Leopard (Neofelis diardi). J Mammal. 2008;89(6):1435-46. https://doi.org/10.1644/08-mamm-a-013.1.

280. Clark HO Jr. Otocyon megalotis. Mamm Species. 2005;766:1-5.

281. Clark TW, Hoffmann RS, Nadler CF. Cynomys leucurus. Mamm Species. 1971; $7: 1-4$.

282. Coals PGR, Rathbun GB. The taxonomic status of Giant Sengis (Genus Rhynchocyon) in Mozambique. J East African Nat Hist. 2013;101(2):241-50. https://doi.org/10.2982/028.101.0203.

283. Colyn M, van Rompaey H. A biogeographic study of cusimanses (Crossarchus) (Carnivora, Herpestidae) in the Zaire Basin. J Biogeogr. 1994; 21(5):479-89.

284. Costa LP, Leite YLR, Patton JL. Phylogeography and systematic notes on two species of gracile mouse opossums, genus Gracilinanus (Marsupialia: Didelphidae) from Brazil. Proc Biol Soc Wash. 2003;116:275-92.

285. Côté SD, Festa-Bianchet M. Mountain Goat (Oreamnos americanus). In: Feldhamer GA, Thompson BC, Chapman JA, editors. Wild Mammals of North America: Biology, Management, and Conservation. 2nd ed. Baltimore: John Hopkins University Press; 2003. p. 1061-75.
286. Crawford-Cabral J. Anâlise de dados craniométricos no género Genetta G. Cuvier (Carnivora, Viverridae). Memórias da Junta de Investigações Científicas do Ultramar. 1981;66:1-329.

287. Cremona T, Baker AM, Cooper SJB, Montague-Drake R, Stobo-Wilson AM, Carthew SM. Integrative taxonomic investigation of Petaurus breviceps (Marsupialia: Petauridae) reveals three distinct species. Zool J Linn Soc. 2020. https://doi.org/10.1093/zoolinnean/zlaa060.

288. Cuthbert RJ, Denny MJH. Aspects of the ecology of the kalubu bandicoot (Echymipera kalubu) and observations on Raffray's bandicoot (Peroryctes raffrayanus), Eastern Highlands Province, Papua New Guinea. Aust Mamm. 2014;36(1):21-8.

289. Cypher BL. Foxes (Vulpes species, Urocyon species, and Alopex lagopus). In: Feldhamer GA, Thompson BC, Chapman JA, editors. Wild Mammals of North America: Biology, Management, and Conservation. 2nd ed. Baltimore: John Hopkins University Press; 2003. p. 511-46.

290. Danilo L, Remy J, Vianey-Liaud M, Mérigeaud S, Lihoreau F. Intraspecific variation of endocranial structures in extant Equus: a prelude to endocranial studies in fossil equoids. J Mammal Evol. 2015;22(4):561-82. https://doi.org/1 0.1007/s10914-015-9293-X.

291. Davis WB. Notes on the Mexican shrew Megasorex gigas (Merriam). Southwest Nat. 1957;2(4):174-5.

292. Diersing VE. Systematics and evolution of the Pygmy Shrews (subgenus Microsorex) of North America. J Mammal. 1980;61(1):76-101.

293. Dietz JM. Chrysocyon brachyurus. Mamm Species. 1985;234:1-4.

294. Dolan PG, Carter DC. Glaucomys volans. Mamm Species. 1977;78:1-6. https://doi.org/10.2307/3504026.

295. Dragoo JW, Sheffield SR. Conepatus leuconotus (Carnivora: Mephitidae). Mamm Species. 2009;827:1-8. https://doi.org/10.1644/827.1.

296. Eisenberg JF, Redford KH. Mammals of the neotropics: the central neotropics, vol. 3. Chicago: University of Chicago Press; 1999.

297. Eisenberg JF, Wilson DE. Relative brain size and demographic strategies in didelphid marsupials. Am Nat. 1981;118(1):1-15.

298. Elbroch M. Animal skulls. A Guide to North American Species Mechanicsburg: Stackpole Books; 2006.

299. Elliott CL, Flinders JT. Spermophilus columbianus. Mamm Species. 1991;372: 1-9. https://doi.org/10.2307/3504178.

300. Ellis LS, Diersing VE, Hoffmeister DF. Taxonomic status of short-tailed shrews (Blarina) in Illinois. J Mammal. 1978;59(2):305-11. https://doi.org/10.2307/13 79914.

301. Endo H, Hikida T, Chou LM, Fukuta K, Stafford BJ. Proportion and cluster analyses of the skull in various species of the tree shrews. J Vet Med Sci. 2004;66(1):1-7.

302. Endo H, Hikida T, Motokawa M, Chou LM, Fukuta K, Stafford BJ. Morphological adaptation of the skull for various behaviors in the tree shrews. J Vet Med Sci. 2003;65(8):873-9.

303. Ernest KA. Nectomys squamipes. Mamm Species. 1986;265:1-5. https://doi org/10.2307/3503779.

304. Evans FG. The osteology and relationships of the elephant shrews (Macroscelididae). Bull Am Mus Nat Hist. 1946;80:85-125.

305. Fedosenko AK, Blank DA. Ovis ammon. Mamm Species. 2005;773:1-15.

306. Feijó A, Patterson BD, Cordeiro-Estrela P. Taxonomic revision of the longnosed armadillos, Genus Dasypus Linnaeus, 1758 (Mammalia, Cingulata). PLoS One. 2018;13(4):e0195084. https://doi.org/10.1371/journal.pone.01 95084.

307. Feldhamer GA. Cervus nippon. Mamm Species. 1980;128:1-7.

308. Figueroa OA. The ecology and conservation of jaguars (Panthera onca) in central Belize: Conservation status, diet, movement patterns, and habitat use. Gainesville: University of Florida; 2013.

309. Fitzgerald CS, Krausman PR. Helarctos malayanus. Mamm Species. 2002;696:1-5.

310. Flores DA, Barquez RM, Díaz MM. A new species of Philander Brisson, 1762 (Didelphimorphia, Didelphidae). Mamm Biol. 2008;73(1):14-24. https://doi. org/10.1016/j.mambio.2007.04.002.

311. Flores DA, Díaz MM, Barquez RM. Mouse opossums (Didelphimorphia, Didelphidae) of northwestern Argentina: systematics and distribution. Z Saugetierkd. 2000;65:321-39.

312. Frase BA, Hoffmann RS. Marmota flaviventris. Mamm Species. 1980;135:1-8.

313. Freitas JNS. Neuroecologia na orden Rodentia: aspectos da cognição espacial em ratos-de-espinho e a evolução da encefalização. São Paulo: Universidad de São Paulo; 2013.

314. French TW. Sorex longirostris. Mamm Species. 1980;143:1-3. https://doi. org/10.2307/3503870. 
315. Fritzell EK, Haroldson KJ. Urocyon cineroargenteus. Mamm Species. 1982 189:1-8.

316. García-Rangel S. Andean bear Tremarctos ornatus natural history and conservation. Mamm Rev. 2012;42(2):85-119.

317. Gardner AL, Sunquist ME: Opossum (Didelphis virginiana). In: Wild Mammals of North America: Biology, Management, and Conservation. Edited by Feldhamer GA, Thompson BC, Chapman JA, 2nd. Baltimore: John Hopkins University Press; 2003: 3-29.

318. Gaudin TJ, Hicks P, Di Blanco Y. Myrmecophaga tridactyla (Pilosa: Myrmecophagidae). Mamm Species. 2018;50(956):1-13. https://doi.org/10.1 093/mspecies/sey001.

319. Gaudin TJ, Wible JR. On the cranial osteology of the yellow armadillo Euphractus sexcinctus (Dasypodidae, Xenarthra, Placentalia). Ann Carnegie Mus. 2004;73(3):117-96.

320. Geraads D. New skulls of Kolpochoerus phacochoeroides (Suidae: Mammalia) from the late Pliocene of Ahl al Oughlam, Morocco. Palaeontol Afr. 2004;40: 69-83.

321. Gittleman JL, Valkenburgh BV. Sexual dimorphism in the canines and skulls of carnivores: effects of size, phylogency, and behavioural ecology. J Zool. 1997;242(1):97-117. https://doi.org/10.1111/j.1469-7998.1 997.tb02932.x

322. Goldman CA. Systematic revision of the African mongoose genus Crossarchus (Mammalia: Viverridae). Can J Zool. 1984;62:1618-30.

323. Gompper ME. Nasua narica. Mamm Species. 1995:487:1-10.

324. Gompper ME, Decker DM. Nasua nasua. Mamm Species. 1998;580:1-9.

325. González BA, Palma RE, Zapata B, Marín JC. Taxonomic and biogeographical status of guanaco Lama guanicoe (Artiodactyla, Camelidae). Mamm Rev. 2006;36(2):157-78. https://doi.org/10.1111/j.1365-2907.2006.00084.x.

326. Goodman SM, Rasoloarison RM, Ganzhorn JU. On the specific identification of subfossil Cryptoprocta (Mammalia, Carnivora) from Madagascar. Zoosystematica. 2004;26(1):129-43.

327. Goodwin GG. Mammals collected in the maritime province of Siberia by the Morden-Graves North Asiatic Expedition, with the description of a new hare from the Amur River. Am Mus Novitates. 1933;681:1-18.

328. Gordon CL. Functional morphology and diet of late Cretaceous mammals of North America. Norman: University of Oklahoma; 2003.

329. Greenberg CH. Response of white-footed mice (Peromyscus leucopus) to coarse woody debris and microsite use in southern Appalachian treefall gaps. Forest Ecol Manag. 2002;164(1):57-66. https://doi.org/10.1016/s03 78-1127(01)00588-6.

330. Groves C. The taxonomy and phylogeny of Ailurus. In: Glatston AR, editor. Red Panda: Biology and Conservation of the First Panda. Burlington: Academic Press; 2011. p. 101-24.

331. Groves C, Grubb P. Ungulate taxonomy. Baltimore: John Hopkins University Press; 2011.

332. Groves CP. On the smaller gazelles of the genus Gazella de Blainville, 1816 Z Saugetierkd. 1969;34(1):38-60.

333. Groves CP. The systematics of tree kangaroos (Dendrolagus; Marsupialia, Macropodidae). Aust Mamm. 1982;5:157-86.

334. Groves $C P$, Bell $\mathrm{CH}$. New investigations on the taxonomy of the zebras genus Equus, subgenus Hippotigris. Mamm Biol. 2004;69(3):182-96. https:// doi.org/10.1078/1616-5047-00133.

335. Groves CP, Grubb P. Do Loxodonta cyclotis and Loxodonta africana interbreed? Elephant. 2000;2(4):4-7. https://doi.org/10.22237/elephant/1521 732173.

336. Grubb P. Types, type locality and subspecies of the gerenuk Litocranius walleri (Artiodactyla: Bovidae). J Zool. 2002;257(4):539-43. https://doi.org/1 $0.1017 /$ S0952836902001127.

337. Grubb P, d'Huart JP. Phacochoerus aethiopicus - Desert Warthog. In: Kingdon J, Hoffmann M, editors. Mammals of Africa, vol. 6. New York: Bloomsbury Publishing; 2013. p. 73-5.

338. Grubb P, Groves CP. Revision and classification of the Cephalophinae. In: Wilson VJ, editor. Duikers of Africa: Masters of the African Forest Floor. Bulawayo: Chipangali Wildlife Trust; 2001. p. 703-28.

339. Guiraud M. Contribution a l'etude du Phacochoerus aethiopicus (Pallas). 1948; 12(2):54-66

340. Haas SK, Hayssen V, Krausman PR. Panthera leo. Mamm Species. 2005;762:111. https://doi.org/10.1644/1545-1410(2005)762[0001:PL]2.0.CO;2.

341. Hafner DJ, Smith AT. Revision of the subspecies of the American pika, Ochotona princeps (Lagomorpha: Ochotonidae). J Mammal. 2010;91(2):40117. https://doi.org/10.1644/09-mamm-a-277.1.
342. Harris JM. Cercartetus nanus (Diprotodontia: Burramyidae). Mamm Species. 2008;815:1-10. https://doi.org/10.1644/815.1.

343. Harris JM. Acrobates pygmaeus (Diprotodontia: Acrobatidae). Mamm Species. 2015;920:32-44. https://doi.org/10.1093/mspecies/sev003.

344. Harrison DL, Bates PJJ. Oryx leucoryx. In: The Mammals of Arabia. 2nd ed. London: Benn; 1991. p. 188-91.

345. Hartwig W, Rosenberger AL, Norconk MA, Owl MY. Relative brain size, gut size, and evolution in New World monkeys. Anat Rec. 2011;294(12):2207-21. https://doi.org/10.1002/ar.21515.

346. Hatt RT. The pangolins and aard-varks collected by the American Museum Congo Expedition. Bull Am Mus Nat Hist. 1934;66:643-91.

347. Hayssen V. Dipodomys microps. Mamm Species. 1991;389:1-9. https://doi. org/10.2307/3504107.

348. Hayssen V. Bradypus variegatus (Pilosa: Bradypodidae). Mamm Species. 2010; 42(850):19-32

349. Hayssen V. Choloepus hoffmanni (Pilosa: Megalonychidae). Mamm Species. 2011;873:37-55

350. Hayssen V. Tamandua tetradactyla (Pilosa: Myrmecophagidae). Mamm Species. 2011;875:64-74. https://doi.org/10.1644/875.1.

351. Heaney LR, Morgan GS. A new species of gymnure, Podogymnura (Mammalia: Erinaceidae) from Dinagat Island, Philippines. Proc Biol Soc Wash. 1982;95:13-26.

352. Hearn AJ, Ross J, Pamin D, Bernard H, Hunter L, MacDonald DW. Insights into the spatial and temporal ecology of the Sunda clouded leopard Neofelis diardi. Raffles Bull Zool. 2013;61(2):871-5.

353. Helgen KM, Flannery TF. Notes on the Phalangerid marsupial genus Spilocuscus, with description of a New Species from Papua. J Mammal. 2004 85(5):825-33. https://doi.org/10.1644/BER-110.

354. Hemmer H. Uncia uncia. Mamm Species. 1972;20:1-5. https://doi.org/10.23 07/3503882

355. Heptner VG, Nasimovich AA, Bannikov AG. Mammals of the Soviet Union. Volume II, Part 2. Carnivora (Hyaenas and Cats). Moscow: Vysshaya Shkola Publishers; 1992.

356. Hershkovitz P. Neotropical Deer (Cervidae): Part 1. Pudus, genus Pudu Gray Fieldiana. Zoology. 1982;11:1-86.

357. Hill JE. Results of the Vernay-Lang Kalahari Expedition. Larger mammals of Bechuanaland Protectorate. Bull Am Mus Nat Hist. 1942;74:367-90.

358. Hollister N. East African mammals in the United States National Museum. Part I: Insectivora, Chiroptera, and Carnivora. Bull US Natl Mus. 1918;99:1194.

359. Hollister N. East African mammals in the United States National Museum. Part III: Primates, Artiodactyla, Perissodactyla, Proboscidea, and Hyracoidea. Bull U S Natl Mus. 1924;99:1-164.

360. Hoogland JL. Cynomys ludovicianus. Mamm Species. 1996;535:1-10.

361. Howell AH. Revision of the American harvest mice (genus Reithrodontomys). North Am Fauna. 1914;36:1-97.

362. Howell AH. Revision of the American marmots. US Dept Agric Bur Biol Surv North Am Fauna. 1915;37:1-80.

363. Hunt RM Jr. Basicranial anatomy of the living linsangs Prionodon and Poiana (Mammalia, Carnivora, Viverridae), with comments on the early evolution of aeluroid carnivorans. Am Mus Novitates. 2001;3330:1-24.

364. Hunter WH. Notes on shooting in the Central Provinces. J Bombay Nat Hist Soc. 1897;10:691-3.

365. Husson AM. The Mammals of Suriname. Zoölogische Monographieën van het Rijksmuseum van Natuurlijke Historie. 1978;2:1-569.

366. Hutterer R, Riegert J, Sedláček O. A tiny new species of Sylvisorex (Mammalia: Soricidae) from the Bamenda Highlands, Cameroon. Bonner Zoologische Beiträge. 2009;56:151-7.

367. Iqbal A, Sarwar G, Khan AM, Waseem MT, lqbal A, Ahmad RM, et al. Craniometrical Analysis of wild boar (Sus scrofa) from Northern Punjab, Pakistan. Punjab Univ J Zool. 2020;35(1). https://doi.org/10.17582/journal. pujz/2020.35.1.157.165

368. Ishikawa A, Tsubota Y, Namikawa T. Morphological and reproductive characteristics of musk shrews (Suncus murinus) collected in Bangladesh, and development of the laboratory line (BAN Line) derived from them. Exp Animals. 1987;36(3):252-60.

369. Janečka JE, Helgen KM, Lim NTL, Baba M, Izawa M. Boeadi, Murphy WJ: Evidence for multiple species of Sunda colugo. Curr Biol. 2008;18(21):R10012. https://doi.org/10.1016/j.cub.2008.09.005.

370. Jenkins PD, Robinson MF. Another variation on the gymnure theme: description of a new species of Hylomys (Lipotyphla, Erinaceidae, 
Galericinae). Bull Nat Hist Mus Zool Ser. 2002;68(1):1-11. https://doi.org/10.1 017/S0968047002000018.

371. Jenkins SH, Eshelman BD. Spermophilus beldingi. Mamm Species. 1984;221: $1-8$.

372. Jennings MR, Rathbun GB. Petrodromus tetradactylus. Mamm Species. 2001; 682:1-6.

373. Joeckel RM. Unique frontal sinuses in fossil and living Hyaenidae (Mammalia, Carnivora): description and interpretation. J Vertebr Paleontol. 1998;18(3):627-39. https://doi.org/10.1080/02724634.1998.10011089.

374. Johnson J. Biology of the Porcupine (Erethizon dorsatum) in northwestern South Dakota. Brookings: South Dakota State University; 1977.

375. Jones C. Dendrohyrax dorsalis. Mamm Species. 1978;113:1-4. https://doi. org/10.2307/3504007.

376. Jones CA, Baxter CN. Thomomys bottae. Mamm Species. 2004;742:1-14. https://doi.org/10.1644/742.

377. Jones FW. The mammals of South Australia. Part II. The bandicoots and the herbivorous marsupials. Government Printer: Adelaide; 1924.

378. Jones FW. Black-tailed wallaby. In: The mammals of South Australia. Adelaide: R.E.E. Rogers; 1924. p. 247-9.

379. Jones ME, Rose RK. Dasyurus viverrinus. Mamm Species. 2001;677:1-9.

380. Jones ME, Rose RK, Burnett S. Dasyurus maculatus. Mamm Species. 2001;676: $1-9$.

381. Joubert E. The taxonomic status of the Black Rhinoceros (Diceros biscornis Linn. 1758) in South West Africa. Madoqua. 1970;2:27-37.

382. Kelt DA. Dipodomys heermanni. Mamm Species. 1988;323:1-7. https://doi. org/10.2307/3504171.

383. Kingdon J. The Kingdon Field Guide to African Mammals. Second ed. Princeton University Press: Princeton; 2015.

384. Kinlaw A. Spilogale putorius. Mamm Species. 1995:511:1-7.

385. Kobryńczuk F, Roskosz T. Correlation of skull dimensions in the European Bison. Acta Theriologica. 1980;25:349-63.

386. Köhncke M, Leonhardt K. Cryptoprocta ferox. Mamm Species. 1986;254:1-5. https://doi.org/10.2307/3503919.

387. Kopperud BT. Artiodactyl brain size evolution: a phylogenetic comparative study of brain-size adaptation. Oslo: University of Oslo; 2017.

388. Koprowski JL. Sciurus niger. Mamm Species. 1994;479:1-9. https://doi.org/1 $0.2307 / 3504263$

389. Kramer KM, Monjeau JA, Birney EC, Sikes RS. Phyllotis xanthopygus. Mamm Species. 1999;617:1-7.

390. Krasińska M, Krasiński ZA. Body mass and measurements of the European bison during postnatal development. Acta Theriologica. 2002;47(1):85-106.

391. Krasińska M, Szuma E, Kobryńczuk F, Szara T. Morphometric variation of the skull during postnatal development in the Lowland European bison Bison bonasus bonasus. Acta Theriologica. 2008;53(3):193-216. https://doi.org/10.1 007/BF03193117.

392. Kumar V. Gross anatomical studies on the bones of skull in blue bul (Boselaphus tragocamelus). Bikaner: Rajasthan University of Veterinary and Animal Sciences; 2017.

393. Lance EW, Cook JA. Biogeography of Tundra Voles (Microtus oeconomus) of Beringia and the Southern Coast of Alaska. J Mammal. 1998;79(1):53-65. https://doi.org/10.2307/1382841.

394. Larivière S. Ictonyx striatus. Mamm Species. 2002;698:1-5. https://doi.org/1 $0.2307 / 0.698 .1$

395. Larivière S. Amblonyx cinereus. Mamm Species. 2003;720:1-5. https://doi. org/10.1644/720.

396. Layne JN. The biology of the red squirrel, Tamasciurus hudsonicus loquax (Bangs) in Central New York. Ecol Monogr. 1954;24(3):227-68.

397. Lee TE Jr, Ritchie AR, Vaca-Puente S, Brokaw JM, Camacho MA, Burneo SF. Small mammals of Guandera Biological Reserve, Carchi Province, Ecuador and comparative Andean small mammal ecology. Occas Papers Mus Texas Tech Univ. 2015;344:1-17.

398. Lemos B, Cerqueira R. Morphological differentiation in the whiteeared opossum group (Didelphidae: Didelphis). J Mammal. 2002;83(2): 354-69. https://doi.org/10.1644/1545-1542(2002)083<0354:mditwe $>2.0$. $\mathrm{CO} ; 2$.

399. Leslie DM Jr. Boselaphus tragocamelus. Mamm Species. 2008;813:1-16.

400. Lessa G, Gonçalves PR, Pessôa LM. Variação geográfica em caracteres cranianos quantitativos de Kerodon rupestris (Wied, 1820) (Rodentia, Caviidae). Arquivos do Museu Nacional, Rio de Janeiro. 2005;63(1):75-88. 401. Lim BK. Lepus townsendii. Mamm Species. 1987;288:1-6.
402. Lindeque M. Jaarsveld ASv: Post-natal growth of elephants Loxodonta africana in Etosha National Park, Namibia. J Zool. 1993;229(2):319-30. https://doi.org/10.1111/j.1469-7998.1993.tb02639.x.

403. Linzey DW, Packard RL. Ochrotomys nuttalli. Mamm Species. 1977;75:1-6. https://doi.org/10.2307/3503860.

404. Lotze J-H, Anderson S. Procyon lotor. Mamm Species. 1979;119:1-8.

405. Lurz PWW, Fielding I, Hayssen V. Callosciurus prevostii (Rodentia: Sciuridae). Mamm Species. 2017;945:40-50. https://doi.org/10.1093/mspecies/sex004.

406. Lydekker R. The Great and Small Game of India, Burma, and Tibet. London: R. Ward; 1900

407. Lyon MW Jr. Mammals of Banka, Mendanau, and Billiton Islands, between Sumatra and Borneo. Proc U S Natl Mus. 1906;31:575-612.

408. Lyon MW Jr. Remarks on the insectivores of the genus Gymnura. Proc U S Natl Mus. 1909;36:449-56.

409. Lyon MW Jr. Mammals collected by Dr. W. L. Abbott on Borneo and some of the adjacent islands. Proc U S Natl Mus. 1911;40:53-146.

410. Macrini TE, Rowe T, VandeBerg JL. Cranial endocasts from a growth series of Monodelphis domestica (Didelphidae, Marsupialia): A study of individual and ontogenetic variation. J Morphol. 2007;268(10):844-65. https://doi.org/10.1 002/jmor.10556

411. Mares MA, Barquez RM, Braun JK, Ojeda RA. Observations on the mammals of Tucuman Province, Argentina. I. Systematics, distribution, and ecology of the Didelphimorphia, Xenarthra, Chiroptera, Primates, Carnivora, Perissodactyla, Artiodactyla, and Lagomorpha. Ann Carnegie Mus. 1996;65: 89-152.

412. Mares MA, Braun A. Systematics and natural history of marsupials from Argentina. In: Choate JR, editor. Reflections of a naturalist: papers honoring professor Eugene D Fleharty. Fort Hays: Fort Hays State University; 2000. p. 23-46.

413. Mares MA, Braun JK, Coyner BS, Van Den Bussche RA. Phylogenetic and biogeographic relationships of gerbil mice Eligmodontia (Rodentia, Cricetidae) in South America, with a description of a new species. Zootaxa. 2008;1753(1):1-33. https://doi.org/10.11646/zootaxa.1753.1.1.

414. Mares MA, Ojeda RA, Braun JK, Barquez RM. Systematics, Distribution, and Ecology of the Mammals of Catamarca Province, Argentina. In: Yates TL, Gannon WL, Wilson DE, editors. Life Among the Muses: Papers in Honor of James S Findlay. Albuquerque: The Museum of Southwestern Biology; 1997. p. $89-141$.

415. Mares MA, Ojeda RA, Kosco MP. Observations on the distribution and ecology of the mammals of Salta Province, Argentina. Ann Carnegie Mus. 1981;50:151-206.

416. Marker LL, Dickman AJ. Morphology, physical condition, and growth of the cheetah (Acinonyx jubatus jubatus). J Mammal. 2003;84(3):840-50. https://doi. org/10.1644/brb-036

417. Marshall LG. Dromiciops australis. Mamm Species. 1978:99:1-5.

418. Martin GM. Intraspecific variability in Lestoros inca (Paucituberculata, (aenolestidae), with reports on dental anomalies and eruption pattern. J Mammal. 2013;94(3):601-17.

419. Martínez-Lanfranco JA, Flores D, Jayat JP, D'Elía G. A new species of lutrine opossum, genus Lutreolina Thomas (Didelphidae), from the South American Yungas. J Mammal. 2014;95(2):225-40. https://doi.org/10.1644/13-ma mm-a-246.

420. Martini P, Geraads D. Camelus thomasi Pomel, 1893 from the Pleistocene type-locality Tighennif (Algeria). Comparisons with modern Camelus. Geodiversitas. 2018;40(1):115-34. https://doi.org/10.5252/geodiversitas201 $8 \mathrm{v} 40 \mathrm{a} 5$.

421. Martinoli A, Preatoni D, Galanti V, Codipietro P, Kilewo M, Fernandes CAR, et al. Species richness and habitat use of small carnivores in the Arusha National Park (Tanzania). Biodivers Conserv. 2006;15(5):1729-44. https://doi. org/10.1007/s10531-004-5020-2.

422. Matson JO, Courtright M, Lester LA. Nongeographic variation in the rufous elephant shrew, Elephantulus rufescens (Peters, 1878), from Kenya. Mammalia. 1984;48(4):593-8. https://doi.org/10.1515/mamm.1984.48.4.593.

423. Mattioli S. Family Cervidae (deer). In: Wilson DE, Mittermeier RA, editors. Handbook of the Mammals of the World, Vol 2 Hoofed Mammals. Barcelona: Lynx Edicions; 2011. p. 350-407.

424. Mayer JJ, Wetzel RM. Tayassu pecari. Mamm Species. 1987;293:1-7. https:// doi.org/10.2307/3503865

425. Mazák V. Notes on the Siberian long-haired tiger, Panthera tigris altaica (Temminck, 1844), with a remark on Temminck's mammal volume of the "Fauna Japonica". Mammalia. 1967:31(4):537-73. 
426. McGhee ME, Genoways HH. Liomys pictus. Mamm Species. 1978;83:1-5. https://doi.org/10.2307/3504048.

427. Medellín RA, Ceballos G, Zarza H. Spilogale pygmaea. Mamm Species. 1998; 600:1-3. https://doi.org/10.2307/3504330.

428. Meijaard E, Groves CP. A taxonomic revision of the Tragulus mouse-deer (Artiodactyla). Zool J Linn Soc. 2004;140(1):63-102. https://doi.org/10.1111/j.1 096-3642.2004.00091.x

429. Meinertzhagen R. Notes on the sitatunga or marsh antelope of the Sesse Islands, Lake Victoria Nyanza. Proc Zool Soc Lond. 1916;1-2:375-81.

430. Meiri S, Meijaard E, Wich SA, Groves CP, Helgen KM. Mammals of Borneo small size on a large island. J Biogeogr. 2008;35(6):1087-94. https://doi.org/1 0.1111/j.1365-2699.2008.01897.x.

431. Mennecart B, Costeur L. Shape variation and ontogeny of the ruminant bony labyrinth, an example in Tragulidae. J Anat. 2016;229(3):422-35. https://doi.org/10.1111/joa.12487.

432. Menon V. Indian Mammals: A Field Guide. Hachette India: Gurugram; 2014

433. Menzies J, Pernetta JC. A taxonomic revision of cuscuses allied to Phalanger orientalis (Marsupialia: Phalangeridae). J Zool. 1986;1(3):551-618. https://doi. org/10.1111/j.1096-3642.1986.tb00647.x.

434. Merchant JC. Swamp wallaby Wallabia bicolor. In: Strahan R, editor. The Mammals of Australia. Chatswood: Reed Books; 1995. p. 404-5.

435. Messick JP, Hornocker MG. Ecology of the badger in southwestern Idaho. Wildl Monogr. 1981;76:3-53.

436. Miller E, Fowler M. Fowler's zoo and wild animal medicine, vol. 8. 1st ed. St. Louis: Elsevier; 2014.

437. Mitchell G, Roberts DG, van Sittert SJ, Skinner JD. Orbit orientation and eye morphometrics in giraffes (Giraffa camelopardalis). Afr Zool. 2015;48(2):3339. https://doi.org/10.1080/15627020.2013.11407600.

438. Møller AP, Cuervo JJ, Soler JJ, Zamora-Muoz C. Horn asymmetry and fitness in gemsbok, Oryx g. gazella. Behav Ecol. 1996;7(3):247-53. https://doi.org/1 0.1093/beheco/7.3.247

439. Monadjem A, Taylor PJ, Denys C, Cotterill FPD. Rodents of Sub-Saharan Africa: a biogeographic and taxonomic synthesis. Berlin: De Gruyter; 2015.

440. Mones A, Ojasti J. Hydrochoerus hydrochaeris. Mamm Species. 1986;264:1-7.

441. Moore CM, Collins PW. Urocyon littoralis. Mamm Species. 1995;489:1-7.

442. Morshed S, Patton JL. New records of mammals from Iran with systematic comments on hedgehogs (Erinaceidae) and mouse-like hamsters (Calomyscus, Muridae). Zool Middle East. 2002;26(1):49-58. https://doi.org/1 0.1080/09397140.2002.10637921.

443. Muchlinski MN. Ecological and morphological correlates of infraorbital foramen size and its paleoecological implications. Austin: University of Texas; 2008.

444. Murray AM, Gardner GL. Leopardus pardalis. Mamm Species. 1997;548:1-10.

445. Murray DL. Snowshoe hare and other hares (Lepus americanus and Allies). In: Feldhamer GA, Thompson BC, Chapman JA, editors. Wild Mammals of North America: Biology, Management, and Conservation. 2nd ed. Baltimore: John Hopkins University Press; 2003. p. 147-78.

446. Muschetto E, Cueto GR, Suárez OV. New data on the natural history and morphometrics of Lutreolina crassicaudata (Didelphimorphia) from centraleastern Argentina. Mastozool Neotrop. 2011;18(1):73-9.

447. Mustrangi MA, Patton JL. Phylogeography and systematics of the slender mouse opossum Marmosops (Marsupialia, Didelphidae). Univ Calif Publ Zool. 1996;130:1-86

448. Nakajima K, Townsend G. A morphometric study of the skulls of two species of wombats (Vombatus ursinus and Lasiorhinus latifrons). Aust Mamm. 1994;17:65-72.

449. Nash DJ, Seaman RN. Sciurus aberti. Mamm Species. 1977;80:1-5. https://doi. org/10.2307/3503958.

450. O'Gara BW. Antilocapra americana. Mamm Species. 1978;90:1-7. https://doi. org/10.2307/3504049.

451. O'Shea TJ. Xerus rutilus. Mamm Species. 1991;370:1-5. https://doi.org/10.23 07/3504277.

452. Oaks EC, Young PJ, Kirkland GL Jr, Schmidt DF. Spermophilus variegatus. Mamm Species. 1987;272:1-8.

453. Ojala-Barbour R, Pinto CM, Brito MJ, Albuja VL, Lee TE, Patterson BD. A new species of shrew-opossum (Paucituberculata: Caenolestidae) with a phylogeny of extant caenolestids. J Mammal. 2013;94(5):967-82. https://doi. org/10.1644/13-mamm-a-018.1.

454. Olds N, Shoshani J. Procavia capensis. Mamm Species. 1982;171:1-7.

455. Osgood WH. Thirty new mice of the genus Peromyscus from Mexico and Guatemala. Proc Biol Soc Wash. 1904;17:55-77.
456. Owen JG. Sorex fumeus. Mamm Species. 1984;215:1-8. https://doi.org/10.23 07/3504058.

457. Padilla M, Dowler RC. Tapirus terrestris. Mamm Species. 1994;481:1-8. https://doi.org/10.2307/3504109.

458. Palma RE. Thylamys elegans. Mamm Species. 1997;572:1-4. https://doi.org/1 $0.2307 / 3504445$

459. Pasitschniak-Arts M, Larivière S. Gulo gulo. Mamm Species. 1995:499:1-10. https://doi.org/10.1644/0.499.1.

460. Patton JL, UFJ P, D'Elía G, editors. Mammals of South America, Volume 2: Rodents. Chicago: University of Chicago Press; 2015.

461. Patton RF. Ecology and behavioral relationship of the skunks of Trans-Pecos Texas: Texas A\&M University; 1974.

462. Paulson DD. Chaetodipus hispidus. Mamm Species. 1988;320:1-4. https:// doi.org/10.2307/3504075.

463. Pavan SE, Rossi RV, Schneider H. Species diversity in the Monodelphis brevicaudata complex (Didelphimorphia: Didelphidae) inferred from molecular and morphological data, with the description of a new species. Zool J Linn Soc. 2012;165(1):190-223. https://doi.org/10.1111/j.1096-3642.2 011.00791.x.

464. Pérez-Barbería FJ, Gordon IJ. Gregariousness increases brain size in ungulates. Oecol. 2005;145(1):41-52.

465. Phillips WWA. Manual of the Mammals of Ceylon. London: Dulau and Co.; 1935

466. Pirlot $P$, Kamiya T. Relative size of brain and brain components in three gliding placentals (Dermoptera: Rodentia). Can J Zool. 1982;60(4):565-72. https://doi.org/10.1139/z82-084.

467. Pocock RI. Primates and Carnivora, Families Felidae and Viverridae, vol. 1. London: Taylor and Francis; 1939.

468. Poglayen-Neuwall I, Toweill DE. Bassariscus astutus. Mamm Species. 1988; 327:1-8.

469. Prothero DR, Sereno PC. Allometry and Paleoecology of Medial Miocene Dwarf Rhinoceroses from the Texas Gulf Coastal Plain. Paleobiology. 1982; 8(1):16-30.

470. Provensal MC, Polop JJ. Morphometric variation in populations of Calomys musculinus. Stud Neotropical Fauna Environ. 1993;28(2):95-103. https://doi. org/10.1080/01650529309360892.

471. Prowse TAA, Correll RA, Johnson CN, Prideaux GJ, Brook BW. Empirical tests of harvest-induced body-size evolution along a geographic gradient in Australian macropods. J Anim Ecol. 2015;84(1):299-309. https://doi.org/1 $0.1111 / 1365-2656.12273$

472. Ralls K. Tragelaphus eurycerus. Mamm Species. 1978;111:1-4.

473. Ray JC. Civettictis civetta. Mamm Species. 1995;488:1-7.

474. Redford KH, Eisenberg JF. Mammals of the Neotropics: The Southern Cone, vol. 2. Chicago: University of Chicago Press; 1992.

475. Redford KH, Wetzel RM. Euphractus sexcinctus. Mamm Species. 1985; 252:1-4.

476. Reed AW, Kennedy PK, Beck ML, Kennedy ML. Using morphologic characters to identify Peromyscus in Sympatry. Am Midland Nat. 2004;152(1): 190-5. https://doi.org/10.1674/0003-0031(2004)152[0190:umctip]2.0.co;2.

477. Reich LM. Microtus pennsylvanicus. Mamm Species. 1981;159:1-8. https:// doi.org/10.2307/3503976.

478. Rideout CB, Hoffmann RS. Oreamnos americanus. Mamm Species. 1975;63: $1-6$.

479. Roberts A. The Mammals of South Africa. Cape Town: Trustees of "The Mammals of South Africa" Book Fund; 1951

480. Roosevelt T, Heller E. Life histories of African game animals. New York: C. Scribner's Sons; 1914.

481. Rosalino LM, Santos MJ, Domingos S, Rodrigues M, Santos-Reis M. Population structure and body size of sympatric carnivores in a Mediterranean landscape of SW Portugal. Revista Biol (Lisboa). 2005;23:13546.

482. Rose RK, Pemberton DA, Mooney NJ, Jones ME. Sarcophilus harrisii. Mamm Species. 2016;942:1-17.

483. Rose RW, Rose RK. Thylogale billardierii (Diprotodontia: Macropodidae). Mamm Species. 2018;965:100-8. https://doi.org/10.1093/mspecies/sey012.

484. Rosenberg HI, Richardson KC. Cephalic morphology of the honey possum, Tarsipes rostratus (Marsupialia: Tarsipedidae); an obligate nectarivore. J Morphol. 1995;223(3):303-23. https://doi.org/10.1002/jmor.1052230307.

485. Rosenberger AL, Coimbra-Filho AF. Morphology, taxonomic status and affinities of the lion tamarins, Leontopithecus (Callitrichinae, Cebidae). Folia Primatologica. 1984;42:149-79. 
486. Rosevear DR. Carnivores of West Africa. London: British Museum of Natural History; 1974.

487. Rossi RV, Voss RS, Lunde DP. A revision of the genus Marmosa. Part 1. The species in Tate's 'mexicana' and 'mitis' sections and other closely related forms. Bull Am Mus Nat Hist. 2010;334:1-83.

488. Rotherham LS. Morphometric and molecular analysis of variation in the southern African hedgehog, Atelerix frontalis (Eulipotyphla: Erinaceidae). Pretoria: University of Pretoria; 2007.

489. Sánchez-Villagra MR, Kay RF, Anaya-Daza F. Cranial anatomy and palaeobiology of the Miocene marsupial Hondalagus altiplanensis and a phylogeny of argyrolagids. Palaeontology. 2000;43(2):287-301.

490. Santana EM, Jantz HE, Best TL. Atelerix albiventris. Mamm Species. 2010;857: 99-110.

491. Schmitt SM, Dalton WJ. Immobilization of moose by carfentanil and xylazine and reversal by naltrexone, a long-acting antagon. Alces. 1987;23:195-219.

492. Schoenfeld M, Yom-Tov Y. The biology of two species of hedgehogs, Erinaceus europaeus concolor and Hemiechinus auritus aegyptius, in Israel. Mammalia. 1985;49(3):339-56. https://doi.org/10.1515/mamm.1 985.49.3.339.

493. Schweinberg RE. Social behavior of the collared peccary (Pecari tajacu) in the Tucson Mountains. Tucson: University of Arizona; 1969.

494. Scognamillo D, Maxit IE, Sunquist M, Polisar J. Coexistence of jaguar (Panthera onca) and puma (Puma concolor) in a mosaic landscape in the Venezuelan Ilanos. J Zool. 2003;259(3):269-79. https://doi.org/10.1017/S0952 836902003230.

495. Seebeck JH, Rose RW. Potoroidae. In: Walton DW, Richardson BJ, editors. Fauna of Australia. Canberra: Australian Government Publishing Service; 1989. p. 716-39.

496. Seymour KL. Panthera onca. Mamm Species. 1989:340:1-9.

497. Shackleton DM. Ovis canadensis. Mamm Species. 1985;230:1-9. https://doi. org/10.2307/3504034.

498. Shoshani J, Goldman CA, Thewissen JGM. Orycteropus afer. Mamm Species. 1988:300:1-8.

499. Shoshani J, Kupsky WJ, Marchant GH. Elephant brain: Part I: Gross morphology, functions, comparative anatomy, and evolution. Brain Res Bull. 2006;70(2):124-57. https://doi.org/10.1016/j.brainresbull.2006.03.016.

500. Sicuro FL, Neves LFM, Oliveira LFB. Sex- and age-related morphofunctional differences in skulls of Tayassu pecari and Pecari tajacu (Artiodactyla: Tayassuidae). J Mammal. 2011;92(4):828-39. https://doi.org/10.1644/10-ma mm-a-336.1.

501. Sillero-Zubiri C, Hoffmann M, MacDonald DW, editors. Canids: foxes, wolves, jackals and dogs status survey and conservation action plan. Cambridge: IUCN; 2004.

502. Smit HA, Robinson TJ, Watson J, van Vuuren BJ. A new species of elephantshrew (Afrotheria: Macroscelidea: Elephantulus) from South Africa. J Mammal. 2008:89(5):1257-69. https://doi.org/10.1644/07-mamm-a-254.1.

503. Smith AT, Xie Y. Mammals of China. Princeton University Press: Princeton; 2013.

504. Smith FA. Neotoma cinerea. Mamm Species. 1997:564:1-8.

505. Smith P. Tolypeutes matacus. FAUNA Paraguay Handb Mammals Paraguay 2007;7:1-12

506. Snyder DP. Tamias striatus. Mamm Species. 1982;168:1-8.

507. Sodeinde OA, Adefuke AA, Balogun OF. Morphometric analysis of Manis tricuspis (Pholidota: Mammalia) from south-western Nigeria. Glob J Pure Appl Sci. 2002;8(1):7-13.

508. Sowls LK, Phelps RJ. Observations on the African bushpig Potamochoerus porcus Linn. in Rhodesia. Zoologica. 1968;53(3):75-84.

509. Stanley WT, Robbins LW, Malekani JM, Mbalitini SG, Migurimu DA, Mukinzi JC, et al. A new hero emerges: another exceptional mammalian spine and its potential adaptive significance. Biol Lett. 2013;9(5):20130486. https://doi. org/10.1098/rsbl.2013.0486

510. Stein AB, Hayssen V. Panthera pardus (Carnivora: Felidae). Mamm Species. 2013;900:30-48. https://doi.org/10.1644/900.1.

511. Stephan H, Baron G, Frahm HD. Insectivora: with a stereotaxic atlas of the hedgehog brain. New York: Springer; 1991.

512. Strahan R. The mammals of Australia, [New rev.] edn. Chatswood: Reed Books; 1995.

513. Sunquist M, Sunquist F. Wild cats of the world. Chicago: University of Chicago Press; 2002.

514. Superina M, Abba AM. Zaedyus pichiy (Cingulata: Dasypodidae). Mamm Species. 2014;905:1-10. https://doi.org/10.1644/905.1.
515. Sutton DA. Tamias amoenus. Mamm Species. 1992;390:1-8. https://doi.org/1 $0.2307 / 3504206$.

516. Tamang KM. The status of the tiger (Panthera tigris tigris) and its impact on principal prey populations in the Royal Chitawan National Park. Nepal, East Lansing: Michigan State University; 1982.

517. Taylor ME, Matheson J. A craniometric comparison of the African and Asian mongooses in the genus Herpestes (Carnivora : Herpestidae). Mammalia. 1999;63(4). https://doi.org/10.1515/mamm.1999.63.4.449.

518. Taylor PJ, Kearney TC, Kerbis Peterhans JC, Baxter RM, Willows-Munro S. Cryptic diversity in forest shrews of the genus Myosorex from southern Africa, with the description of a new species and comments on Myosorex tenuis. Zool J Linn Soc. 2013;169(4):881-902. https://doi.org/10.1111/zoj.12 083.

519. Taylor WP. A new Perognathus from the San Joaquin Valley, California. Univ Calif Publ Zool. 1912;10:155-66.

520. Teta P, Madozzo-Jaén MC, Bezerra AMR, Ortiz PE, Lucero SO, Jayat JP. Morphological reassessment and new locality records for Galea comes Thomas, 1919 (Rodentia, Caviidae). Mammalia. 2019;83(6):601-9. https://doi. org/10.1515/mammalia-2018-0157.

521. Thorn E, Peterhans JK. Small mammals of Uganda, vol. 55. Zoologisches Forschungsmuseum Alexander Koenig: Bonn; 2009.

522. Tinnin DS, Dunnum JL, Salazar-Bravo J, Batsaikhan N, Burt MS, Gardner SL, et al. Contributions to the mammalogy of Mongolia, with a checklist of species for the country. Spec Publ Mus Southwest Biol. 2002;6:1-38.

523. Tirira DG, Högström CA. Mamíferos ecuatorianos en museos de historia natural y colecciones científicas: 3. El Museo de Historia Natural de Gotemburgo (Suecia). Boletín Técnico 10. Serie Zoológica. 2019;7:14-46.

524. Travouillon KJ. Investigating dental variation in Perameles nasuta Geoffroy, 1804, with morphological evidence to raise $P$. nasuta pallescens Thomas, 1923 to species rank. Zootaxa. 2016:4114(4):351-92.

525. Travouillon KJ, Gurovich Y, Beck RMD, Muirhead J. An exceptionally wellpreserved short-snouted bandicoot (Marsupialia; Peramelemorphia) from Riversleigh's Oligo-Miocene deposits, northwestern Queensland, Australia. J Vertebr Paleontol. 2010;30(5):1528-46. https://doi.org/10.1080/02724634.201 0.501463 .

526. Tribe CJ. A new species of Rhipidomys (Rodentia, Muroidea) from northeastern Brazil. Arquivos do Museu Nacional, Rio de Janeiro. 2005;63(1):13146.

527. Tsuji Y, Prayitno B, Norwana O, Nishi E, Widayati KA, Mikami A, et al. The notes on mammal carcasses collected in Pangandaran Nature Reserve, West Java, Indonesia. HAYATI J Biosci. 2016;23(1):35-8. https://doi.org/10.1016/j. hjb.2016.01.001.

528. Van Dyck S. The bronze quoll, Dasyurus spartacus (Marsupialia: Dasyuridae), a new species from the savannahs of Papua New Guinea. Aust Mamm. 1987:11:145-56

529. Van Gelder RG. The genus Conepatus (Mammalia: Mustelidae): variation within a population. Am Mus Novitates. 1968;2322:1-37.

530. van Staaden MJ. Suricata suricatta. Mamm Species. 1994;483:1-8. https://doi. org/10.2307/3504085.

531. Vanderhaar JM, Hwang YT. Mellivora capensis. Mamm Species. 2003;721:1-8.

532. Vassallo Al, Echeverría Al. Evolution of brain size in a highly diversifying lineage of subterranean rodent genus Ctenomys (Caviomorpha: Ctenomyidae). Brain Behav Evol. 2009;73(2):138-49. https://doi.org/10.1159/ 000218738.

533. Verts BJ, Carraway LN. Neotoma lepida. Mamm Species. 2002;699:1-12. https://doi.org/10.2307/0.699.1.

534. Verts BJ, Carraway LN, Kinlaw A. Spilogale gracilis. Mamm Species. 1995;674: $1-10$.

535. Volf J. Chov antilopy vrané (Hippotragus niger) v Zoologické zahradě v Praze (Artiodactyla: Bovidae). Lynx. 2013;44:173-80.

536. Volf J. Chov adaxe (Addax nasomaculatus) v Zoologické zahradě v Praze (Artiodactyla: Bovidae). Lynx. 2014;45:81-8.

537. Voss RS. Revisionary notes on neotropical porcupines (Rodentia: Erethizontidae) 3. An Annotated Checklist of the Species of Coendou Lacépède, 1799. Am Mus Novitates. 2011;2011(3720):1-36. https://doi.org/1 $0.1206 / 3720.2$

538. Voss RS, Díaz-Nieto JF, Jansa SA. A revision of Philander (Marsupialia: Didelphidae), part 1: P. quica, P. canus, and a new species from Amazonia. Am Mus Novitates. 2018;3891:1-70. https://doi.org/10.1206/3891.1.

539. Voss RS, Fleck DW. Mammalian diversity and Matses ethnomammalogy in Amazonian Peru Part 2: Xenarthra, Carnivora, Perissodactyla, Artiodactyla, 
and Sirenia. Bull Am Mus Nat Hist. 2017;417:1-118. https://doi.org/10.1206/ 00030090-417.1.1.

540. Voss RS, Lunde DP, Jansa SA. On the contents of Gracilinanus Gardner and Creighton, 1989, with the description of a previously unrecognized clade of small didelphid marsupials. Am Mus Novitates. 2005;3482. https://doi.org/1 0.1206/0003-0082(2005)482[0001:OTCOGG]2.0.CO;2.

541. Voss RS, Lunde DP, Simmons NB. The mammals of Paracou, French Guiana: a neotropical lowland rainforest fauna. Part 2. Nonvolant species. Bull Am Mus Nat Hist. 2001;262:1-236.

542. Voss RS, Tarifa T, Yensen E. An introduction to Marmosops (Marsupialia: Didelphidae), with the description of a new species from Bolivia and notes on the taxonomy of other Bolivian forms. Am Mus Novitates. 2004;3466:140. https://doi.org/10.1206/0003-0082(2004)466<0001:AITMMD>2.0.CO;2.

543. Wade-Smith J, Verts BJ. Mephitis mephitis. Mamm Species. 1982;173:1-7.

544. Wan Q-H, Wu H, Fang S-G. A new subspecies of giant panda (Ailuropoda melanoleuca) from Shaanxi, China. J Mammal. 2005;86(2):397-402. https:// doi.org/10.1644/BRB-226.1.

545. Wang X, Carranza-Castañeda Ó. Earliest hog-nosed skunk, Conepatus (Mephitidae, Carnivora), from the early Pliocene of Guanajuato, Mexico and origin of South American skunks. Zool J Linn Soc. 2008;154(2):386-407. https://doi.org/10.1111/j.1096-3642.2008.00411.x.

546. Webster WD, Jones JK Jr. Reithrodontomys megalotis. Mamm Species. 1982; 167:1-5. https://doi.org/10.2307/3504020.

547. Wetzel RM. The Chacoan peccary Catagonus wagneri (Rusconi). Bull Carnegie Mus Nat Hist. 1977;3:1-36.

548. Whitaker JO Jr. Sorex cinereus. Mamm Species. 2004;743:1-9. https://doi. org/10.1644/743.

549. White TG, Alberico MS. Dinomys branickii. Mamm Species. 1992;410:1-5.

550. Wible JR. On the cranial osteology of the short-tailed opossum Monodelphis brevicaudata (Didelphidae, Marsupialia). Ann Carnegie Mus. 2003;72(3):137-202.

551. Wible JR, Spaulding M. On the Cranial Osteology of the African Palm Civet, Nandinia binotata (Gray, 1830) (Mammalia, Carnivora, Feliformia). Ann Carnegie Mus. 2013;82(1):1-114. https://doi.org/10.2992/007.082.0101.

552. Williams SL, Genoways HH. Morphological variation in the southeastern pocket gopher, Geomys pinetis (Mammalia: Rodentia). Ann Carnegie Mus. 1980:49(23):405-53.

553. Wilson GS. Taxonomic status and relationships of the Swan Island Hutia, Geocapromys thoracatus (Mammalia: Rodentia: Capromyidae), and the zoogeography of the Swan Islands vertebrate fauna. Proc Biol Soc Wash. 1985;98:29-46

554. Woolley PA. The species of Dasycercus Peters, 1875 (Marsupialia: Dasyuridae). Mem Mus Vic. 2005;62(2):213-21.

555. Woolley PA. Revision of the three-striped dasyures, Genus Myoictis (Marsupialia: Dasyuridae), of New Guinea, with description of a new species. Rec Aust Mus. 2005;57:321-40.

556. Wrigley RE. Systematics and biology of the woodland jumping mouse, Napaeozapus insignis. Illinois Biol Monogr. 1972;47:1-117.

557. Wroughton RC. Bombay Natural History Society's mammal survey of India. J Bombay Nat Hist Soc. 1913;22:29-66.

558. Wroughton RC. Bombay Natural History Society's mammal survey of India, Burma, and Ceylon. J Bombay Nat Hist Soc. 1914;23:695-720.

559. Yensen E, Sherman PW. Ground squirrels (Spermophilus and Ammospermophilus species). In: Feldhamer GA, Thompson BC, Chapman JA, editors. Wild Mammals of North America: Biology, Management, and Conservation. 2nd ed. Baltimore: John Hopkins University Press; 2003. p. 211-31.

560. Yom-Tov Y, Nix H. Climatological correlates for body size of five species of Australian mammals. Biol J Linn Soc. 1986;29(4):245-62. https://doi.org/1 0.1111/j.1095-8312.1986.tb00278.x.

561. Young CJ, Jones JK Jr. Spermophilus mexicanus. Mamm Species. 1982;164: 1-4. https://doi.org/10.2307/3503778.

562. Yusefi GH, Kiabi BH, Khalatbari L, Faizolahi K, Monteiro NM. Morphological analysis of Brandt's hedgehog (Paraechinus hypomelas) reflects the isolation history of Persian Gulf islands and has implications for taxonomy. Biol J Linn Soc. 2016;119(2):497-510. https://doi.org/10.1111/bij.12842.

563. Zarza H, Ceballos G, Steele MA. Marmosa canescens. Mamm Species. 2003; 725:1-4.

564. Zegers DA. Spermophilus elegans. Mamm Species. 1984;214:1-7.

\section{Publisher's Note}

Springer Nature remains neutral with regard to jurisdictional claims in published maps and institutional affiliations.

Ready to submit your research? Choose BMC and benefit from:

- fast, convenient online submission

- thorough peer review by experienced researchers in your field

- rapid publication on acceptance

- support for research data, including large and complex data types

- gold Open Access which fosters wider collaboration and increased citations

- maximum visibility for your research: over $100 \mathrm{M}$ website views per year

At BMC, research is always in progress.

Learn more biomedcentral.com/submissions 